\title{
AMPA receptors and their minions: auxiliary proteins in AMPA receptor trafficking
}

\author{
Diane Bissen $^{1,2} \cdot$ Franziska Foss $^{1} \cdot$ Amparo Acker-Palmer $^{1,2,3}$
}

Received: 29 November 2018 / Revised: 12 February 2019 / Accepted: 7 March 2019 / Published online: 1 April 2019

(c) The Author(s) 2019

\begin{abstract}
To correctly transfer information, neuronal networks need to continuously adjust their synaptic strength to extrinsic stimuli. This ability, termed synaptic plasticity, is at the heart of their function and is, thus, tightly regulated. In glutamatergic neurons, synaptic strength is controlled by the number and function of AMPA receptors at the postsynapse, which mediate most of the fast excitatory transmission in the central nervous system. Their trafficking to, at, and from the synapse, is, therefore, a key mechanism underlying synaptic plasticity. Intensive research over the last 20 years has revealed the increasing importance of interacting proteins, which accompany AMPA receptors throughout their lifetime and help to refine the temporal and spatial modulation of their trafficking and function. In this review, we discuss the current knowledge about the roles of key partners in regulating AMPA receptor trafficking and focus especially on the movement between the intracellular, extrasynaptic, and synaptic pools. We examine their involvement not only in basal synaptic function, but also in Hebbian and homeostatic plasticity. Included in our review are well-established AMPA receptor interactants such as GRIP1 and PICK1, the classical auxiliary subunits TARP and CNIH, and the newest additions to AMPA receptor native complexes.
\end{abstract}

Keywords AMPA receptors · Trafficking · Synapse · GRIP1 · PICK1 · MAGUK · TARP · CNIH

\begin{tabular}{|c|c|c|c|c|}
\hline \multicolumn{3}{|c|}{ Abbreviations } & Atad & ATPase family AAA domain-containing \\
\hline \multirow{2}{*}{\multicolumn{2}{|c|}{ ABHD }} & a/b-hydrolase domain-containing protein; & BAR & Bin-amphiphysin-Rvs \\
\hline & & monoacylglycerol lipase & BMP & Bone morphogenetic protein \\
\hline \multirow{4}{*}{\multicolumn{2}{|c|}{$\begin{array}{l}\text { ABP } \\
\text { ADAM } \\
\text { AKAP } \\
\text { AMPA(R) }\end{array}$}} & AMPAR-binding protein & CACNG & Calcium channel $\gamma$ subunit \\
\hline & & A disintegrin and metalloproteinase & $\mathrm{CaM}$ & Calmodulin \\
\hline & & A kinase anchoring protein & CaMK & Calcium/calmodulin-dependent protein \\
\hline & & $\alpha$-Amino-3-hydroxy-5-methyl-4- & & kinase \\
\hline \multirow{2}{*}{\multicolumn{2}{|c|}{ AP }} & isoxazolepropionic acid (receptor) & CASK & Calcium/calmodulin-dependent serine pro- \\
\hline & & Adaptor protein complex & & tein kinase \\
\hline \multicolumn{2}{|c|}{ ApoER2 } & Apolipoprotein E receptor 2 & $\mathrm{CK}$ & Caseine kinase \\
\hline \multicolumn{2}{|c|}{ APP } & Amyloid precursor protein & CKAMP & Cystine-knot AMPAR modulating protein \\
\hline \multicolumn{2}{|c|}{ Arp } & Actin-related protein & CNIH & Cornichon homolog protein \\
\hline \multicolumn{3}{|c|}{ ASIC } & CPEB & $\begin{array}{l}\text { Cytoplasmic polyadenylation element-bind- } \\
\text { ing protein }\end{array}$ \\
\hline \multirow[t]{3}{*}{ 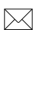 } & \multirow{3}{*}{\multicolumn{2}{|c|}{$\begin{array}{l}\text { Amparo Acker-Palmer } \\
\text { Acker-Palmer@bio.uni-frankfurt.de }\end{array}$}} & cpg & Candidate plasticity gene \\
\hline & & & $\mathrm{CPT}$ & Carnitine palmitoyltransferase \\
\hline & & & DHPG & Dihydroxyphenylglycine \\
\hline & \multirow{2}{*}{\multicolumn{2}{|c|}{$\begin{array}{l}\text { Institute of Cell Biology and Neuroscience and Buchmann } \\
\text { Institute for Molecular Life Sciences (BMLS), }\end{array}$}} & DLG & Discs large homolog \\
\hline & & & DSP A-D & Dispanin subfamily A-D \\
\hline & \multicolumn{2}{|c|}{$\begin{array}{l}\text { University of Frankfurt, Max-von-Laue-Str. } 15 \text {, } \\
60438 \text { Frankfurt am Main, Germany }\end{array}$} & EEA & Early endosome antigen \\
\hline & & & EphB & Erythropoietin-producing human hepatocel- \\
\hline & \multicolumn{2}{|c|}{$\begin{array}{l}\text { Max Planck Institute for Brain Research, Max von Laue } \\
\text { Str. 4. } 60438 \text { Frankfurt am Main. Germany }\end{array}$} & & lular receptor \\
\hline & & & ER & Endoplasmic reticulum \\
\hline & $\begin{array}{l}\text { Cardio-Pr } \\
60438 \mathrm{Fr}\end{array}$ & nonary Institute (CPI), Max-von-Laue-Str. 15, & ERK & Extracellular signal-regulated kinase \\
\hline
\end{tabular}




$\begin{array}{llll}\text { FRRS1L } & \text { Ferric-chelate reductase 1-like protein } & \text { RasGEF } & \text { Ras guanine nucleotide exchange factor } \\ \text { GABA } & \text { Aminobutyric acid } & \text { Sac } & \text { Phophatidylinositide phosphatase Sac } \\ \text { GIT } & \text { ARF GTPase-activating protein } & \text { SAP } & \text { Synapse-associated protein } \\ \text { GK } & \text { Guanylate kinase } & \text { Ser } & \text { Serine } \\ \text { GPC } & \text { Glypican } & \text { SH3 } & \text { Src homology 3 } \\ \text { GPI } & \text { Glycosylphosphatidylinositol } & \text { SNAP } & \text { Soluble NSF attachment protein } \\ \text { GRASP } & \text { GRIP1-associated protein } & \text { SNARE } & \text { Soluble NSF attachment protein receptor } \\ \text { GRIP } & \text { Glutamate receptor-interacting protein } & \text { SorCS } & \text { Sortilin-related VPS10 domain-containing } \\ \text { GSG1L } & \text { Germline-specific gene 1-like } & & \text { receptor } \\ \text { GSK } & \text { Glycogen synthase kinase } & \text { stg } & \text { Stargazer } \\ \text { ICA } & \text { Islet cell autoantigen } & \text { SynCAM } & \text { Synaptic cell adhesion molecule } \\ \text { IgSF } & \text { Immunoglobulin superfamily member } & \text { SynDIG } & \text { Synapse differentiation induced gene } \\ \text { JNK } & \text { c-Jun-N-terminal pathway } & \text { TARP } & \text { Transmembrane AMPAR regulatory protein } \\ \text { KIBRA } & \text { Kidney and brain expressed protein } & \text { Thr } & \text { Threonine } \\ \text { KIF } & \text { Kinesin superfamily } & \text { TSPAN } & \text { Tetraspanin } \\ \text { KSR } & \text { Kinase suppressor of Ras } & \text { TTX } & \text { Tetrodotoxin } \\ \text { LAR-RPTP } & \text { Leukocyte common antigen-related receptor } & \text { Tyr } & \text { Tyrosine } \\ & \text { protein tyrosine phosphatase } & \text { UPR } & \text { Unfolded protein response }\end{array}$

LRP Low-density lipoprotein receptor-related protein

LRRTM Leucine-rich repeat transmembrane protein

LTD Long-term depression

LTP Long-term potentiation

MAGI Membrane-associated guanylate kinase, WW and PDZ domain-containing protein

MAGUK Membrane-associated guanylate kinase

MAP Microtubule-associated protein

MAPK Mitogen activated protein kinase

MAP-LC MAP light chain

Mdm Mouse double minute

MPP MAGUK p55 subfamily member

NEEP Neuron-enriched endosomal protein

NMDA(R) $\quad N$-methyl-D-aspartate (receptor)

NO Nitric oxide

nPIST Neuronal isoform of protein interacting specifically with TC-10

NSF $\quad N$-ethylmaleimide-sensitive fusion protein

PACSIN Protein kinase $\mathrm{C}$ and casein kinase substrate in neurons

Par Partitioning-defective kinase

PDZ Postsynaptic density (PSD) 95, Dros-

ophila discs large homolog (Dlg) 1, zonulaoccludens 1 protein (zo1)

PICK Protein interacting with C Kinase

PK Protein kinase

PORCN Protein-serine O-palmitoleoyltransferase porcupine

PP Protein phosphatase

PRRT Proline-rich transmembrane protein

PSD Postsynaptic density

PTP Protein tyrosine phosphatase

PV Parvalbumin

Rap Ras-related protein

\section{Introduction}

Synaptic plasticity is a core feature of neuronal networks and describes their ability to adjust the strength of their connections in response to extrinsic stimuli. It is, therefore, highly regulated at both ends of the synaptic cleft. On the postsynaptic side, neuronal sensitivity is regulated by adapting the number and properties of available receptors at the membrane. When these changes are long-lasting, they are referred to as long-term potentiation (LTP) or long-term depression (LTD), depending on whether the synaptic strength is increased or decreased, respectively. This type of plasticity is collectively called Hebbian plasticity, underlies learning and memory, and represents one of the first brain functions to suffer in neurodegenerative diseases $[1,2]$. Moreover, neurons are also able to sense their own activity levels and to return to their baseline, thereby ensuring a certain stability in the network. This process, called homeostatic synaptic scaling, also depends on the insertion or removal of receptors from the membrane-insertion increases neuronal sensitivity to neurotransmitters (scaling up), whereas removal decreases it (scaling down) [3].

Glutamate is the major excitatory neurotransmitter in the central nervous system, and its major ionotropic receptors are the $N$-methyl-D-aspartate (NMDA) and $\alpha$-amino3-hydroxy-5-methyl-4-isoxazolepropionic acid (AMPA) receptors. NMDA receptors (NMDARs) are both ligand- and voltage-gated: their activation depends not only on the binding of glutamate, but also on the concomitant depolarization of the postsynaptic membrane following neuronal activity, which relieves the block of their ion channel by magnesium. AMPA receptors (AMPARs), on the other hand, are ligandgated only and the primary mediators of fast excitatory 
transmission. The dynamic regulation of AMPARs trafficking to, at, and from the synaptic membrane is a key aspect of synaptic plasticity [4]. From their assembly onwards as homo- or heterotetramers of four highly homologous subunits GluA1-4, AMPARs are, however, never alone but surrounded by a multitude of proteins throughout their lifetime, which guide their subcellular destination and fate. The role of these interacting proteins has attracted more and more attention over the past few years, as it became clearer that they were playing a major role in regulating AMPAR trafficking and function. Their temporally and spatially regulated expression, leading to different combinations according to age, brain region, neuronal type, and even cellular localization, also provides a molecular framework underlying the spatio-temporal specific features of AMPAR trafficking ([5]; reviewed in Ref. [6]). For instance, mutant mice lacking the interacting protein transmembrane AMPAR regulatory protein (TARP) $\gamma 2$ or $\gamma 8$ present defects in their major region of expression-the cerebellum or hippocampus, respectively $[7,8]$. Similarly, pharmacological companies select now interacting proteins as drug targets, as their restricted expression pattern allows for a more specific modulation of receptor signaling (reviewed in Ref. [9]).

In addition to their timing and location, the strength and stability of the interaction between the auxiliary proteins and AMPARs is of course variable. Some of them were found repeatedly in proteomics studies, and have, therefore, been classified as parts of native AMPAR macrocomplexes. Those include an "inner core", composed of the strongest bound proteins [TARPs, cornichon proteins (CNIHs), and germline-specific gene 1-like (GSG1L)], and an "outer core" of peripheral, more variable content [10]. Interestingly, not all of the historically well-known AMPAR interacting proteins, such as glutamate receptor-interacting protein (GRIP) 1 and protein interacting with $\mathrm{C}$ kinase (PICK) 1 , were identified in proteomic studies. These diverging results may, of course, arise from technical differences between the protocols, which were designed for different purposes (stringency of the interaction, confirmation of single partners versus unbiased protein screening). More interestingly, highly dynamic interactions and/or subunit specificity might also be the reason for the lack of some interactors in those studies $[11,12]$. This could apply very well to GRIP1 and PICK1, which also act as scaffolds for larger complexes.

This review will focus on the major direct interacting partners of AMPA receptors regulating their trafficking. Due to the impossibility of describing the variety of roles undertaken by these proteins, we will refer our readers to recent reviews regarding their role in AMPAR complex assembly, gating, and function, but also AMPAR trafficking specifically at the endoplasmic reticulum (ER) and during aging and diseases [13-17]. In this review, we will give an overview of the complex network of interactions surrounding
AMPARs, concentrating on the role of AMPAR partners in regulating AMPAR trafficking in mature neurons, especially at the synapse. We will start with proteins containing PDZ [Postsynaptic density (PSD) 95, Drosophila discs large homolog (Dlg) 1, and zonula-occludens 1 protein (zo1)] domains, i.e., GRIP1, PICK1, and the MAGUK (membrane-associated guanylate kinase) family; we will continue with the typical auxiliary subunits TARP and CNIH, and finish with the partners newly identified by Schwenk and colleagues.

\section{PDZ domain-containing interactants}

\section{Glutamate receptor-interacting proteins (GRIPs)}

AMPAR subunits GluA2 and GluA3 share a common sequence (-SVKI) at the end of their C-terminus, through which they can interact with PDZ domain-containing proteins [18]. Two groups have been identified so far: the GRIP family of proteins [18, 19] and PICK1 [20]. GRIP proteins include the original member GRIP1 [18], as well as GRIP2 $[21,22]$ and AMPAR-binding protein (ABP; [19]). GRIP1/2 contains seven PDZ domains, while ABP, a shorter splice variant of GRIP2, lacks the seventh PDZ domain [22]. The role of GRIP proteins in regulating AMPAR trafficking to and at the synapse has been intensively studied. GRIP1, but not GRIP2, binds to the motor protein kinesin superfamily protein (KIF) 5 and acts as a cargo for AMPARs and other proteins, such as erythropoietin-producing human hepatocellular receptor (EphB) receptors and N-cadherin, transporting them into the dendrites [23-27] (Fig. 1). GRIP1 release from KIF5 is regulated by the phosphorylation of the threonine residue 956 of GRIP1, which subsequently binds another partner, the 14-3-3 proteins; this is an important step for the function of AMPARs at the synapse. Mutating this threonine to an alanine, and thereby preventing its phosphorylation, impairs GRIP1 function; phosphodeficient mice show impaired cargo trafficking, but also decreased dendritogenesis [25]. This phosphorylation is carried by the kinase Akt1 [27].

At the synapse, GRIP1 role is more ambiguous. Several studies have, indeed, shown GRIP1 requirement in AMPAR insertion to the synaptic surface [28-36], while others have linked it to AMPAR removal from the synaptic membrane and intracellular anchorage [37-39]. On one hand, GRIP1 binding to GluA2 is regulated by GluA2 phosphorylation on the serine 880 (pSer880) by protein kinase C (PKC), which decreases GluA2 affinity for GRIP1, but does not affect its interaction with PICK1 [29, 40]. pSer880 has, therefore, been suggested as a "switch" regulating GluA2 interaction with both PDZ-containing proteins. Upon Ser880 phosphorylation, GluA2 release from GRIP1 is associated 


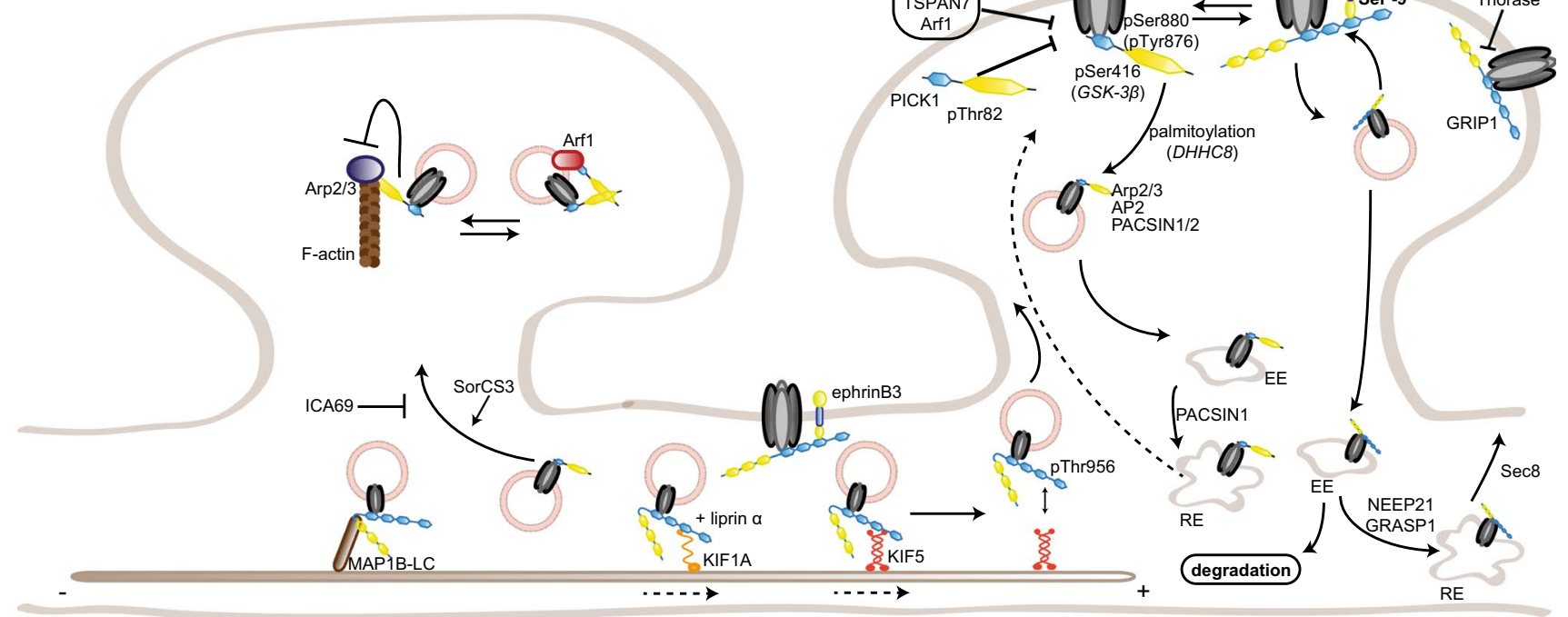

Fig. 1 Regulation of AMPAR trafficking by GRIP1 and PICK1. The PDZ domain-containing GRIP1 and PICK1 regulate surface AMPAR in opposite directions: GRIP1 primarily promotes AMPAR surface insertion, stabilization, and reinsertion after internalization, while PICK1 acts on internalization and intracellular anchorage. Their interaction with GluA2 subunits is regulated by GluA2 phosphorylation on the serine 880, which favors GluA2-PICK1 binding over GluA2-GRIP1. GRIP1 interaction with ephrinB ligands stabilizes surface AMPARs, at spine (ephrinB2, via the phosphorylation of ephrinB2 serine-9) or shaft (ephrinB3) synapses. Following internalization, PICK1-GluA2 also inhibits actin polymerization. PICK1

with its internalization and the dissociation of its postsynaptic clusters [32], and its subsequent binding to PICK1 is required for the maintenance of cerebellar LTD [33]. A similar mechanism has been proposed for hippocampal LTD, suggesting a complementary role for GRIP1 and PICK1 in regulating the insertion and internalization of AMPARs at the surface, respectively [29, 31, 34]. Consistently, GluA2 phosphorylation on Ser880 is required for cerebellar LTD [30]. In addition, GRIP1/2 double knockout mice show increased pSer880- GluA2 levels and decreased surface AMPARs, while transgenic mice with gain-of-function mutations display enhanced surface distribution and faster recycling of AMPARs [41, 42]. On the other hand, GRIP1 has also been shown to bind internalized GluA2 receptors and tether them intracellularly following LTD induction or AMPA-induced endocytosis, suggesting a role in preventing AMPAR reinsertion at the membrane [37, 39, 43]. A similar role has been proposed for GRIP2 [44]. In agreement with this, GRIP1/2 double knockout Purkinje cells are unable to express LTD [45]. In addition to AMPAR insertion or internalization, GRIP1 may also regulate activity-dependent AMPAR reinsertion into the membrane, by interacting with the exocyst protein Sec8 [46]. To add a further level of complexity, PICK1 is also able to bind the second linker domain regulates AMPAR sorting, while GRIP1 also transports AMPARs to the synapse by interacting with the motor proteins KIF1A and KIF5; cargo release from KIF5 and the microtubules requires phosphorylation of GRIP1-Thr956 residue. Conversely, GRIP1 interaction with MAP1B-LC leads to AMPAR-GRIP1 trapping on the microtubules. $E E$ early endosome, $R E$ recycling endosome. Note for all figures: posttranslational modifications (with the causative enzymes, when known) and direct partners of AMPAR interactants relevant for their regulation of AMPAR trafficking are also included. No stoichiometry is implicated; binding sites are indicative only, and size ratios are not to scale

of GRIP proteins; interfering with such interaction decreases Ser880 phosphorylation and surface GluA2 expression, NMDAR-induced GluA2 internalization and its subsequent reinsertion into the membrane, suggesting a regulatory role for PICK1/GRIP1 interaction as well [47]. Finally, GluA2 phosphorylation on the tyrosine 876 also regulates its binding to PDZ-containing proteins similarly to Ser880 phosphorylation, as it decreases GRIP1/2 binding without affecting PICK1 interaction; mutating this residue leads to a reduction of GluA2 receptors at the membrane, further emphasizing the main role for GRIP1 in regulating surface expression of AMPARs [48].

All these functions are, however, not mutually exclusive, if one considers the existence of multiple AMPAR pools at the synapse, with different recycling rates, and possibly involving different regulatory proteins and responding to different stimuli. Indeed, not all GluA2-containing receptors are internalized upon Ser880 phosphorylation by PKC; a subpopulation stays inserted at the membrane, suggesting that binding to GRIP1 is not required by all the receptors for surface expression [49]. Moreover, triggering NMDAR- or mGluR-dependent LTD in hippocampal neurons leads to the endocytosis of different AMPAR populations: while the former induces internalization of rapidly recycling AMPARs, 
which are not bound to GRIP, the latter triggers the endocytosis of stable, GRIP-bound AMPARs [50].

Recently, a new function of GRIP1 in homeostatic synaptic scaling has also been uncovered $[35,36]$. Using either shRNA against GRIP1 or GRIP1/2 double knockout neurons, two studies showed that GluA2-GRIP1 interaction is required for the trafficking and insertion of AMPARs in the membrane during scaling up following silencing of neuronal activity; it is, however, not required for scaling down, consistently with a major role of GRIP1 in surface AMPAR insertion rather than internalization [36].

Another level of regulation arises from the existence of several GRIP1/2 isoforms that undergo different modes of posttranslational modification. GRIP1, indeed, has five isoforms to date (GRIP1a-e) and GRIP2 two [38, 51-53]. GRIP1c-e display different subcellular localization and are also found in inhibitory-aminobutyric acid (GABA) expressing synapses, but their specific function is still unknown [52, 53]. GRIP1a/b and the two GRIP2 isoforms differ by an 18 amino acid variant at the extreme $\mathrm{N}$-terminus that can be palmitoylated [38, 51]. Palmitoylation regulates GRIP1a/b intracellular localization and its role in NMDAR-induced AMPAR internalization, which is enhanced by overexpression of palmitoylated GRIP1b, but inhibited by overexpression of unpalmitoylable GRIP1a [54]. In agreement, GRIP1b palmitoylation by DHHC5/8 directs GRIP1b to dendritic endosomes and enhances AMPAR recycling [55]. While GRIP2 colocalizes with internal membranes, palmitoylated GRIP2 (p-GRIP2) is targeted to the plasma membrane in spines, suggesting a differential role as synaptic and intracellular anchoring sites for AMPARs during activity-induced recycling [38]. Overexpressing p-GRIP2 increases surface AMPAR abundance and synaptic transmission, as well as colocalization with $\mathrm{N}$-cadherin [56]. Interestingly, these results suggest a different role of palmitoylation in regulating GRIP functions, as palmitoylation of GRIP2 but not GRIP1 has an effect on basal AMPAR trafficking.

In addition to AMPARs, GRIP1 interacts with several other proteins, including the extracellular matrix protein Fras1, whose mutations cause the Fraser syndrome in human patients. GRIP1 knockout mice show similar defects to Fras1 knockout mice, such as subepidermal hemorrhagy, renal agenesis, and closing of eyelids, and the absence of this interaction is most likely the reason why GRIP1 knockout mice die embryonically [57]. GRIP1 also binds the MAGUK protein calcium/calmodulin-dependent serine protein kinase (CASK), another protein involved in glutamate receptor trafficking $[58,59]$. GRIP1 interacts as well with neuron-enriched endosomal protein of $21 \mathrm{kDa}$ (NEEP21), an early endosomal protein which is crucial for proper receptor recycling in neurons $[60,61]$ and colocalizes with GluA2/3 receptors at the postsynaptic density (PSD) [62]. Overexpression of NEEP21 slows recycling of AMPARs to the dendritic membrane, while depletion decreases surface GluA2 abundance and basal synaptic transmission, and, in turn, blocks LTP, suggesting a role for the GRIP1-NEEP21 interaction in constitutive AMPAR cycling, but also activity-dependent sorting and reinsertion of AMPARs from the endosomes [61, 63] (Fig. 1). GRIP1-NEEP21 binding is regulated by phosphorylation of the serine 917 of GRIP1a; such phosphorylation occurs after the formation of the complex and is likely involved into GRIP1 dissociation from the endosomes to allow insertion of AMPARs into the membrane [64].

GRIP1 interacts as well with the neuron-specific guanine exchange factor GRIP1-associated protein 1 (GRASP1). GRASP1 is part of the complex including GRIP1 and GluA2, and is involved in constitutive and NMDA-induced AMPAR synaptic targeting [65]. Recently, GRASP1 was also involved in LTP maintenance following activation by the translational regulator cytoplasmic polyadenylation element-binding protein 2 (CPEB2; [66]). Of note, GRASP1 synaptic abundance is increased by prenatal cocaine exposure via PKC- and Src-mediated hyperphosphorylation of GRIP1, likely mediating AMPAR dysfunction and dendritic defects observed in cocaine-exposed brains $[67,68]$. GRASP1 has, furthermore, been shown to coordinate endosomal recycling by segregating Rab4 and early endosome antigen 1 (EEA1)/NEEP21/Rab5 early endosomes via its binding to the soluble NSF attachment protein receptor (SNARE) protein syntaxin 13, a protein that also interacts with NEEP21, thereby regulating AMPAR recycling to the surface $[60,69]$. This regulatory role has not only functional but also morphological consequences, as it is necessary for proper AMPAR recycling, synaptic plasticity, and spine morphology. Consistently, GRASP1 knockout mice display lower glutamatergic synapse density, reduced LTP, and impaired learning-induced AMPAR delivery and cognitive ability. GRASP1 mutations have been now found in human patients with intellectual disability, and these mutations affect AMPAR recycling as well, opening the door to a better understanding of the etiology of such impairments [70]. Interestingly, loss- or gain-of-function of GRIP proteins affects social interactions, and in humans, five missense GRIP1 variants leading to a gain-of-function have also been associated with autism [41, 42].

In addition, GRIP1 scaffolds a complex including the focal adhesion protein liprin $\alpha$, the leukocyte common antigen-related (LAR) family receptor protein tyrosine phosphatases (LAR-RPTP), and AMPARs, which is enriched at postsynaptic sites. Interfering with the GRIP1-liprin $\alpha$ binding decreases surface expression and clustering of AMPARs [71]. A similar reduction was observed when interfering with the binding of an additional member of the complex, the actin regulatory protein ARF GTPase-activating protein (GIT) 1 [72]. Cadherin and $\beta$-catenin may also be included 
into this complex, whose transport to the dendrite is regulated by the LAR-RPTP, implicating GRIP1 in regulating spine morphology [73]. Interestingly, GRIP1-liprin $\alpha$ interaction has also been involved in muscarinic-induced hippocampal LTP [74]. GRIP1 and liprin $\alpha$ also associate with the motor protein KIF1A [75], suggesting that GRIP1 can interact with more than one motor protein. Indeed, GRIP1 has also been shown to bind the light chain of microtubuleassociated protein (MAP) 1B, an interaction required for dihydroxyphenylglycine (DHPG)-induced AMPAR internalization and regulating its trafficking towards the dendrite [76, 77].

Another partner of GRIP1 is the AAA + ATPase Thorase, or ATPase family AAA domain-containing 1 (Atad1), which regulates in an ATP-dependent fashion AMPAR internalization by disassembling GRIP1-GluA2 complexes (Fig. 1). Upon Thorase depletion, AMPAR internalization and LTD are consequently decreased, while LTP is enhanced [78]. Thorase-deficient mice display disrupted AMPAR internalization and recycling and behavioral deficits, which can be rescued by the FDA-approved drug Perampanel [79]. Interestingly, Thorase variants have been found in schizophrenia patients and Perampanel use in patients improved hypertonicity and resolution of seizures, showing a promising start [80]. Very recently, additional Thorase mutants were found in patients with lethal encephalopathy. In mice, those mutations result in a gain-of-function that affects expression levels of multiple proteins as well as the disassembly of GRIP1-GluA2 complexes, leading to a decreased surface GluA2 expression [81]. Altogether, these studies directly involve GRIP1 in the etiology of several human diseases, underlying the importance of understanding its function in AMPAR trafficking.

Last but not least, GRIP1 also interacts with the Eph family of receptor tyrosine kinases and their ephrin ligands; more precisely, with ephrinB ligands, their cognate receptor EphB2, but also EphA7 [82]. The Eph/ephrin family of signaling molecules displays a bidirectional mode of signaling, as binding of ephrin ligands to Eph receptors triggers signaling downstream of Eph (forward signaling), but also of ephrin (reverse signaling). In addition to their crucial roles in multiple processes during brain development, the Eph/ephrin family has also been involved in synaptogenesis and synaptic plasticity (reviewed in Ref. [83]). Regarding AMPARs specifically, Eph receptors have been involved in regulating their clathrin-mediated endocytosis, their localization, transsynaptic glutamatergic synaptogenesis, and downregulation during homeostatic plasticity [84-87]. Transsynaptic binding of presynaptic ephrinBs to postsynaptic EphB receptors induces binding of GRIP1 to EphB that is necessary for the induction of mossy fiber LTP [88]. Postsynaptic ephrinB3 interaction with GRIP1 was also shown to specifically promote the formation of shaft synapses in hippocampal cultures. The same study showed that ephrinB3 knockout mice display reduced shaft synapses, while spine density was unaffected [89]. Interestingly, synaptic AMPAR expression is also reduced in ephrinB3 knockout mice, and ephrinB3 regulates the anchoring and stability at the synapse of another crucial synaptic scaffolding protein, PSD95 [90, 91]. GRIP1-EphB2 interactions are also important for dendritic development. GRIP1 transports EphB2 to the dendritic compartment via its binding to KIF5 and by doing so regulates dendritogenesis [24]. EphrinB ligands recruit GRIP1 and GRIP2 to lipid rafts upon activation by EphB2, suggesting a role of GRIP1 proteins as scaffolds for large multiprotein complexes downstream of Eph/ephrin signaling [21]. As AMPAR internalization rate is increased in raft-depleted neurons, this supports a role of such GRIPscaffolded complex in AMPAR stabilization at the surface [92]. In fact, activation of ephrinB2 reverse signaling was shown to regulate the insertion and stabilization of AMPARs at the surface and ephrinB2 knockout neurons displayed an enhanced constitutive AMPAR internalization and impairment in synaptic transmission [93]. A serine residue (Ser9) in ephrinB ligands was found to regulate the binding to GRIP1 (Fig. 1). In a parallel study, the PDZ-binding site of ephrinB2 was shown to be required for both LTP and LTD at the CA3-CA1 hippocampal synapse [94]. Recently, additional insight on the regulation of AMPA receptor insertion at the synaptic membrane came from studies that described a cooperation model between the ephrinB2 ligands and the Reelin receptor apolipoprotein E receptor 2 (ApoER2 [95]). ApoER2 had been previously implicated in AMPAR trafficking following stimulation with Reelin and ApoER2 knockout mice showed an impaired LTP [96-98]. Mechanistically, this new study by Pfennig and colleagues shows that GRIP1 bridges a whole complex at the membrane that includes ephrinB2, AMPAR, and ApoER2. The formation of the complex is required for the new insertion and stabilization of AMPARs at the synaptic membrane, following either neuronal activity or stimulation with Reelin. Such complex is regulated by phosphorylation of the Ser-9 in ephrinB2 and is necessary for LTP maintenance [95].

\section{Protein interacting with C kinase (PICK1)}

Originally identified as a partner of PKC $\alpha$, PICK1 binds via its PDZ domain the C-terminus of the AMPAR subunits GluA2 and GluA3, like GRIP1 [20, 99]. PICK1 role in AMPAR trafficking has been extensively studied, and, in a relatively consensual model, acts as the counterpart to GRIP1 by regulating AMPAR endocytosis [20, 29, 31, 100, 101] (Fig. 1). PICK1 is, indeed, required for NMDARinduced internalization of AMPARs [100, 102] as well as for LTD in the hippocampus [31, 103-105], the cerebellum [106], but also the cortex [107] and ventral tegmental 
area [108]. PICK1 is also able to bind activated PKC $\alpha$ and target it to the synapses, where it can phosphorylate GluA2Ser880, thereby facilitating AMPAR endocytosis [101]. According to other studies, PICK1 regulates AMPAR recycling after NMDAR-induced internalization by retaining AMPARs intracellularly, but is not required for endocytosis itself, as PICK1 knockout neurons displayed an increased recycling rate of AMPARs to the surface but no impaired internalization [43, 109-111]. Both functions are not mutually exclusive, and actually not antagonistic, as both underlie the role of PICK1 in downregulating surface GluA2 expression. In addition, PICK1 has been involved in regulating calcium-permeable AMPAR trafficking, and its overexpression favors GluA2-lacking over GluA2-containing receptors [104, 112, 113].

PICK1 may also be involved in NMDAR-dependent LTP, as LTP is prevented by PICK1 knockdown and occluded by PICK1 overexpression [105]. However, another study found no defective LTP in PICK1 knockout slices [111]. The precise function of PICK1 may also be highly stimulus-dependent: while low NMDAR activation triggers an increase of PICK1 endosomal clustering (consistent with higher AMPAR endocytosis), a higher NMDAR activation (similar to LTP induction protocols) leads to the dissociation of GluA2-PICK1 complexes and an increase of surface GluA2 expression mediated by the $N$-ethylmaleimidesensitive fusion protein (NSF), another AMPAR interactant, and calcium $[110,114]$. Another study investigated LTP and LTD in juvenile and adult PICK1 knockout mice and found that both LTP and LTD were completely unaffected in juvenile mice, whereas a specific form of LTP only and multiple forms of LTD were impaired in adult mice; consistently, only adult mice displayed learning deficits [115]. These findings are strikingly similar to the phenotype shown by knockout mice for kidney and brain expressed protein (KIBRA), a gene related to human memory capabilities; KIBRA binds PICK1 and forms a complex with AMPARs, and its deletion impairs hippocampal LTP and LTD, and thereby learning, in adult mice, but not juvenile [116]. The precise function of PICK1 appears, therefore, highly contextual, depending on the brain region, age, and stimulus. Finally, in addition to LTD and LTP, PICK1 is also involved in homeostatic scaling up, which is occluded in PICK1 knockout neurons; it is not, however, required for scaling down [117].

Like GRIP1, PICK1 function in AMPAR trafficking is regulated by posttranslational modifications. While Thr82 phosphorylation on PICK1 prevents GluA2 binding, Ser416 phosphorylation by glycogen synthase kinase (GSK) $3 \beta$ is required for PICK1 interaction with GluA2 [118, 119]. PICK1 palmitoylation by DHHC8 is required for cerebellar LTD [120]. Interestingly, the monoubiquitination of PICK1 by parkin1 triggers the excessive potentiation of the acidsensing ion channels (ASICs), which also bind PICK1 PDZ domain; channel hyperactivity can lead to excitotoxicity, thereby potentially linking PICK1 and the neuronal degeneration seen in Parkinson's disease [121].

In addition to GluA2/3, PICK1 binds a multitude of other proteins, some of which also modulate the regulation of AMPAR trafficking by PICK1. For instance, upon calcium release from the ER, PICK1 forms a complex with calcium/ calmodulin-dependent protein kinase type II (CaMKII) and GluA2 that facilitates GluA2 exit from the ER and trafficking towards the dendrites [122] (Fig. 7). PICK1 can also act directly as a calcium sensor, and PICK1-GluA2 interactions are increased upon calcium stimulation. Thus, PICK1 binding to calcium is required for NMDAR-induced AMPAR internalization or their intracellular retention $[102,111]$. Calcium also regulates the formation of a complex including PICK1, NSF, GluA2, and the SNARE protein $\beta$ soluble NSF attachment protein ( $\beta S N A P)$, which modulates surface GluA2 expression, as NSF stabilizes AMPARs at the surface by destabilizing GluA2-PICK1 complexes [123, 124].

In addition, PICK1 also regulates spine morphology by binding to the small GTPase Arf1, F-actin, and the actinnucleating complex actin-related protein Arp2/3 (Fig. 1). The formation of this complex, indeed, inhibits actin elongation and branching promoted by Arp $2 / 3$, which underlie vesicle trafficking and spine morphogenesis. Consistently, Arf1 binding, by preventing PICK1-Arp $2 / 3$ interaction, impairs NMDAR-induced AMPAR endocytosis and spine shrinkage during LTD [125-127]. Interestingly, PICK1 also binds the Rho family members Cdc42 and Rac1, providing a direct mechanistic link from AMPAR stimulation to the regulation of spine morphology [128]. One study, however, reported that PICK1 did not bind Arp2/3 nor F-actin directly, but was involved in nondirectional organelle motility driven by myosin motors [129]. PICK1 was also involved in axonal trafficking via its newly identified partner the kinesin-binding protein syntabulin [130], which might, therefore, act as a motor protein for PICK1 regulation of presynaptic AMPAR trafficking [131, 132]. Recently, PICK1 was also shown to interact with a central player in clathrin-mediated endocytosis, the adaptor protein AP2, which bridges cargo proteins and clathrin. This interaction is required for AMPAR clustering and internalization upon NDMAR stimulation [133].

Another important binding partner of PICK1 is islet cell autoantigen $69 \mathrm{kDa}$ (ICA69), which blocks synaptic targeting of PICK1 and, concomitantly, of AMPARs [134] and PKC $\alpha$ [135]. This role is not only important for plasticity, but also during development, as ICA69 negatively regulates synaptic trafficking and clustering of GluA2-containing AMPARs by PICK1 during synaptogenesis, an important step for synapse maturation [136]. Furthermore, PICK1 bridges the protein kinase $\mathrm{C}$ and casein kinase substrate in neurons (PACSIN) family members PACSIN 1 and 2 in a complex with AMPARs; this interaction depends on the 
phosphorylation of the PACSIN proteins and is required for AMPAR endocytosis and cerebellar LTD, but also regulates the subsequent AMPAR recycling to the surface [137, 138]. The vesicle sorting protein sortilin-related VPS10 domaincontaining receptor 3 (SorCS3) also binds PICK1, and the impaired PICK1 localization and subsequent AMPAR synaptic targeting in SorCS3 knockout mice are proposed to underlie their deficits in cerebellar LTD and hippocampal learning behaviors $[139,140]$. Finally, PICK1 also interacts with tetraspanin 7 (TSPAN7), in which mutations have been found in some types of X-linked intellectual disability. By competing with GluA2 to bind PICK1 PDZ domain, TSPAN7 limits PICK1 availability to AMPARs and, therefore, stabilizes them at the surface. PICK1/TSPAN7 interaction also regulates spine morphogenesis [141].

In addition to its PDZ domain, PICK1 possesses a bin-amphiphysin-Rvs (BAR) domain, through which it binds lipids; this binding regulates synaptic targeting of PICK1, and, therefore, of AMPARs, and consequently, mutating the BAR domain decreases synaptic surface clustering of AMPARs and LTD [103, 106]. Additional studies have focused on the reciprocal influences of the BAR and PDZ domains, as well as the $\mathrm{N}$ - and $\mathrm{C}$-terminal domains of PICK1, and their importance for AMPAR trafficking [47, 142]. The BAR domain has also been proposed to enable PICK1 to form long-distance interactions and thereby facilitate its scaffolding of multiple membrane-bound proteins [143]. Contradictory findings were reported regarding PICK1 higher structure ([129]; see also Refs. [144, 145]). Further studies are required to delineate PICK1 structure and its functional influence on AMPAR trafficking.

\section{Membrane-associated guanylate kinase (MAGUK) family}

MAGUKs form a large family of PDZ domain-containing scaffolding proteins that are essential for the development and plasticity of synapses. The MAGUK family is divided into several subclasses based on their domain organization, including the Discs large homologs (DLGs), calcium/ calmodulin-dependent serine protein kinase (CASK), and palmitoylated membrane proteins (MPPs) [146].

The DLG family has been associated with AMPAR trafficking and plasticity for years. However, until recently, a direct association with AMPARs had only been demonstrated for synapse-associated protein 97 (SAP97 or DLG1), which binds the C-terminus of the GluA1 subunit. Other DLG members such as PSD93 (DLG-2), PSD95 (DLG4, or SAP90), and SAP102 (DLG-3) were found to bind directly NMDARs, but not AMPARs [147-149]. Intriguingly, PSD95, SAP97, SAP102, and the relatively unknown MPP2, were recently shown to belong to AMPAR native macromolecular complexes [10]. More detailed studies are now required to dissect this newly discovered association between DLG family members and AMPARs.

\section{Postsynaptic density (PSD) 95 and 93}

The prototypical member of the DLG family is PSD95, which was nearly simultaneously identified as a postsynaptic protein in rat synaptosomes and as SAP90 in the presynaptic compartment of Purkinje cells, prefiguring the wide array of functions served by the protein at both sides of the synaptic cleft $[150,151]$. PSD95 appears to play a pivotal role in plasticity, and mice impaired for PSD95 signaling display, indeed, learning deficits and abnormal anxiety-like behavior $[152,153]$. As a scaffold protein, PSD95 affects spine density and morphology. For example, spine number and size are increased upon overexpression, while PSD95 knockdown prevents spine morphological development, but also spine growth and stabilization after LTP induction [154, 155]. In addition, PSD95 drives the maturation of glutamatergic synapses, i.e., the insertion of AMPARs into synapses that previously only contained NMDARs, which converts them from "silent" to "functional" synapses [154]. Many studies modulated the levels (overexpression or knockdown) of PSD95 to investigate the function of PSD95 in synaptic plasticity, and the scenario is thought extremely puzzling. On one hand, several studies have shown that PSD95 overexpression increases the proportion of AMPAR expressing synapses, AMPAR synaptic clustering, and AMPAR-mediated synaptic transmission and, as a consequence, occludes LTP, since the strengthened synapses cannot further potentiate [7, $154,156-159]$. Very intriguingly, PSDS95 overexpression enhances LTD [156, 157]. On the other hand, the converse strategy (reducing PSD95 levels or using a ligand-binding deficient mutant) produces even more confusing results. In the adult hippocampus, LTP is, indeed, intact [155] or even (somewhat surprisingly) enhanced [152, 160, 161]. However, in the developing superior colliculus [162] and in the barrel cortex [158], LTP is blocked. On the other hand, in mice with lower PSD95 levels or functionally impaired PSD95, LTD is disrupted in the adult hippocampus [152, $155,161]$, but it is intact in the developing hippocampus [153] and superior colliculus [162].

There are likely several mechanisms behind all this diversity of phenotypes. First, PSD95 functions appear clearly developmentally and spatially regulated. As the conversion of silent to functional synapses primarily takes place in the developing brain, it is not surprising to see a differential effect of PSD95 between the young and adult brain. In addition, PSD95 is not the only synaptic MAGUK; PSD93 and SAP102 are also present and may undertake similar functions, which might explain why PSD95 is not unconditionally required for LTP and why not all synapses are equally affected in PSD95 knockout mice ([159] and see below). 
Finally, PSD95 acts at multiple levels at the synapse- on the stability of the PSD itself, and also as a scaffold for a wide array of proteins in addition to AMPARs and NMDARs, all of which may be affected upon the changes of PSD95 levels. PSD95 may, therefore, also act not as a primary regulator of plasticity, but as a mediator. Regarding LTD, its major involvement seems to transduce NMDAR-mediated calcium influx by scaffolding additional proteins required for LTDinduced AMPAR endocytosis [163].

PSD95 does not only play a role in Hebbian plasticity; it has also been involved in homeostatic synaptic scaling, in an age-dependent fashion. Indeed, scaling up is only affected by PSD95 knockdown in young cortical neurons, while scaling down is impaired by PSD95 knockdown or overexpression, in young or adult cortical neurons [205]. This differential involvement of PSD95 is likely mediated by different domains and interaction partners of PSD95, some of which have been shown to be also required for scaling down [205].

The role of PSD95 as a scaffold protein for AMPARs has been extensively studied in the last decade. Mechanistically, PSD95 stabilizes AMPARs at the synaptic surface by scaffolding nanodomains at the synapse which are preferentially enriched in AMPARs rather than NMDARs. Such concentration in nanodomains, which enhances synaptic efficacy and is activity-regulated [164-166], involves the formation of a complex with the transmembrane AMPAR regulatory protein (TARP) $\gamma 2$ (stargazin) necessary for the correct targeting and diffusion of AMPARs to the synaptic surface [7, 167-169] (Fig. 2). PSD95/stargazin complexes have also been suggested to regulate AMPAR "slots" at the synapse, where freely diffusing AMPARs are "trapped" to regulate synaptic strength; the precise molecular mechanisms underlying the formation of these slots are, however, still unclear (reviewed in Ref. [170]). In addition to stargazin, PSD95 also binds other TARPs, including $\gamma 3$ and $\gamma 8$, but the function of this interaction in synaptic plasticity has not been further investigated [171]. Surface AMPAR diffusion toward synapses is required for hippocampal LTP and for in vivo contextual learning [172]. Nanodomain formation also involves the capture of diffusing AMPARs by the adhesion molecules neurexin/neuroligin, which assemble them in PSD95 scaffolds in competition with the preexisting synapses [173]. Moreover, PSD95 has been recently shown to interact with the adhesion molecules immunoglobulin superfamily member 11 (IgSF11) and $\alpha$-actinin, both of which are involved in AMPAR stabilization at the synapse [174, 175]. IgSF11 knockdown leads to a decreased AMPAR clustering and increased surface motility, suggesting that IgSF11 might also be involved in regulating the formation or maintenance of the nanodomains [174]. $\alpha$-Actinin knockdown phenocopied PSD95 knockdown and knockout, as there is a reduction in the number of synapses but not in AMPAR content [175].

Two isoforms of PSD95 have been identified, which differ at their $\mathrm{N}$-terminus. The $\alpha$ isoform is predominant and normally palmitoylated; under baseline conditions, it masks the effects of the $\beta$ isoform. The regulation of synaptic strength by either isoform is activity-dependent [176, 177]. Palmitoylation, mediated by DHHC-containing palmitoyl transferases and a/b-hydrolase domain-containing 17 (ABHD17) depalmitoylase, is crucial for PSD95 sorting, synaptic targeting, its integration into the PSD lattice, and the clustering of AMPARs in nanodomains [178-183].
Fig. 2 Regulation of AMPAR trafficking by PSD95 and TARP $\gamma 2 /$ stargazin. PSD95 and TARP $\gamma 2 /$ stargazin regulate AMPAR synaptic trapping. PSD95 anchors stargazin-bound freely diffusing AMPARs at the PSD, thereby enhancing synaptic strength. Stargazin phosphorylation in its cytoplasmic tail promotes PSD95 binding; upon dephosphorylation, stargazinbound AMPARs are endocytosed or diffuse out of the synapse. Additional posttranslational modifications on PSD95 or stargazin modulate this binding in either direction. Stargazin also regulates AMPAR synaptic trafficking by interacting with MAP1A-LC2

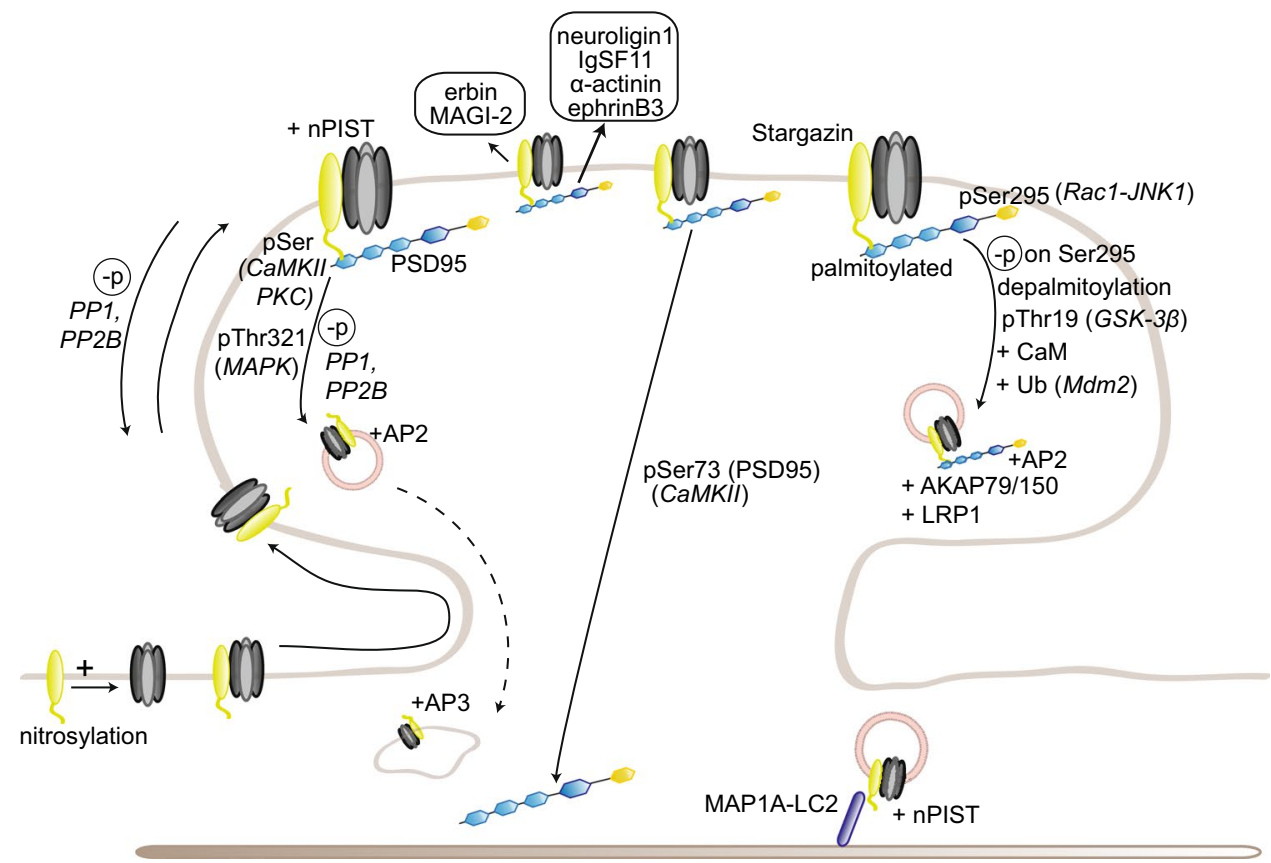


Palmitoylation also regulates PSD95 binding to stargazin and is prevented by an interaction with calmodulin $(\mathrm{CaM})$. $\mathrm{CaM}$ binding enables the calcium-induced release of PSD95 and its anchored proteins from the postsynaptic membrane, a necessary step for the reorganization of the PSD following NMDAR-induced LTD [183, 184]. Consistently, palmitoylation is induced by chronic activity blockade during homeostatic scaling up, leading to an increased synaptic AMPAR clustering. CaM binding to PSD95 was very recently shown to mediate AMPAR internalization during synaptic scaling down [185, 186]. In addition to CaM binding, CaMKII itself also positively regulates PSD95 trafficking out of the spines following LTP induction by phosphorylating PSD95 on Ser73, which blocks LTP and LTP-induced spine growth, suggesting that CaMKII modulates the end of LTP-triggered cascades [183, 187]. Other phosphorylation sites of PSD95 include Ser295, whose phosphorylation by the Rac1/c-JunN-terminal pathway 1 (JNK1) pathway enhances synaptic targeting of PSD95 and AMPAR clustering and whose dephosphorylation is required for AMPAR internalization during LTD [188]; and Thr19, whose phosphorylation by GSK-3 $\beta$ is a contrario required for AMPAR endocytosis and LTD [189]. Recently, Ser561 phosphorylation by partitioning-defective (Par) 1 kinases was shown to function as a structural switch between open and closed conformations of PSD95; a phosphodeficient mutant favors an open conformation, increasing PSD95 synaptic stability and its ability to act as a scaffold by binding multiple proteins [190]. Ser561 phosphorylation is also required for AMPAR internalization following NMDAR activation. In addition, multiple phosphorylation sites modulating protein interactions have been newly identified in PSD95, but their role in synaptic plasticity remains to be investigated [191]. Finally, PSD95 is also ubiquitinated by the E3 ligase mouse double minute 2 (Mdm2) upon NMDAR activation, leading to its removal from the surface; this process is regulated by the kinase Cdk5 and modulates PSD95 binding to the clathrin adaptor protein complex AP-2, providing a mechanistic link between NMDAR activation and AMPAR endocytosis. And, indeed, blocking this ubiquitination prevents subsequent AMPAR endocytosis [192, 193].

In addition to the N-terminal PDZ domains, PSD95 contains also a C-terminal Src homology 3 (SH3) and guanylate kinase (GK) like domain. PSD95 interaction with A kinase anchoring protein (AKAP) 79/150 via its C-terminal SH3 and GK domains is necessary for NMDA-induced AMPAR endocytosis [194, 195]. PSD95 may also mediate AMPAR internalization via its complex with GluA1 and low-density lipoprotein receptor-related protein 1 (LRP1), a protein involved in regulating synaptic integrity; LRP1 knockdown, indeed, leads to accelerated turnover and decreased surface GluA1 and GluA1-induced neurite growth [196]. Finally, PSD95 binds also directly ephrinB3, which stabilizes it at the synapse; activity-induced phosphorylation of ephrinB3 Ser332 by mitogen activated protein kinase (MAPK) prevents this association and leads to an increased PSD95 turnover [91].

A last factor to be taken into consideration when studying MAGUK proteins is, as mentioned before, the presence of multiple family members at the synapse-presence which may itself differ depending on the age, brain region, and neuronal type considered. For instance, the closely related PSD93 is present at the postsynapse and displays a similar but not identical expression pattern to PSD95 in the adult rat brain, with a unique pattern in the cerebellar Purkinje cells [197]. Like PSD95, several isoforms of PSD93 have been identified - 6 in total — with different impacts on AMPARand NMDAR-mediated functions; the most abundant isoforms in the hippocampus can also be palmitoylated [176, 198]. PSD93 can be phosphorylated by the kinases Fyn and extracellular signal-regulated kinase (ERK); it also mediates NMDAR phosphorylation by Fyn, an important regulatory modification of NMDAR function [199-201].

PSD93 and PSD95 seem to be present in a largely nonoverlapping subset of synapses, and may, therefore, confer different properties to the synapses for which they are main MAGUK ([159, 202, 203], but see [204]). This differential pattern may explain why not all synapses are similarly affected in PSD95 knockout mice [159, 160]. Contrary to PSD95, PSD93 knockout mice display normal LTD, but an impaired LTP [161]. PSD93 is also able to support on its own scaling down in young cortical neurons, but not scaling up, nor scaling down or up in adult neurons [205]. In addition, in Purkinje cells at least, PSD93 binds the microtubule protein MAP1A, suggesting a potential role in regulating the dendritic trafficking of its partners, such as NMDARs and PSD95, with which it can form heteromers [197, 206].

\section{Synapse-associated protein (SAP) 102}

SAP102, originally identified as the first synaptic protein binding NMDARs, regulates NMDAR synaptic clustering and clearance and mediates NMDA-dependent plasticity and spine remodeling. Consistently, SAP102 knockout mice display impairments in ERK-dependent LTP and spike-time dependent plasticity, as well as cognitive deficits [207-211]. SAP102 also regulates AMPAR clustering at immature synapses. SAP102 knockdown strikingly leads to the removal of all AMPARs from the surface during synaptogenesis [159]. Synapse maturation requires the switch from SAP102 to PSD95 and PSD93, and SAP102 only supports AMPAR trafficking in mature synapses to compensate for the simultaneous knockdown of the normally predominant PSD95 and PSD93 [212]. SAP102 also functionally interacts with PSD95 (potentially by direct binding or via TARPs) and regulates its ability to enhance AMPAR-mediated synaptic 
transmission [213]. Contrary to PSD95 and PSD93 localization and general immobility in the sole PSDs, SAP102 is localized in the whole spine volume, in and around PSDs, and is highly mobile, a feature depending on actin and glutamate receptor activation [204, 214, 215]. This suggests that SAP102 function might be more related to AMPAR trafficking towards the synapse rather than stabilization at the surface. Recently, SAP102 synaptic targeting and spine motility were found to be regulated via phosphorylation by casein kinase II (CKII) of its Ser632 residue, a residue present in one of the three isoforms of SAP102. Phosphorylation of Ser632 was found to be induced by activity, leading to an increase of SAP102 density and stability at the synapse [216].

SAP102 interacts as well with neurobeachin, a brain-specific AKAP that regulates AMPAR trafficking [217-219]. SAP102 also forms a complex with EphB2 and the Ras guanine nucleotide exchange factor (RasGEF) effector Kalirin7 and regulates surface EphB2. Mechanistically, SAP102 is necessary for actin reorganization, synapse formation, and AMPAR synaptic trafficking upon EphB activation by ephrinB [220].

Further insights about the role of PSD95 and SAP102 come from studies where all three MAGUK proteins involved in regulating baseline transmission, i.e., PSD95, PSD93, and SAP102, were knocked down simultaneously by RNAi in organotypic slices [221, 222]. This knockdown causes a vast reduction in global AMPAR and NMDAR transmission, due to a decrease in glutamate receptor containing synapses; the synaptic strength of surviving synapses is, however, unaffected [221]. MAGUK loss triggers first a reduction in quantal postsynaptic currents, which then recovers via a consolidation process involving calcium channels, CaMKII and GluA2, similarly to a homeostatic process [221]. Furthermore, the knockdown leads to a decreased PSD size, a large loss of the PSD95 containing vertical filaments structuring PSDs and concomitantly of AMPAR or NMDAR complexes, and a subsequent decrease in synaptic transmission [222]. Collectively, these results strongly suggest a basic role for MAGUK proteins as a PSD scaffold, on which glutamate receptor trafficking is then grafted. These roles seem restricted during synaptogenesis, as MAGUK knockdown in adult CA1 in rats only slightly affected synaptic transmission acutely, causing a significant reduction only after several weeks; $a$ contrario, the same procedure in young rats immediately leads to a large reduction continuing until adulthood [223]. Interestingly, MAGUK loss in the adult dentate gyrus leads to a similar effect as in a young CA1, emphasizing the role of MAGUK proteins during development. Consistently, a very recent study investigating SAP102 expression in adult and aging hippocampi suggests a developmentally and subregionally regulated role, which can be altered during neurodegenerative diseases such as Alzheimer's [224].

\section{Synapse-associated protein (SAP) 97}

SAP97 occupies a special place in the MAGUK-DLG family as it specifically binds GluA1, and not GluA2-4; this specificity depends on a small sequence outside of GluA1 canonical PDZ-binding sequence [147, 149]. SAP97 appears to be involved in GluA1 early trafficking to the dendritic membrane, as well as the regulation of the extrasynaptic and synaptic pools of AMPAR at the surface [225-228] (Fig. 3).

Like PSD95, the N-terminus of SAP97 exists in two isoforms, the palmitoylable $\alpha$ isoform and the non-palmitoylable, L27 domain-containing $\beta$ isoform. While the $\alpha$ isoform regulates AMPAR-mediated transmission in an activityindependent manner, the $\beta$ isoform, most abundant, does it in an activity-dependent and CaMKII-regulated manner [176]. $\alpha$ SAP97 is directly targeted to the PSD, while $\beta$ SAP97 is present at the perisynaptic regions [227]. These results are consistent with earlier reports of $\beta$ SAP97 expression at the edges of PSDs in synapses expressing homomeric GluA1 channels or heteromeric GluA1-containing AMPARs; this pattern, in opposition to PSD95 and PSD93, points towards a role of $\beta$ SAP97 in recycling GluA1 receptors in and out of the PSD [204, 226, 229]. Structurally, the presence of the L27 domain enables SAP97 to adopt an open conformation, indicating that $\alpha$ SAP97 and $\beta$ SAP97 have a compact or extended conformation, respectively, providing a structural basis for the functional differences observed between the isoforms [230]. In addition, $\beta$ SAP97 L27 domain is crucial for SAP97 dimerization and the modulation of synaptic strength; overexpression of L27-mutated SAP97 potentiates

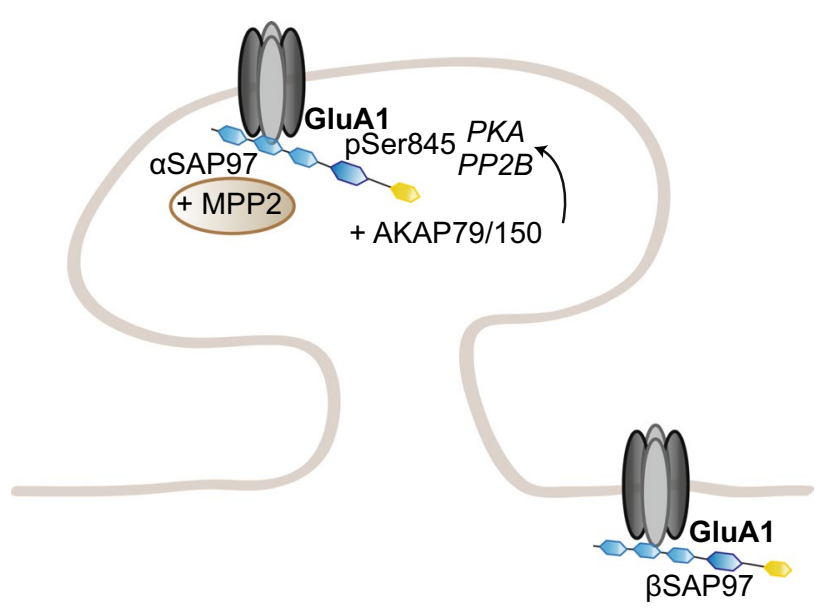

Fig. 3 Regulation of GluA1 trafficking by SAP97. SAP97 specifically regulates GluA1-containing AMPARs in an isoform-specific manner. $\beta$ SAP97 directs GluA1 to the extrasynaptic pool, while $\alpha$ SAP97 preferentially targets GluA1 to synapses 
GluA1-dependent transmission, but does not affect synaptic delivery, suggesting a role for $\beta$ SAP97 dimers in regulating GluA1 expression at the surface [231]. $\beta$ SAP97 also contains an I3 splice variant in the hook region between the $\mathrm{SH} 3$ and GK domains, which includes a binding site for the actin-binding protein $4.1 \mathrm{~N}$, another AMPAR interactant; overexpression of $\beta$ SAP97-I3 drives an increase in spine head size, as well as in surface AMPAR expression and synaptic transmission [226].

Intriguingly, further investigation of the specific roles of SAP97 isoforms reveals a common effect on synaptic plasticity via distinct mechanisms; indeed, while overexpression of both isoforms impairs LTP and enhances LTD, $\alpha$ SAP97 acts solely on synaptic AMPARs, while $\beta$ SAP97 regulates extrasynaptic AMPA and NMDARs [228]. $\alpha$ SAP97 overexpression increases the synaptic pool of AMPARs, thereby occluding further potentiation by LTP; $\beta$ SAP97 overexpression directs AMPARs and NDMARs at the perisynapse, thereby preventing LTP induction. Conversely, $\beta$ SAP97 knockdown increases the synaptic pool of AMPA and NMDARs. Consistently, overexpression of both isoforms was recently reported to increase AMPAR pool at the surface, but by different mechanisms [232]. $\alpha$ SAP97 acts, indeed, at the PSD itself, increasing its size and, therefore, the number of AMPAR slots, but also at the presynaptic clusters; $\beta$ SAP97, on the other hand, increases AMPAR density at the PSD edges and its immediate surrounding regions, but not within the PSD. Taken collectively, these studies emphasize a different role of $\alpha$ SAP97 and $\beta$ SAP97 in regulating the synaptic and perisynaptic pools of GluA1containing AMPARs, respectively.

In addition to a role at the synapse, several studies suggest a function of SAP97 in early trafficking to the synapse. SAP97 association with GluA1 was reported to occur mainly in the early secretory pathway, at the ER or Golgi apparatus, with only a small portion of GluA1 receptors bound to SAP97 at the synapse [225]. Consistently, SAP97 expression was found mainly in regions coinciding with ER and Golgi apparatus; its SH3 and GK domains were not required for its role in GluA1 delivery [233]. Moreover, SAP97 binds directly myosin VI and SAP97-GluA1-myosin VI complexes are detected in vesicles; disrupting SAP97-myosin VI interaction leads to a decrease in synapse number, surface AMPAR, and synaptic strength, emphasizing a role for SAP97 as adaptor protein in GluA1 transport [234, 235].

SAP97 also acts as a scaffold protein bridging GluA1 to other partners. One of them is AKAP79/150, which itself interacts with PKA and protein phosphatase 2 regulatory subunit (PP2B); SAP97, thus, provides a platform regulating GluA1 phosphorylation at Ser845, and thereby GluA1-mediated synaptic transmission [236]. AKAP79/150 binds a specific isoform of SAP97 containing the C-terminal I3 or I5 sequence; at this position, SAP97 can also be phosphorylated on Ser39 by CaMKII, a step necessary for synaptic delivery of SAP97, and concomitantly GluA1; this phosphorylation prevents AKAP79/150-SAP97 binding [237, 238]. This interaction is also important for the switch from GluA1-containing to GluA4-containing AMPARs between the early and late stages of behavioral conditioning; SAP97-AKAP79/PKA-GluA1 complexes are formed initially, and then replaced by SAP97-kinase suppressor of Ras (KSR) 1/PKC-GluA4 complexes, and at both times, SAP97 interacts with PSD95 to deliver the corresponding AMPAR subunit at the synapse [239]. This suggests a more general role for SAP97 in AMPAR trafficking, even without a direct interaction to GluA2-4, and is consistent with a previous study showing an involvement of SAP97-PSD95 interaction in regulating GluA1 trafficking at the synapse [240]. SAP97 can also compensate when PSD95 and PSD93 are knocked down, and using conditional SAP97 knockout mice, SAP97 involvement in GluA1 trafficking was shown to be most important during early development [241]. SAP97 also binds to the MAGUK CASK; this interaction stabilizes SAP97 in its extended conformation, which preferentially colocalizes with NMDARs, contrary to the unbound SAP97, which adopts the compact conformation and colocalizes with GluA1 receptors [242]. Consistently, CASK-SAP97 complex mediates NMDAR sorting through a specific secretory pathway, separated from AMPARs [243].

In addition, SAP97 links GluA1 to a disintegrin and metalloproteinase 10 (ADAM10), a membrane-bound secretase cleaving neuronal amyloid precursor protein (APP) at the synapse. SAP97 ability to bridge the ADAM10-GluA1 complex was significantly decreased in the hippocampi of Alzheimer's patients, and ADAM10 and GluA1 synaptic levels were consequently lower; in rodents, such a decrease in ADAM10 levels favors the amyloidogenic pathway [244, 245]. In addition to Alzheimer's disease, altered SAP97-GluA1 interactions have also been involved in schizophrenia [246]. Finally, SAP97 also has a transsynaptic action; SAP97 overexpression at the postsynapse increases presynaptic size and function, via the recruitment of GluA1, but also adhesion molecules, including cadherins, integrins, and the EphB/ephrinB family at the membrane [247]. This transsynaptic effect is exerted primarily by $\alpha$ SAP97, although $\beta$ SAP97 can also slightly increase presynaptic Bassoon levels [232]. This indicates an extensive role of SAP97 in regulating GluA1 delivery to the dendrites and relative abundance in the perisynaptic and synaptic pools, but also in synapse formation and function.

\section{MAGUK p55 subfamily member (MPP) 2}

Barely anything is known about the neuronal functions of MPP2. MPP2 is localized at the postsynapse and interacts with many PSD proteins, including itself, PSD95, SAP97, 
and actin, but also CaMKII $\alpha$, suggesting a role as a scaffold protein [248]. Recently, MPP2 was found to interact also with guanylate kinase-associated protein (GKAP) and the synaptic cell adhesion molecule (SynCAM1) 1, a protein also involved in structuring PSDs [249]. MPP2 also interacts with small conductance-activated potassium SK2 channels and positions them properly at the synapse, a crucial element for their role in synaptic plasticity [250]. A similar role for AMPARs is open for investigation.

\section{Transmembrane AMPAR regulatory proteins (TARPs)}

Transmembrane AMPAR regulatory proteins form the first family to have been identified as auxiliary proteins to neuronal AMPARs, and more generally to any neurotransmitter-gated ion receptor [148, 251, 252]. Structurally, TARPs are part of the calcium channel $\gamma$ subunit (CACNG) family, which comprises of eight members, CACNG $1-8$ or $\gamma 1-\gamma 8$. CACNG1 and 6 function primarily as calcium channel auxiliary proteins in skeletal muscles and do not interact with AMPARs at all [253]. The TARP family includes the other six members, the prototypical $\gamma 2$ or stargazin, $\gamma 3, \gamma 4, \gamma 5, \gamma 7$, and $\gamma 8$, and is subdivided into two types based on sequence homology and function: Type I contains $\gamma 2, \gamma 3, \gamma 4$, and $\gamma 8$, and is itself split into Type Ia ( $\gamma 2$ and $\gamma 3)$ and Type Ib $(\gamma 4$ and $\gamma 8$ ), while Type II encompasses the remaining $\gamma 5$ and $\gamma 7$ [252]. The spatial and temporal expression pattern of TARPs is partially overlapping and, therefore, single TARP knockout mice do not show any gross phenotype, with the exception of $\gamma 2$, suggesting partial functional redundancy $[252,254,255]$. Differences have also been observed in the stoichiometry of the TARP-AMPAR complexes, thereby influencing AMPAR function; a complex includes up to four TARP/AMPAR for $\gamma 2$ and $\gamma 3$, but seldom more than two TARP/AMPAR for $\gamma 4$. The stoichiometry varies also according to the neuronal cell type [256-258]. Type I TARPs can bind all GluA subunits, but in a mutually exclusive fashion—one TARP type per complex [259]. Finally, TARPs do not only regulate AMPAR trafficking, but also its physiological properties such as agonist/antagonist response, gating, and kinetics [252]. We will, in this review, focus on the function in AMPAR trafficking of the TARPs identified by Schwenk and colleagues as auxiliary proteins to native AMPARs, i.e., $\gamma 2, \gamma 3, \gamma 4, \gamma 7$, and $\gamma 8$ [10].

\section{TARP $\mathbf{2}$ /stargazin}

Stargazin was first identified as a disrupted gene in the mutated chromosome 15 of the stargazer mice, a spontaneous mouse mutant displaying absence epilepsy [260]. Subsequent studies in the stargazer cerebellum revealed that stargazin interacts with AMPARs and PSD proteins, including PSD95, PSD93, SAP97, and SAP102 [167]. Since then, stargazin was found to regulate several aspects of AMPAR trafficking, including synaptic targeting [167, 261, 262], surface receptor delivery [263], stabilization [264], diffusion [265, 266], and endocytosis [267], and is, therefore, involved in plasticity processes such as LTP and LTD [268, 269] and synaptic scaling [270, 271]. Stargazin function is highly specific for AMPARs, as surface delivery of NMDA and kainate receptors is stargazin-independent [272].

The multiple functions of stargazin are preferentially mediated by its different domains, with the C-terminal cytoplasmic tail and the extracellular domain influencing mainly receptor trafficking and channel properties, respectively [273-275]. Stargazin binds GluA subunits intra- and extracellularly, and its interaction with the glutamate-binding domain of AMPARs is important for channel desensitization [276]. On the other hand, the C-terminal domain contains a membrane sorting signal important for stargazin regulation of AMPAR synaptic delivery [261]. The first reconstruction of stargazin structure, performed in a lipid bilayer, showed that the C-terminus strongly interacts with the lipidic membrane, leading to an extended open conformation and thereby facilitating protein interactions [277]. Several recent studies further investigated the AMPAR-stargazin complex [278-282]. They dissected the role of stargazin in modulating AMPAR gating, first via the destabilization of closed receptors by its initial binding, and by the subsequent stabilization of AMPAR activated state by electrostatic interactions between stargazin and the receptors [278, 281, 282]. Its positioning below the AMPAR ligand-binding domain enables stargazin to modulate receptor gating by regulating intra- and inter-dimer interactions, but also to act as a scaffold bridging the receptors to other regulatory proteins, emphasizing the intricate connections between the various functions assumed by stargazin [279, 280].

Stargazin plays an essential role in AMPAR synaptic targeting; surface expression of the receptors is, indeed, reduced in stargazer cerebella, where stargazin is the major TARP [167]. As mentioned before, stargazin-PSD95 interaction is essential for its regulation of AMPAR synaptic targeting [167] (Fig. 2). In the ER, stargazin has been suggested to act as a chaperone-like protein ensuring the correct folding of AMPAR subunits, although it differs from classical chaperones in its continuous association with its targets outside of the ER [263]. AMPARs in the stargazer cerebellum are not completely $\mathrm{N}$-glycosylated and, therefore, do not properly mature [259] and the unfolded protein response (UPR) is upregulated in the cerebellum of stargazer mice [263]. However, another study found that stargazin played a major role at later stages of AMPAR maturation, and that its chaperone-like duties may become necessary only upon high levels of AMPAR synthesis [283]. Stargazin forms, indeed, 
a complex with GluA2 and MAP1A light chain (MAP1ALC2), which is important for AMPAR early trafficking, likely prior to entering the PSD, as the complex does not include PSD proteins [284]. At a later stage of trafficking, stargazin also bridges AMPARs and PSD95 to the Golgienriched neuronal isoform of protein interacting specifically with TC-10 (nPIST), an important interaction for surface expression and clustering of AMPARs [285].

Stargazin-PSD95 interaction is also crucial for controlling synaptic abundance of AMPARs by regulating their diffusion between extrasynaptic and synaptic pools [7, 168]. Consistently, enhancing PSD95 binding by extending the length of stargazin cytoplasmic tail was more recently shown to increase AMPAR trapping at synaptic sites [286]. Phosphorylation of Thr321 within stargazin PDZ-binding domain by PKA disrupts its binding to PSD95 and thereby synaptic clustering and function of AMPARs [287, 288]. Intriguingly, Thr321 can also be phosphorylated by MAPK, but with different consequences: blocking PKA-mediated phosphorylation prevents LTP, while preventing MAPK-mediated phosphorylation blocks LTD, but not LTP [268]. These results are consistent with MAPK role in AMPAR removal during LTD; they also suggest that PSD95 is required for some, but not all, of stargazin functions. Taken collectively, these studies underlie the role of phosphorylation as bidirectional switch for stargazin role in AMPAR trafficking and in plasticity.

Stargazin can also be phosphorylated at nine serine residues of its cytoplasmic tail; the phosphorylation is carried out by CaMKII and PKC, and dephosphorylation by phosphatase 1 (PP1) downstream of PP2B/calcineurin [289]. Phosphorylation on these residues increases stargazin binding to PSD95, but prevents its binding to lipid bilayers; these mutually exclusive interactions add a further level of complexity to stargazin regulation of AMPAR synaptic delivery [290]. Interestingly, synaptic NMDAR activity can trigger serine phosphorylation and dephosphorylation, depending on the stimulation protocol and the type of plasticity induced - phosphorylation for LTP; dephosphorylation for LTD [289, 291]. Consistently, calcineurin-mediated dephosphorylation of stargazin is also required for cerebellar LTD [269]. Mechanistically, dephosphorylated stargazin binds the clathrin complex AP-2, triggering clathrinmediated endocytosis of AMPARs, which are then delivered to late endosomes/lysosomes upon binding of stargazin to AP-3 [267]. Interestingly, the role of stargazin in endocytosis might also be stimulus-dependent: glutamate-induced desensitization indeed leads to the dissociation of stargazin/AMPAR complexes, and while stargazin remains stably at the membrane, AMPARs are subsequently internalized [264]. Here, stargazin passively sets up AMPARs for internalization simply by unbinding them, contrary to the active part taken in NMDAR-induced endocytosis. Another study indicates that, following the decreased affinity between stargazin and AMPARs due to glutamate-induced desensitization, AMPARs leave the synapse by lateral diffusion rather than endocytosis; this increased surface motility facilitates their replacement with naive receptors [266]. These results are not mutually exclusive; several conformations of desensitized AMPARs, with potentially different affinities for stargazin and, therefore, set up for separate pathways, have also been reported [292].

In addition to AMPAR synaptic delivery and cycling, stargazin phosphorylation by CaMKII regulates their lateral diffusion: NMDAR-induced calcium influx activates CaMKII, leading to stargazin phosphorylation and increasing its binding to PSD95, thereby trapping PSD95-stargazinAMPAR complexes at the synapse [265]. Similarly, stargazin serine phosphorylation is required for the new synaptic insertion of AMPARs during tetrodotoxin (TTX)-induced synaptic upscaling; it is also important for the experiencedependent development of the retinogeniculate synapse, and it is increased upon visual deprivation during that phase [270]. Conversely, inducing synaptic downscaling leads to the dephosphorylation of stargazin serine residues, an increased surface motility of stargazin and AMPARs, and a higher AMPAR endocytosis, the latter being mediated by stargazin interaction with AP-2 and AP-3 [271].

Interestingly, stargazin is also nitrosylated by nitric oxide (NO) under basal conditions, enhancing its binding to AMPARs and their surface expression; nitrosylation is increased upon NMDAR activation, adding a further regulatory residue to NMDAR-governed stargazin modulation of AMPAR trafficking [293]. Stargazin can also be glycosylated, although the influence of this posttranslational modification on stargazin functions remains to be investigated [294].

In addition to DLG-MAGUK and the clathrin adaptor complex, stargazin also binds several other proteins regulating its functions in AMPAR trafficking. Stargazin interacts, for instance, with the adaptor protein Erbin in cortical parvalbumin-positive (PV) interneurons; this interaction is essential for stargazin stability at the surface, and, therefore, AMPAR surface expression and function [295]. Consistently, stargazer mice were shown recently to display altered AMPAR subunit composition in PV interneurons, leading to a loss of the feedforward inhibitory circuit in the somatosensory cortex; these data provide a mechanistic link between stargazin and the absent epileptic seizures characteristic of the stargazer mouse models $[296,297]$. This may stem from a differential regulation of AMPAR subunits trafficking by stargazin; indeed, while stargazin targets GluA2 subunits to the dendritic surface, it directs GluA1 receptors only to the dendrites, but not the surface [298]. Stargazin exerts additionally a protective effect for GluA1-containing receptors against lysosomal degradation, but not for GluA2/GluA3 
heterodimers. Interestingly, stargazin also binds another MAGUK protein, membrane-associated guanylate kinase 2 (MAGI-2), a scaffold protein interacting with many proteins involved in neuronal morphology, such as dendrin, axin, and catenins; this interaction is important for MAGI-2 localisation at the synapse and provides a link between AMPARs, TARPs, and neuronal morphology [299]. Consistently, Type I TARPs influence the development of cortical pyramidal dendritic trees, stargazin specifically at later stages [300]. Taken collectively, these studies underlie the importance of stargazin as a scaffolding protein, bridging AMPAR trafficking and other crucial neuronal processes.

\section{$\operatorname{TARP} \gamma 3, \gamma 4$, and $\gamma 8$}

Functionally, $\gamma 3, \gamma 4$, and $\gamma 8$ were classified as TARPs when it was shown that their transfection in stargazer cerebellar granule cells could restore AMPAR-mediated responses [264]. Like stargazin, they are enriched in the PSD and are important for surface expression of AMPARs in the brain regions where they are expressed; $\gamma 3$ is mainly, but not exclusively, present in the cerebral cortex, $\gamma 4$ in the olfactory bulbs, striatum, and glia, and $\gamma 8$ in the hippocampus [264]. Contrarily to stargazin, $\gamma 3$ and $\gamma 8, \gamma 4$ expression reaches its peak during embryonic and early postnatal development and slowly decreases afterwards [264]. Like stargazin, $\gamma 3$ and $\gamma 8$ interact with PSD95 and PSD93; it is currently unknown, but probable, for $\gamma 4$ [171].

$\gamma 3$ and $\gamma 4$ knockout mice do not show any gross phenotype; neither do $\gamma 3 / \gamma 4$ double knockout mice [254, 255, 301]. However, stargazer $(s t g) / \gamma 3$ double knockout mice die a couple of weeks after birth, a stronger phenotype than pure stargazer mice [254]. This suggests that the lack of phenotype in $\gamma 3$ knockout mice comes from a compensation by overlapping TARPs, i.e., stargazin, but also $\gamma 8$. Indeed, synaptic AMPAR content and function is unaffected in $s t g /$ $\gamma 3$ double knockout hippocampal neurons, where $\gamma 8$ is still expressed, but impaired in cerebellar Golgi neurons, where $\gamma 8$ is not. This loss of synaptic AMPARs reflects specifically a decrease in GluA2-containing receptors, implying a subunit-specific trafficking regulation by stargazin and $\gamma 3$. Interestingly, Golgi neurons are unaffected in single knockout mice, suggesting that stargazin or $\gamma 3$ alone is sufficient to regulate AMPAR trafficking and function [254].

The phenotype of $s t g / \gamma 4$ double knockout mice appears to be background-dependent, as this strain has been reported viable by Menuz and colleagues, but with very low levels of birth by Letts and colleagues [255, 301]. To compensate for the lack of viable $s t g / \gamma 4$ double knockout mice in their hands, Letts and colleagues crossed $\gamma 4$ knockout mice to milder alleles of the stargazin gene, waggler and stargazer3J. These double mutants were viable and displayed an increased number of seizures compared to single waggler or stargazer3J mice; this worsened phenotype indicates that $\gamma 4$ acts as a seizure repressor, although the exact mechanisms are unclear [301]. This may be related to the specific modulation of AMPAR function by $\gamma 4$; indeed, while most properties are regulated to a similar extent to stargazin, AMPAR desensitization is much more strongly modulated by $\gamma 4$ [302]. Triple knockout mice for stargazin, $\gamma 3$ and $\gamma 4$ die at birth from apnea and are paralyzed, pointing towards a developmental role for $\gamma 3$ as well [255]. Intriguingly, AMPAR targeting to the perisynaptic and synaptic surface is unaffected in cortical and spinal neurons [255]. This suggests a compensation by another TARP; as it is expressed in both neuronal populations shortly after birth and can influence AMPAR function at that age, $\gamma 8$ is a likely candidate [255]. In the nucleus accumbens, $\gamma 4$ was found to mainly localize in perisynaptic membranes, contrary to the synaptic localization of stargazin, suggesting a preferential role in regulating the perisynaptic AMPAR pool [303] (Fig. 4).

While $\gamma 8$ knockout mice appear normal, they do show a strong impairment of AMPAR trafficking, contrary to $\gamma 3$, $\gamma 4$, or $\gamma 7$ knockout mice [8]. $\gamma 8$ loss leads to a striking $85 \%$ reduction of GluA proteins in the hippocampus, where $\gamma 8$ is primarily expressed; the remaining receptors are mislocalized and do not reach the dendritic membrane. Consistently, $\gamma 8$ overexpression enhances surface AMPAR expression, indicating a role in AMPAR synaptic delivery. In $\gamma 8$ knockout mice, both extrasynaptic and synaptic AMPAR pools are affected; however, the extrasynaptic pool is much more depleted, suggesting a selective delivery of the available AMPARs to the synaptic pool. Basal synaptic transmission and LTP are impaired, likely due to an insufficient extrasynaptic pool of AMPARs; on the other hand, LTD is intact, implicating that $\gamma 8$ is not involved in NMDARinduced AMPAR endocytosis $[8,304]$. The stronger reduction in surface AMPARs in $s t g / \gamma 8$ double knockout mice suggests that stargazin mediates the trafficking of the few AMPARs expressed at the membrane in $\gamma 8$ knockout mice [8]. $\gamma 3$ may also complement $\gamma 8$ and stargazin, but as $s t g /$ $\gamma 3 / \gamma 8$ mice die embryonically, it is difficult to assess. On the other hand, $\gamma 4$ is most likely not involved, as $\gamma 3 / \gamma 4 / \gamma 8$ triple knockout mice, who are viable and fertile, do not show a stronger phenotype than $\gamma 8$ knockout mice [255].

Another mouse line lacking $\gamma 8$ on a different background shows a similar phenotype, as surface AMPARs are reduced in hippocampal synapses, while intracellular AMPARs are unaffected [305]. However, the synaptic and extrasynaptic pools are here similarly reduced; as the global abundance of AMPARs is also much less decreased (55\% instead of $85 \%$ reduction), this is still consistent with a preferential delivery to the synaptic pool, with a greater amount of AMPARs now available to the extrasynaptic pool [305]. Both studies indicate a role for $\gamma 8$ in AMPAR delivery to the surface and the activity-induced mobilization of the extrasynaptic pool 
Fig. 4 Regulation of AMPAR trafficking by TARP $\gamma 3, \gamma 4$, $\gamma 7$, and $\gamma 8$, CNIH and GSG1L. TARP $\gamma 3, \gamma 4, \gamma 7$, and $\gamma 8$, CNIH2 and 3, and GSG1L modulate AMPAR trafficking to and at the synapse. $\gamma 3, \gamma 4$, and $\gamma 8$ and $\mathrm{CNIH} 2$ together, target AMPARs to the extrasynaptic pool. $\gamma 8$ and $\mathrm{CNIH} 2$ also cooperatively regulate AMPAR lateral diffusion to and anchoring at the synapse, by binding MAGUK proteins. TARP $\gamma 7$ and CNIH3 are also present at the synapse. GSG1L, on the other hand, promotes AMPAR endocytosis and negatively regulates AMPAR trafficking to the synapse

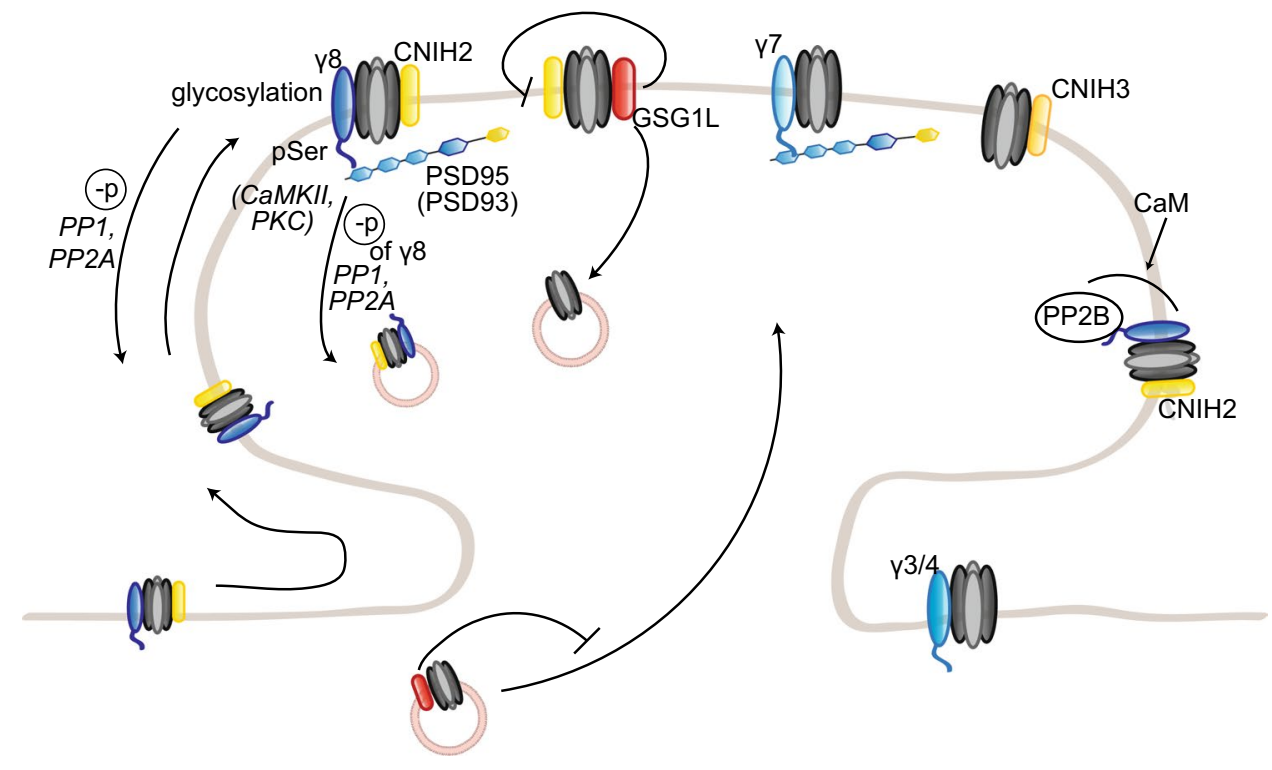

by lateral diffusion (Fig. 4). Consistently, $\gamma 8$ was recently described as the only TARP expressed at the nonperforated synapses of the hippocampal Schaffer collaterals onto CA1 pyramidal cells, which have a lower AMPAR density compared to perforated synapses, where stargazin and $\gamma 3$ were also detected [306]. In stg perforated synapses, compensatory $\gamma 8$ upregulation failed to completely rescue surface AMPAR expression; conversely, in $\gamma 8$ knockout perforated synapses, compensation was successfully carried by stargazin upregulation. This suggests that stargazin and $\gamma 8$ regulate AMPAR trafficking and synaptic density at different levelsstargazin being required for high synaptic expression and $\gamma 8$ for low density, basal expression; the lack of changes in $\gamma 3$ knockout mice points toward a different role for $\gamma 3$ in the hippocampus [306].

While the PDZ-binding domains are identical between Type I TARPs, $\gamma 8$ possesses unique stretches at the C-terminus and diverges from stargazin at the other two intracellular domains, suggesting the existence of a different regulatory mechanism [289]. Indeed, swapping all cytoplasmic domains between stargazin and $\gamma 8$ is enough to completely exchange the synaptic AMPAR phenotype between the two TARPs, showing that intracellular domains as a whole regulate synaptic AMPAR trafficking [307]. The role of the PDZbinding domain is still ambiguous; it has been hypothesized to be required for the synaptic localization of AMPAR/ TARP complexes via PSD95 binding by TARP, and, therefore, subsequent LTP. Consistently, a recent study reported that LTP was impaired in single-cell genetic experiments, where GluA1 homomers tethered to PDZ-binding domainlacking $\gamma 8$ were expressed on a triple GluA knockout background [308]. However, knockin mice expressing $\gamma 8$ lacking its PDZ-binding domain display an impaired basal transmission, but normal LTP, suggesting that different mechanisms are regulating synaptic AMPAR localization in these two events [304]. Another possibility is compensation by other TARPs in the knockin mice, or a differential regulation for AMPAR heteromers compared to GluA1 homomers; additional work is required to elucidate this model. In both studies, however, the decreased basal transmission is attributed to lower synaptic AMPAR content, while the extrasynaptic pool is unaffected, suggesting that the backbone of $\gamma 8$ is important for extrasynaptic AMPAR targeting, in line with other studies [8, 304, 306]. Consistently, and contrary to stargazin PSD localization, $\gamma 8$ is preferentially found in the extrasynaptic membranes [304, 309].

Like stargazin, $\gamma 8$ is subjected to several posttranslational modifications. $\gamma 8$ is notably phosphorylated at several C-terminal serine residues by CaMKII and PKC, and dephosphorylated by PP1 and/or PP2A, but not PP2B [289, 309]. $\gamma 8$ phosphorylation was recently found to be required for LTP, as demonstrated by an impaired LTP in mice expressing phosphodeficient $\gamma 8$; this is consistent with the requirement for LTP of the $\gamma 8$ backbone, outside of the PDZ-binding domain [310]. Contrary to stargazin, which does not bind $\mathrm{PP} 2 \mathrm{~B}$, but is a substrate, $\gamma 8$ binds the phosphatase PP2B/ calcineurin in a CaM-dependent manner, but is not a target; via this association, $\gamma 8$ may regulate AMPAR phosphorylation levels and, therefore, their trafficking during basal conditions, but also LTP and LTD [311]. $\gamma 8$ is also N-glycosylated, a modification essential for its trafficking to the membrane and surface expression; moreover, unglycosylated $\gamma 8$ on $\gamma 8$ knockdown background is unable to rescue the decreased AMPAR surface expression, suggesting that the maturation of $\gamma 8$ is required for the correct synaptic delivery and surface expression of AMPARs [294].

$\gamma 3, \gamma 4$, and $\gamma 8$ have, therefore, all been involved in regulating AMPAR trafficking. $\gamma 8$ is now well established as the 
major TARP in the hippocampus, and its main role appears to modulate AMPAR delivery to the extrasynaptic pool and its lateral diffusion to the synapse. On the other hand, the exact roles of $\gamma 3$ and $\gamma 4$ are still uncertain due to the general compensation by the preponderant stargazin and $\gamma 8$, and require further work.

\section{Tarp Y7}

TARP $\gamma 7$ was first identified as a regulatory protein for voltage-gated calcium channels; its low-sequence homology to Type I TARPs and its different structure suggested that it did not function as a TARP, like $\gamma 5$ [312]. However, $\gamma 7$ was then shown to be highly expressed in the cerebellum, especially in Purkinje cells, granule cells, and stellate cells [313, 314]. $\gamma 7$ is enriched in the PSD and binds all GluA subunits and PSD95 (Fig. 4); furthermore, $\gamma 7$ modulates AMPAR trafficking and gating, and its overexpression enhances glutamate-evoked AMPAR currents [313]. $\gamma 7$ regulates also specifically GluA2-containing AMPARs and its modulation depends on GluA2 editing [315].

In addition, $\gamma 7$ and stargazin are abundantly detected at various cerebellar asymmetrical synapses (such as the parallel or climbing fiber synapses onto Purkinje cells) but absent from symmetrical synapses (basket or stellate cell synapses onto Purkinje cells) [314]. Knockout mice for stargazin (stg), $\gamma 7$, or double knockout for $s t g / \gamma 7$ showed a selective reduction in synaptic AMPAR subunits content-GluA2/3 were markedly affected in stg, GluA1/4 moderately in $\gamma 7$ knockout, and GluA2/3/4 in double knockout mice. Intriguingly, these losses were predominant at different asymmetrical synapses, pointing towards a cooperation between stargazin and $\gamma 7$ to promote AMPAR synaptic expression [314]. The lack of phenotype displayed by $\gamma 7$ knockout mice and the cerebellar impairments shown by the stargazer mice suggest, however, that $\gamma 7$ function is relatively small and unable to fully compensate for the lack of stargazin. Indeed, as shown by the lack of further impairment in $s t g / \gamma 7$ double knockout compared to $s t g$ mice, $\gamma 7$ contribution to excitatory transmission is negligible [316]. Nonetheless, in the double knockout mice, the climbing fiber-to-Purkinje cell synapses are affected and their excitatory transmission impaired, suggesting a specific modulation by $\gamma 7$ of this class of synapses. Consistently, selective deletion of stargazin in Purkinje cells on a wild-type background did not cause any motor defects, while this deletion on a $\gamma 7$ knockout background severely impaired multiple motor behaviors [316]. These results suggest that stargazin and $\gamma 7$ cooperation is specifically regulating the climbing fiber input onto Purkinje cells, and that this collaboration is essential for motor control.

On the other hand, $\gamma 7$ has also been implicated in regulating the trafficking and perisynaptic accumulation of
GluA2-lacking, calcium-permeable AMPARs in stellate and granule cells [317]. These receptors are, however, unable to cluster at the synapse and AMPAR-mediated transmission is then ensured by "TARPless" AMPARs, suggesting that neither stargazin nor $\gamma 7$ is required for surface expression and a role for $\gamma 7$ in trapping AMPARs in the extrasynaptic pool [317]. Consistently, $\gamma 7$ selectively increases calciumpermeable AMPAR expression at the synapse of granule cells and downregulates GluA2-containing, calcium-impermeable AMPARs [318]. Conversely, however, another study has shown the requirement of stargazin for surface AMPAR expression in cerebellar stellate cells [262]. All in all, the role of $\gamma 7$ in cerebellar granule and stellate cells appears still controversial; its role in Purkinje cells seems so far unchallenged. Its small contribution to AMPAR trafficking may indicate a greater role in unrelated functions; indeed, $\gamma 7$ regulates the stability of specific mRNAs via its interaction with the RNA-binding heterogeneous nuclear ribonucleoprotein (hnRNP) A2 and promotes neurite outgrowth via the retrograde transport of signaling vesicles $[319,320]$.

\section{Cornichon proteins (CNIHs)}

$\mathrm{CNIH} 2$ and 3 are transmembrane proteins first identified as cargo transporters in Drosophila, and only more recently as AMPAR auxiliary subunits in a proteomic analysis of AMPAR complexes [321, 322]. CNIHs appear to bind the majority of AMPARs in the rat brain, even more so than TARPs. Like TARPs, CNIHs are involved in both AMPAR trafficking and channel kinetics, as $\mathrm{CNIH}$ overexpression increases surface AMPAR expression and slows down inactivation and desensitization, suggesting a role in stabilizing the channel in an open, active configuration [322]. CNIH2 and 3 expression patterns in the brain show a peak during the first two postnatal weeks and a slow decrease over time, contrary to GluA subunits; however, the proportion of $\mathrm{CNIH}$ bound to AMPARs remains constant, indicating a specific reduction in AMPAR-free CNIH and suggesting a switch from general cargo transporter to AMPAR auxiliary subunit [323].

Immediately after CNIH identification as auxiliary subunits, two partially conflicting studies regarding their exact functions were published [324, 325]. While Shi and colleagues found a major role in cargo trafficking, with very little surface expression in hippocampal neurons [325], Kato et al. showed that $\mathrm{CNIH} 2$ is not only present in postsynaptic densities, but it also associates with TARP $\gamma 8$ and AMPARs in a complex cooperatively regulating channel gating and pharmacology, specifically AMPAR desensitization [324]. Intriguingly, CNIH2 levels were strikingly reduced in $\gamma 8$ knockout mice, similarly to the reduced levels of GluA1/2 subunits observed in these mice $[8,324]$. CNIH proteins lack 
a synaptic targeting PDZ-binding site, which is consistent with a role for AMPAR trafficking towards the extrasynaptic pools together with $\gamma 8$. In agreement, Shi et al. showed that $\mathrm{CNIH} 2$ overexpression is able to partially rescue extrasynaptic, but not synaptic AMPAR pool in stargazer granule cells; coexpression with $\gamma 8$, as found by Kato and colleagues, enhances that rescue [324, 325]. Furthermore, the roles of $\mathrm{CNIH} 2$ as cargo transporter and auxiliary subunit are not mutually exclusive; in hippocampal neurons, $\mathrm{CNIH} 2$ mediates primarily AMPAR transport between the ER and Golgi complexes, but interaction with GluA subunits leads to its escape from the early anterograde pathway and its transport with the receptor to the cell surface, where it stays associated and becomes a membrane protein [326] (Figs. 4, 7). A similar double role in trafficking and gating regulation was found for the sole CNIH homolog in C. elegans, suggesting a conserved dual function [327].

The role of CNIH proteins may also depend on the neuronal cell type, especially via the differential expressions of TARP isoforms. While CNIH2 differentially modulates AMPAR gating by regulating the stoichiometry of TARPs within AMPAR complexes, it only reaches the surface when coexpressed with $\gamma 8$, explaining the localization and channel gating differences between $\gamma 8$-expressing hippocampal neurons and $\gamma 8$-lacking Purkinje cells [328, 329] (Fig. 4). In addition, the role of CNIH proteins may also be GluA subunit-dependent. CNIH2 and 3 bind preferentially to GluA1 subunits and facilitate the transit to and expression at the surface of GluA1/A2 heteromers over GluA2/A3 receptors; $\mathrm{CNIH} 2$ and 3 conditional knockout mice show a deep reduction in AMPAR function due to a retention of immature receptors at the ER, a shift in AMPAR transmission consistent with a loss of GluA1 receptors, and impaired LTP [330]. In agreement, both $\mathrm{CNIH} 2$ and 3 are associated at the surface with GluA2-lacking, calcium-permeable AMPARs and regulate their desensitization [331]. However, another study reports that $\mathrm{CNIH}$ proteins bind equally to GluA1 and GluA2 subunits, and that the lack of binding to GluA2 might rise from a technical issue; in this report, CNIH2 was found to mediate the switch from fast to slow AMPAR-mediated transmission in hilar mossy cells, further emphasizing the role of CNIH in AMPAR kinetics [332].

Structurally, CNIH proteins bind AMPARs via their membrane-proximal domain; compared to $\mathrm{CNIH} 1$ and 4, $\mathrm{CNIH} 2$ and 3 have an additional extracellular loop interacting with the ligand-binding domain and transmembrane domain of GluA subunits and necessary to exert their regulatory functions [333, 334]. These elements are both bound by CNIH and $\gamma 8$, but lead to a regulation of AMPAR gating in opposite directions by each auxiliary protein, providing a structural basis for the regulation by CNIH of $\gamma 8$-mediated AMPAR de- and resensitization and the differential pharmacology induced by the binding of either auxiliary protein $[334,335]$. Further studies are required to investigate the domains involved in regulating AMPAR trafficking from the ER to the membrane and to distinguish the specific roles of $\mathrm{CNIH} 2$ and 3.

\section{Germline-specific gene 1-like (GSG1L)}

GSG1L was recently identified as an AMPAR auxiliary subunit with a structural similarity to the TARP family [10, 336]. In heterologous systems and Xenopus oocytes, GSG1L slows down AMPAR desensitization and deactivation, similarly to TARPs [10, 336]. In hippocampal CA1 neurons, however, GSG1L modulates AMPAR trafficking and gating in a very different way to TARPs, as it downregulates AMPAR trafficking to the synaptic and extrasynaptic pools and enhances deactivation and desensitization, thereby favoring a reduction in AMPAR function at the synapse [337] (Fig. 4). Furthermore, AMPAR endocytosis is promoted upon GSG1L overexpression and reduced in GSG1L knockout rats. LTP is enhanced in these rats, consistently with the increased availability of extrasynaptic AMPARs and the reduced endocytosis rate [337]. Intriguingly, GSG1L reverts CNIH2 modulation of AMPAR kinetics both in Xenopus oocytes and CA1 neurons; as loss of CNIH2 occludes GSG1L effects, GSG1L function might actually be exerted via CNIH2 [10, 337]. Remarkably, in hippocampal granule cells, while GSG1L also negatively regulates AMPAR trafficking and surface expression, the protein only influences AMPAR gating when overexpressed, but not upon knockout suggesting that, in this population, GSG1L is only required for synaptic trafficking and not for channel properties [338]. In the brainstem nucleus abducens, GSG1L acts as a chaperone protein during classical conditioning, which requires the consecutive delivery of GluA1-containing receptors, followed by GluA4-containing heteromers; the former are bound and chaperoned by $\gamma 8$, and the latter by GSG1L, providing the necessary subunit specificity for the learning paradigm; these results further emphasize the role of GSG1L in AMPAR trafficking [339]. Structurally, the cytoplasmic region of GSG1L and especially the Loop1 domain are crucial to mediate its regulation of AMPAR function [337]. GSG1L binding to AMPARs induces a conformation promoting the desensitized state, providing a structural basis for its physiological functions [340, 341]. Further investigation is required to understand the specific role of GSG1L in conjunction with other auxiliary proteins.

\section{Shisa 6 and 9 (cystine-knot AMPAR modulating proteins (CKAMP) 52 and 44)}

The Shisa family of scaffold proteins are characterized by an N-terminal cysteine-rich and a proline-rich C-terminal regions and include several subclasses supporting a very wide range of cellular functions [342]; one subgroup is 
formed by the members Shisa6-9, which are also known after their function and molecular weight as cystine-knot AMPAR modulating proteins (CKAMPs) [343, 344]. Shisa9, or CKAMP44, was the first Shisa protein to be identified as interacting with AMPARs, but also with PSD95 and stargazin; Shisa9 is localized at the PSD and modulates AMPAR desensitization and short-term plasticity at hippocampal synapses [343] (Fig. 5). Shisa9 can bind AMPARs in complex with other auxiliary proteins, such as TARP $\gamma 2, \gamma 4$ or $\gamma 8$, suggesting that they do not share the same binding site [345]. In the hippocampus, Shisa9 is lowly expressed in CA1 neurons and seems to play a very minor role; however, in the dentate gyrus, it is highly expressed and associated with AMPAR/ $\gamma 8$ complexes. Shisa9 binding to PSD95 and the reduction in AMPAR/ $\gamma 8$ complexes in Shisa9 knockout mice suggest that Shisa9 stabilizes AMPARs at the surface. Consistently, spine density is positively regulated by Shisa 9 and $\gamma 8$ [345]. Shisa9 knockout mice display a decreased surface AMPAR expression equally at the synaptic and extrasynaptic sites, indicating that Shisa9 does not regulate preferentially one of these pools. LTP in dentate granule cells was also unaffected in these mice, contrary to $\gamma 8$ knockout mice, where it is strongly reduced, consistently with LTP at the Schaffer collaterals $[8,345]$. AMPAR de- and resensitization and short-term plasticity is regulated by $\gamma 8$ and Shisa 9 in opposite directions; interestingly, this means that AMPAR desensitization in double knockout mice is actually similar to wild-type mice, as the knockout compensate each other [345]. Very recently, Shisa9 was shown to be crucial for the integration of visual inputs at the reticulogeniculate synapse, which depends on short-term depression of AMPARs; in agreement with the literature, Shisa9 attenuates AMPAR resensitization, thereby enhancing short-term depression and

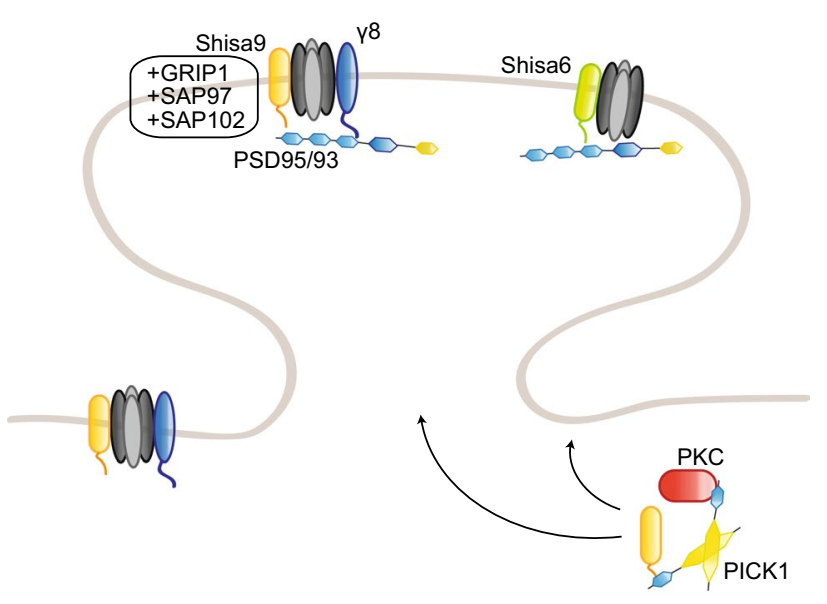

Fig. 5 Regulation of AMPAR trafficking by Shisa proteins. Shisa6 and Shisa9 favor AMPAR stabilization at the synapse by binding to PSD95. Shisa9 is present in $\gamma 8$-bound AMPAR complexes and binds several other PDZ domain-containing synaptic proteins; it also forms a complex with PICK1 and PKC upon trafficking to the synapse preventing neuronal hyperactivation, but it also promotes surface AMPAR expression and thereby synaptic strength, suggesting that Shisa9 exerts a carefully balanced modulation on the relay of visual signals [346].

Structurally, AMPAR binding requires a region downstream of Shisa9 transmembrane domain and the cystineknot domain is essential for its modulation of AMPAR trafficking and gating [345]. In addition to PSD95, the cytosolic PDZ-binding domain of Shisa9 binds to several other scaffold proteins, including PSD93, SAP97, SAP102, GRIP1, and PICK1 [347, 348]. Disrupting PDZ interactions is enough to phenocopy the effect on AMPAR synaptic localization and transmission of Shisa9 knockout suggesting that at least one of these partners is essential for Shisa9 regulatory function [347]. Recently, interaction with PICK1 was shown to bridge Shisa9 with PKC, inducing Shisa9 phosphorylation; PICK1 association requires binding of another N-terminal domain of Shisa9, which is important for its regulation of AMPAR function, suggesting a possible competition between AMPAR and PICK1 [348]. As PICK1 interaction with PKC is important for its targeting to the membrane, this could provide a mechanism for the membrane targeting of Shisa9/PICK1, followed by a switch of Shisa9 to AMPAR/TARP/PSD95 complexes at the surface.

In addition to Shisa9, Shisa6, or CKAMP52, was also identified specifically as part of the native AMPAR complexes [10, 349]. Like Shisa9, Shisa6 is present at the PSD and binds PSD95 via its cytosolic domain, forming a complex with AMPARs and trapping them at the synapse; moreover, Shisa6 regulates AMPAR gating by preventing desensitization, thereby protecting hippocampal CA1 neurons from depression [349] (Fig. 5). Of note, while not part of the native complexes as described by Schwenk and colleagues [10], Shisa7 has also recently been found to associate with AMPARs and regulate their synaptic function; Shisa7 knockout mice impaired LTP initiation and maintenance, and decreased short-term and long-term contextual fear memory [350]. As the expression pattern of Shisa6-9 is developmentally regulated and as they differentially regulate AMPAR trafficking and gating in a cell-type-dependent manner [344], additional studies are necessary to determine more precisely their specific role in the various different brain regions.

\section{Leucine-rich repeat transmembrane protein (LRRTM) 4}

LRRTM4 belongs to the four-member leucine-rich repeat transmembrane protein (LRRTM) family of cell adhesion molecules, and alone in this family has been reported as a member of native AMPAR complexes [10]. Little is known about LRRTM4 role in synaptic function. LRRTMs are predominantly expressed in the brain, with partially overlapping 
patterns; LRRTM4 itself is highly expressed from the end of embryonic development in several brain regions, including the cerebral cortex, the dentate granule cells and the CA3, but not CA1, pyramidal cells in the hippocampus, and a subset of cerebellar Purkinje cells [352]. The LRRTM family has been mainly characterized for its role as synaptic organizers (recently reviewed in Ref. [353]). LRRTMs are present at the postsynaptic sites; during development, they promote presynaptic differentiation in contacting axons [354], and as no effect on inhibitory synapses has been reported so far, their synaptogenic role appears specific to excitatory synapses [353]. Contrary to LRRTM1-3, which acts as receptors in trans for presynaptic neurexins, similarly to neuroligins, LRRTM4 interacts with glypicans (GPCs), a family of heparan sulfate proteoglycans [355-359]. More specifically, LRRTM4 binding to axonal GPC-4 induces their clustering on their respective side of the synaptic cleft, and inhibiting this interaction using heparinases blocks LRRTM4 synaptogenic function [357, 360]. GPC-4 additionally binds the LAR tyrosine phosphatase PTP $\sigma$, and the formation of the LRRTM4/GCP-4/PTPs complex mediates presynaptic differentiation and excitatory transmission [358]. In LRRTM4 knockout mice, dentate granule cells, but not CA1 pyramidal cells, exhibit a lower number of excitatory synapses; they also displayed lower synaptic levels of PSD95, an impaired excitatory (but not inhibitory) transmission and an inability to insert or stabilize new AMPARs at the surface following chemical LTP induction [360].

Interestingly, a regulatory role in AMPAR trafficking has also been found for LRRTM1 and 2. Indeed, LRRTM2 has been shown to directly bind PSD95 and regulate surface AMPAR trafficking [351]. Additionally, knocking down both proteins leads to decreased surface AMPARs following chemical LTP and an impaired LTP in the adult Schaffer collaterals [361]. These findings were very recently confirmed in genetic double knockout mice, where the complete deletion allowed Malenka and colleagues to uncover a role for LRRTM1 and 2 in basal AMPAR transmission, strongly suggesting a role in maintaining a sufficient pool of AMPARs at the surface [362]. Taken together, these results indicate a common role for LRRTMs in regulating AMPAR trafficking and function, albeit in different neuronal populations (Fig. 6). As LRRTM expression patterns are not completely mutually exclusive, further work is required to determine the existence of member-specific mechanisms.

\section{Proline-rich transmembrane (PRRT) proteins 1-2}

PRRT 1 and 2 are type II transmembrane proteins; they were recently classified as members of the newly identified Dispanin family of transmembrane proteins, which are characterized by

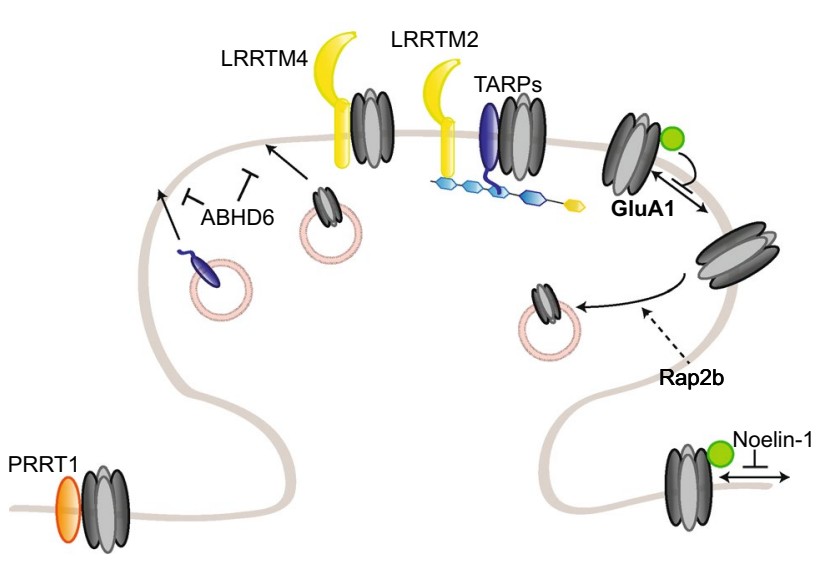

Fig. 6 Newcomers in AMPAR complexes. Newly described constituents of synaptic AMPAR complexes include PRRT1, which targets AMPARs to the extrasynaptic pool; LRRTM proteins, which maintain the pool of surface AMPARs; ABHD6, which negatively regulates surface AMPARs and stargazin; Noelin-1, which negatively regulates lateral mobility of AMPARs (extrasynaptic GluA1- and GluA2-containing receptors; synaptic GluA1-containing receptors); and Rap2b, which has been shown to trigger AMPAR endocytosis indirectly, by recruiting effectors. A postsynaptic role of other interactants, such as neuritin, brorin, brorin-like or PRRT2, is still unknown

two transmembrane helices with several conserved motives [363]. The C-terminus of PRRT1 (or Dispanin subfamily D member 1, DSPD1) shares extensive similarity with the C-terminus of another Dispanin member, Dispanin subfamily C member 2 (DSPC2), initially identified as synapse differentiation induced gene (SynDIG) 1; hence the other name of PRRT1, SynDIG4 [364]. Interestingly, SynDIG1 is a known AMPAR interactant: it is associated with AMPARs at synaptic and extrasynaptic sites and promotes their clustering, and SynDIG1 distribution is regulated via activity-dependent palmitoylation [365, 366]. In vitro and in vivo, SynDIG1 also promotes the activity-dependent maturation of AMPAR-containing synapses by increasing synaptic AMPAR and PSD95 contents, thereby regulating synaptic number and strength ([365, 368]; but see [369]). PRRT1 presents a complementary expression pattern to SynDIG1 and is especially enriched in the CA1 region of the hippocampus; intriguingly, it is only present in the PSD in low amounts and mainly colocalizes with extrasynaptic AMPARs [364] (Fig. 6). Consistently, PRRT1 knockout mice mice show reduced extrasynaptic AMPARs, but also weaker synapses, impaired tetanus-induced (but not theta-burst induced) LTP, and cognitive impairments, suggesting that PRRT1 is required for specific forms of synaptic plasticity, possibly by ensuring the existence of a sufficient pool of extrasynaptic AMPARs [370]. On the other hand, PRRT2 (or Dispanin subfamily B member 3, DSPB3) has been identified as the causative gene for multiple paroxysmal disorders arising from different mutations (reviewed in Ref. [371]). PRRT2 is expressed in subpopulations within the 
Fig. 7 Endosomal constituents of AMPAR complexes. ERspecific AMPAR complexes ensure their proper biogenesis and prime them for synaptic partners, such as TARP and CNIH. These ER-specific interactants include CPT- $1 \mathrm{c}$ and FRRS1L, which bind together, providing a platform for GluA subunits and subsequently Sac1, PORCN, and ABHD6/12 binding. Several TARPs, CNIH2, PICK1, and Noelin-1 have also been involved in regulating AMPAR early trafficking

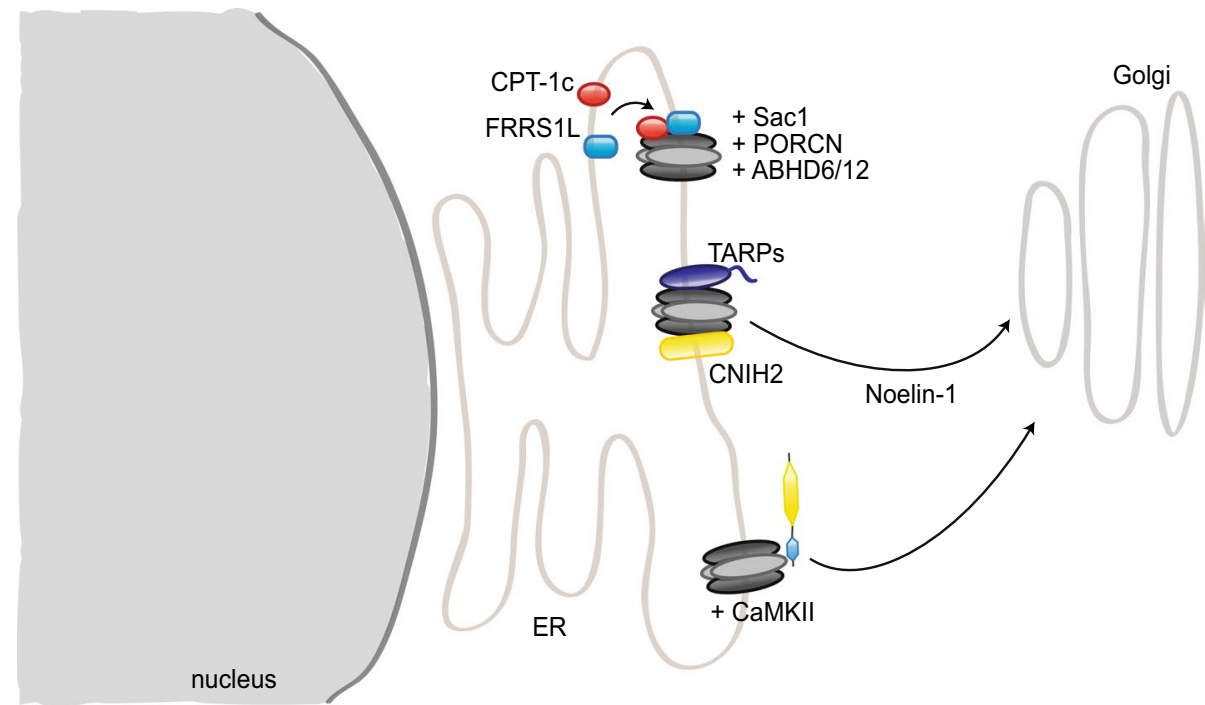

cortex, hippocampus, cerebellum, and basal ganglia; it appears to be mainly a presynaptic protein and is only detected at low levels in the PSD [372]. At the presynapse, PRRT2 interacts with SNAP25, a component of the SNARE machinery, and synaptotagmins 1 and 2; it negatively regulates the priming of neurotransmitter-containing vesicles by blocking the SNARE machinery, thereby modulating synaptic transmission [372, 373]. In addition, PRRT2 also binds intersectin 1, a presynaptic scaffold protein [367]. Consistently with the observed symptoms, PRRT2 mutations found in human patients disrupt this regulation and thereby synaptic transmission [373, 374]. In addition, PRRT2 plays a role in neuronal migration and synaptic development [374]. At the postsynapse, barely anything is known: PRRT2 has been detected at the tip of dendritic spines and reported to restrict surface AMPAR levels [374, 375]. Additional studies are certainly needed to confirm and characterize its role as AMPAR auxiliary subunit.

\section{Neuritin}

Neuritin is part of the neurotrophin family and was originally identified as candidate plasticity gene (cpg) 15 in a screen for plasticity-related genes in the rat hippocampus [376]. Neuritin has since then been established as a major player in activity-dependent remodeling of dendritic and axonal arborization by combining cell and non-cell autonomous actions: following the upregulation of its expression by activity, neuritin enhances axonal growth and branching, but can also be released from the axonal membrane by cleavage of its glycosylphosphatidylinositol (GPI) anchor, subsequently uptaken by the postsynapse, and thereby promoting dendritic arborization [377-382]. Neuritin thus supports the stabilization and maturation of active synapses and is thereby crucial for experience-driven neuronal network development, as shown by the disrupted visual receptor fields displayed by neuritin knockout mice [383]. In addition, neuritin knockout mice display delayed hippocampal development, decreased spine stability leading to a reduced spine density, and a lengthened learning process, although memory persistence is unaffected [384]. Neuritin also has been involved in synaptic transmission via its regulation of potassium and calcium channels $[66,385]$. However, in addition to Schwenk and colleagues [10], neuritin has only been associated with AMPARs by a single study: Cantallops and colleagues showed that, in a non-cell autonomous manner, neuritin leads to the recruitment of AMPARs to the contacting postsynapses in Xenopus optic tectal neurons and the conversion of silent synapses to functional synapses [379]. These data are consistent with an association with AMPAR complexes; however, the mechanisms and additional possible functions during plasticity in mature networks are open to investigation.

\section{Noelin}

Noelin is a secreted glycoprotein belonging to the larger olfactomedin family and transcribed in four alternative splice isoforms, Noelin 1-4, also known as olfactomedin $1-4$ in zebrafish [386, 387]. Noelin isoforms play important roles during various stages of the development of the neural system and head structure [388-391]. Regarding plasticity, both Noelin-1 and 2 have also been shown by independent studies to interact directly with AMPARs [10, 392-395]. Noelin-1 interacts with additional AMPAR auxiliary subunits, such as TARP $\gamma 8$ and neuritin; in addition, Noelin-1, 2 , and 3 are able to form heterodimers and have a similar expression pattern, suggesting the possible coexistence of multiple Noelin isoforms within a given AMPAR complex [394, 395] (Fig. 6). Noelin-1 knockout mice display abnormal social- and anxiety-related behaviors and impaired olfaction, increased resting and activity-induced calcium 
concentrations in the hippocampus and olfactory bulbs, and upregulated calcium-dependent signaling pathways; however, AMPAR function was unaffected [392]. Consistently, Pandya and colleagues recently showed that Noelin-1 did not influence AMPAR channel properties [395]. On the contrary, Noelin-1 regulates the lateral mobility and interaction with the extracellular matrix of AMPARs, in a subunit-specific manner: increasing Noelin-1 amounts in hippocampal neurons affects both synaptic and extrasynaptic GluA1-containing AMPARs, but only extrasynaptic GluA2containing AMPARs. This suggests that additional auxiliary subunits are involved in regulating the lateral mobility of synaptic GluA2-containing AMPARs [395]. In zebrafish double knockout for olfactomedin $1 \mathrm{a} / \mathrm{b}$, the homologs of Noelin-1, levels of synaptic AMPARs are significantly reduced; as GluA2 palmitoylation is decreased (but phosphorylation unaffected), this suggests that Noelin-1 regulates GluA2 maturation and thereby trafficking from the ER to the dendritic compartment, a role not mutually exclusive with regulating AMPAR lateral mobility [393] (Fig. 7). Another hypothesis would be that Noelin-1 enhances AMPAR surface stabilization, as it is present in lipid rafts, which have been shown to be important for this process [38]; however, the fact that AMPAR endocytosis is reduced in the mutant makes this possibility unlikely. Intriguingly, Noelin-1 is also present in the presynapse and interacts with SNARE proteins, which are also reduced in the presynaptic compartment in knockout fish [393]. Noelin-2 knockout mice show impaired behaviors and olfaction similar to Noelin-1 knockout mice, with additional slight motor defects; the composition of synaptic AMPAR complexes was also altered, with increased levels of GluA2, but decreased Noelin-1, PSD95, and CNIH-2 [394]. How this relates to AMPAR function, and which role plays Noelin-3, the additional isoform identified by Schwenk and colleagues, remain to be investigated.

Of note, another pair of secreted proteins, brorin and brorin-like, have also been identified by Schwenk and colleagues as AMPAR interactants [10]. Very little is known about them; they act as neural-specific bone morphogenetic protein (BMP) antagonists in mouse and zebrafish and as regulators of neural development [396-399]. Their expression in the adult brain leaves the door open for functions in postmitotic neurons, but extensive work is still required to identify an AMPAR-related role.

\section{Ras-related protein (Rap) $\mathbf{2 b}$}

Rap2b is one of the three alternatively spliced isoforms of Rap2, a member of the Ras family of small GTPases, which also includes Ras and Rap1. Only Rap2b has been identified as a member of native AMPAR complexes by Schwenk and colleagues [10]. This is rather surprising, as the sequence of these isoforms is over 90\% identical, and no known Rap2 effector has shown so far isoform-selective activity in vitro [400]. However, they are differentially palmitoylated, and contrary to Rap2a and c, Rap2b does not require palmitoylation for its binding to the plasma membrane [401]. Multiple functions specific for Rap2b have already been characterized, many of which cancer-related (reviewed in Ref. [402]), but no study on Ras/Rap signaling in plasticity has so far focused on a given Rap2 isoform, and the available information, as presented in this section, is, therefore, applicable to all Rap2 isoforms. The Ras family regulates AMPAR trafficking bidirectionally: while Ras is important for AMPAR insertion and LTP, Rap1 and 2 mediate AMPAR removal during LTD and depotentiation, respectively [403-407]; reviewed in Ref. [408]) (Fig. 6). Rap2 activates JNK and induces AMPAR dephosphorylation, while Rap1 acts via p38 MAPK; neurons expressing a constitutively active Rap 2 show reduced surface AMPAR levels and lower synaptic function, and are unable to maintain LTP [404, 409].

Together with Ras, Rap2 also mediates activity-induced synapse-specific AMPAR trafficking: Ras promotes transfer from the cytoplasmic to the synaptic pool, and Rap2 induces AMPAR removal from the synapse to the cytoplasm, enabling an activity-dependent reallocation of the receptors to other synapses [405] (Fig. 6). Consistently, Rap2 negatively regulates dendritic and axonal arborization: when constitutively active, Rap2 induces a decreased complexity and spine loss; intriguingly, despite a similar role in physiological plasticity, Rap1 does not affect neuronal morphology [409]. Transgenic mice expressing a constitutively active Rap2 show a similar phenotype, although Rap2 affects LTD but not depotentiation, and via ERK but not JNK signaling [410]. While these discrepancies are puzzling, this report is still consistent with a major role for Rap2 in AMPAR removal from the synaptic pool. Very recently, Zhang and colleagues studied the localization of Ras/Rap proteins in subcellular microdomains and showed that Ras mediates LTP via ER PI3K and lipid raft ERK, Rap1 transduces LTD via lysosomal p38 MAPK and Rap2 signals depotentiation via bulk membrane JNK, confirming and adding a further level of complexity to the current paradigm [407]. Efforts have so far focused on identifying coregulators and effectors of Rap2-mediated plasticity [406, 411], but not yet on the effects of its direct binding to AMPARs, which has yet to be confirmed independently. Further studies are thus required to tease out the specific role of Rap2b in AMPAR trafficking. 


\section{a/b-hydrolase domain-containing (ABHD) 6 and 12}

ABHD6 and 12 are monoacylglycerol lipases-a primary function a priori surprising in a review dedicated to AMPAR trafficking. However, they were both identified as constituents of the native AMPAR complexes and ABHD6 expression has been detected specifically in dendritic spines [10, 412]. ABHD6 overexpression leads to a decrease of AMPAR-mediated transmission and impaired LTP, while a knockdown has the opposite effect; NMDAR and GABA receptor-mediated transmissions are unaffected [413]. Moreover, surface AMPAR and stargazin are reduced in ABHD6 overexpressing cells, suggesting a role in restricting the surface pool of AMPARs (Fig. 6). In addition, this function does not require ABHD6 enzymatic activity, and is, therefore, also independent from the endocannabinoid pathway [413, 414]. Finally, ABHD6 binds GluA1-3 at their $\mathrm{C}$-terminus and its effect is subunit-independent; it is also independent from stargazin [415]. Unexpectedly, ABHD6 and 12 were also identified as part of AMPAR complexes at the ER, suggesting a dual regulatory role, at least for ABHD6 (see below) [416].

\section{ER AMPARs interactants: carnityl palmitoyltransferase (CPT) 1C, ferric chelate reductase 1 like (FRRS1L), Sac1, and protein-serine O-palmitoleoyltransferase porcupine (PORCN)}

CPT-1C is a brain-specific isoform of the depalmitoylating enzyme CPT1, mainly characterized for its role in food intake and energy homeostasis (reviewed in Ref. [417]). CPT-1C is expressed in hippocampal pyramidal cells and localized in the ER, in the soma but also in the spines; CPT$1 \mathrm{C}$ deficiency leads to a decreased number in mature spines and, consistently, impaired spatial learning [418]. Although this has been linked to CPT-1C enzymatic activity via ceramide depalmitoylation, this phenotype is reminiscent of the role of GluA2 in promoting spine density and maturation [419]. CPT-1C, indeed, interacts with AMPARs and enhances their surface level and function; however, consistently with earlier reports, it colocalizes with intracellular AMPARs, but not at the plasma membrane [420]. Furthermore, while GluA1 must be depalmitoylated at the C585 residue, CPT-1C is not the causative enzyme. CPT-1C knockout mice show reduced surface AMPAR amounts and function, due to a decreased translation efficiency; transcription and degradation are unaffected [421]. This reduced amount of synaptic AMPARs provides an additional mechanistic explanation for the decreased number of mature spines in CPT-1C knockout mice, and a mediation of CPT-1C action by AMPARs, beside ceramide, is a distinct possibility.

Recently, Brechet and colleagues reported that CPT1C, together with FRRS1L and the phosphatidylinositide phosphatase Sac1, defines a distinct type of AMPAR complexes, located only at the ER, representing $15-20 \%$ of all AMPARs, and lacking all classical auxiliary subunits [416] (Fig. 7). CPT-1C and FRRS1L first bind each other, providing a platform for Sac1, and the ternary complex then associates with AMPARs in the ER. CPT-1C/FRRS1L knockdown leads to a decreased AMPAR function and number of functional AMPARs in the synaptic and extrasynaptic pools, strongly suggesting that, despite their exclusive location at the ER, these proteins do influence AMPAR trafficking, possibly through the priming of these early complexes for transfer to the Golgi apparatus and binding to other auxiliary subunits.

These results are consistent with a previous report on Sac1 involvement in AMPAR secretory trafficking; stressinduced palmitoylation of JNK3 led to its binding to and sequestration of Sac1, thereby reducing surface levels of AMPARs [422]. FRRS1L modulation of AMPAR function was also shown in two other recent studies, one of which detected FRRS1L in dynein vesicles, indicating a possible additional role in AMPAR trafficking beyond the ER [423, 424]. Notably, the impact of FRRS1L on synaptic function is independent of any enzymatic activity, as FRRS1L lacks a ferrochelatase domain, and is consistent with the symptoms of human patients suffering from FRRS1L loss of function, which leads to encephalopathies and severe intellectual disabilities; disease mutations do indeed disrupt FRRS1L binding to AMPARs, suggesting that these mutations impair the regulation of AMPAR early biogenesis by FRRS1L [416, 423].

Finally, another auxiliary subunit, PORCN, has been recently characterized as regulating AMPAR trafficking in the ER [414]. PORCN was first identified in Drosophila as an ER protein processing members of the Wnt pathway [425]. The porcupine family is highly conserved and several alternatively spliced isoforms exist, with different spatiotemporal expression patterns, but all encode transmembrane ER proteins [426]. While PORCN overexpression in hippocampal neurons has no effects, suggesting saturating protein levels, its knockdown leads to a dramatic reduction in total amounts of AMPARs and several auxiliary subunits, including TARP $\gamma 2, \gamma 8$, and CNIH2. Consistently, in conditional PORCN knockout mice, synaptic and extrasynaptic surface levels of AMPARs are decreased, as well as synaptic function; LTP induction and maintenance are, however, normal, likely due to a proportionate reduction in basal and potentiated synaptic transmission. PORCN knockdown also 
alters AMPAR kinetics, most likely through an altered composition of the complexes, as association with $\gamma 8$ is reduced. Combined with the subcellular localization of PORCNmainly at the ER, with only a small portion at the PSDthis suggests that PORCN regulates the early formation of AMPAR complexes at the ER level. Of note, like CPT-1C, FRRS1L, and ABHD6, this role of PORCN is independent of its enzymatic activity [414].

Like ABHD6 and 12, PORCN was identified as part of this early type of AMPAR complexes by Brechet and colleagues [416]. However, the formation of the CPT-1C/ FRRS1L/Sac1 complexes in the ER predates the binding of GluA complexes, which is itself required for the subsequent association of PORCN and ABHD6 and 12; this suggests a precise timing in the regulation of the first steps of AMPAR complex formation (Fig. 7). As the constitution of AMPAR complexes at the surface differs between neuronal types, and as ER-specific AMPAR complexes were identified in the hippocampus, future investigation is required to determine whether a similar complex is present in the ER of other neuronal types, if the composition of this ER complex varies according to neuronal types, and if this ER complex influences the composition of the subsequent complexes accompanying AMPARs to the synapse, and thereby its regulation of AMPAR trafficking and function.

\section{Concluding remarks}

AMPA receptor trafficking to, at, and from the synapse has now been established as one of the core mechanisms underlying synaptic plasticity. It is tightly controlled throughout development and adulthood, and dysregulation is not only one of the hallmarks of physiological and pathological aging, but also of many neurological disorders [16]. Over the last two decades, the importance of AMPAR interacting partners in regulating AMPAR trafficking has become increasingly clear-not only because removing or impairing these proteins affects AMPAR trafficking in research models, but also because mutations in AMPAR interactants have been often found in human patients suffering from schizophrenia or autistic spectrum disorders (see, e.g., for reviews [427, 428]). In recent years, a significant headway has been made to understand the roles of these interactants as regulators of AMPAR trafficking; however, much remains shrouded in mystery. While the major role of some of the better known proteins seems well-established-GRIP1 in AMPAR insertion and stabilization, PICK1 in AMPAR internalization and anchorage, and PSD95 in AMPAR synaptic trappingdetailed mechanisms are still unclear; additional tasks have also been uncovered for some interactants, and the functions of the most recent members of AMPAR complexes are still enigmatic. Further intricacy is brought by the dependence of the function of some AMPAR interactants on age, brain region, neuronal population, and even subcellular localization. As these proteins often act in association, such complex roles may also arise from the combination of the different AMPAR interactants available, given their restricted spatiotemporal expression patterns. As if the situation was not convoluted enough, AMPAR interactants-like AMPAR subunits themselves-are also subjected to a variety of posttranslational modifications regulating their function, such as palmitoylation or ubiquitination, and which also need to be integrated into regulatory models of AMPAR trafficking (see for reviews $[429,430])$. A major challenge of the upcoming research on AMPAR trafficking will, hence, be to study AMPAR interactants not only in different neuronal types and at different time points, but also to widen the focus from one protein of interest to the combination present in the given neuronal population. Increased collaborations and interdisciplinary research, combining findings from the structural to the behavioral level, but also including data from human patients, are, therefore, required to progress towards a comprehensive picture of AMPAR trafficking.

Funding Work in the authors' laboratory is supported by ERC_AdG_ Neurovessel (Project Number: 669742), grants from the Deutsche Forschungsgemeinschaft (SFB 834, SFB1080, FOR2325, EXC 115, EXC 147, EXC 2026), and the Max Planck Fellow Program to A.A.P.

Open Access This article is distributed under the terms of the Creative Commons Attribution 4.0 International License (http://creativeco mmons.org/licenses/by/4.0/), which permits unrestricted use, distribution, and reproduction in any medium, provided you give appropriate credit to the original author(s) and the source, provide a link to the Creative Commons license, and indicate if changes were made.

\section{References}

1. Citri A, Malenka RC (2008) Synaptic plasticity: multiple forms, functions, and mechanisms. Neuropsychopharmacology 33:18-41

2. Bliss TVP, Collingridge GL, Morris RGM (2013) Synaptic plasticity in health and disease: introduction and overview. Philos Trans R Soc B 369:2013029

3. Turrigiano G (2012) Homeostatic synaptic plasticity: local and global mechanisms for stabilizing neuronal function. Cold Spring Harb Perspect Biol 4:1-17

4. Traynelis SF, Wollmuth LP, McBain CJ, Menniti FS, Vance KM, Ogden KK, Hansen KB, Yuan H, Myers SJ, Dingledine R (2010) Glutamate receptor ion channels: structure, regulation, and function. Pharmacol Rev 62:405-496

5. Schwenk J, Baehrens D, Haupt A, Bildl W, Boudkkazi S, Roeper J, Fakler B, Schulte U (2014) Regional diversity and developmental dynamics of the AMPA-receptor proteome in the mammalian brain. Neuron 84:41-54

6. Jacobi E, von Engelhardt J (2017) Diversity in AMPAR complexes in the brain. Curr Opin Neurobiol 45:32-38 
7. Schnell E, Sizemore M, Karimzadegan S, Chen L, Bredt DS, Nicoll RA (2002) Direct interactions between PSD-95 and stargazin control synaptic AMPA receptor number. Proc Natl Acad Sci 99:13902-13907

8. Rouach N, Byrd K, Petralia RS, Elias GM, Adesnik H, Tomita S, Karimzadegan S, Kealey C, Bredt DS, Nicoll RA (2005) TARP $\gamma-8$ controls hippocampal AMPA receptor number, distribution and synaptic plasticity. Nat Neurosci 8:1525-1533

9. Maher MP, Matta JA, Gu S, Seierstad M, Bredt DS (2017) Getting a handle on neuropharmacology by targeting receptorassociated proteins. Neuron 96:989-1001

10. Schwenk J, Harmel N, Brechet A, Zolles G, Berkefeld H, Müller CS, Bildl W, Baehrens D, Hüber B, Kulik A, Klöcker N, Schulte U, Fakler B (2012) High-resolution proteomics unravel architecture and molecular diversity of native AMPA receptor complexes. Neuron 74:621-633

11. Bildl W, Haupt A, Müller CS, Biniossek ML, Thumfart JO, Hüber B, Fakler B, Schulte U (2012) Extending the dynamic range of label-free mass spectrometric quantification of affinity purifications. Mol Cell Proteomics 11(M111):007955

12. Müller CS, Haupt A, Bildl W, Schindler J, Knaus H-G, Meissner M, Rammner B, Striessnig J, Flockerzi V, Fakler B, Schulte U (2010) Quantitative proteomics of the Cav2 channel nanoenvironments in the mammalian brain. Proc Natl Acad Sci USA 107:14950-14957

13. Greger IH, Watson JF, Cull-Candy SG (2017) Structural and functional architecture of AMPA-type glutamate receptors and their auxiliary proteins. Neuron 94:713-730

14. Zhu S, Gouaux E (2017) Structure and symmetry inform gating principles of ionotropic glutamate receptors. Neuropharmacology 112:11-15

15. Henley JM, Wilkinson KA (2016) Synaptic AMPA receptor composition in development, plasticity and disease. Nat Rev Neurosci 17:337-350

16. Jurado S (2018) AMPA receptor trafficking in natural and pathological aging. Front Mol Neurosci 10:1-14

17. Pick JE, Ziff EB (2018) Regulation of AMPA receptor trafficking and exit from the endoplasmic reticulum. Mol Cell Neurosci 91:3-9

18. Dong H, O'Brien RJ, Fung ET, Lanahan AA, Worley PF, Huganir RL (1997) GRIP: a synaptic PDZ domain-containing protein that interacts with AMPA receptors. Nature 386:279-284

19. Srivastava S, Osten P, Vilim FS, Khatri L, Inman G, States B, Daly C, Desouza S, Abagyan R, Valtschanoff JG, Weinberg RJ, Ziff EB (1998) Novel anchorage of GluR2/3 to the postsynaptic density by the AMPA receptor-binding protein ABP. Cell 21:581-591

20. Xia J, Zhang X, Staudinger J, Huganir RL (1999) Clustering of AMPA receptors by the synaptic PDZ domain-containing protein PICK1. Neuron 22:179-187

21. Brückner K, Labrador JP, Scheiffele P, Herb A, Seeburg PH, Klein R (1999) EphrinB ligands recruit GRIP family PDZ adaptor proteins into raft membrane microdomains. Neuron 22:511-524

22. Dong H, Zhang P, Song I, Petralia RS, Liao D, Huganir RL (1999) Characterization of the glutamate receptor-interacting proteins GRIP1 and GRIP2. J Neurosci 19:6930-6941

23. Setou M, Seog DH, Tanaka Y, Kanai Y, Takei Y, Kawagishi M, Hirokawa N (2002) Glutamate-receptor-interacting protein GRIP1 directly steers kinesin to dendrites. Nature 417:83-87

24. Hoogenraad CC, Milstein AD, Ethell IM, Henkemeyer M, Sheng M (2005) GRIP1 controls dendrite morphogenesis by regulating EphB receptor trafficking. Nat Neurosci 8:906-915

25. Geiger JC, Lipka J, Segura I, Hoyer S, Schlager MA, Wulf PS, Weinges S, Demmers J, Hoogenraad CC, Acker-Palmer A (2014)
The GRIP1/14-3-3 pathway coordinates cargo trafficking and dendrite development. Dev Cell 28:381-393

26. Heisler FF, Lee HK, Gromova KV, Pechmann Y, Schurek B, Ruschkies L, Schroeder M, Schweizer M, Kneussel M (2014) GRIP1 interlinks N-cadherin and AMPA receptors at vesicles to promote combined cargo transport into dendrites. Proc Natl Acad Sci 111:5030-5035

27. Lv K, Chen L, Li Y, Li Z, Zheng P, Liu Y, Chen J, Teng J (2015) Trip6 promotes dendritic morphogenesis through dephosphorylated GRIP1-dependent myosin VI and F-actin organization. J Neurosci 35:2559-2571

28. Osten P, Khatri L, Perez JL, Köhr G, Giese G, Daly C, Schulz TW, Wensky A, Lee LM, Ziff EB (2000) Mutagenesis reveals a role for ABP/GRIP binding to GluR2 in synaptic surface accumulation of the AMPA receptor. Neuron 27:313-325

29. Chung HJ, Xia J, Scannevin RH, Zhang X, Huganir RL (2000) Phosphorylation of the AMPA receptor subunit GluR2 differentially regulates its interaction with PDZ domain-containing proteins. J Neurosci 20:7258-7267

30. Chung HJ, Steinberg JP, Huganir RL, Linden DJ (2003) Requirement of AMPA receptor GluR2 phosphorylation for cerebellar long-term depression. Science 300:1751-1755

31. Kim CH, Chung HJ, Lee HK, Huganir RL (2001) Interaction of the AMPA receptor subunit GluR2/3 with PDZ domains regulates hippocampal long-term depression. Proc Natl Acad Sci USA 98:11725-11730

32. Matsuda S, Launey T, Mikawa S, Hirai H (2000) Disruption of AMPA receptor GluR2 clusters following long-term depression induction in cerebellar Purkinje neurons. EMBO J 19:2765-2774

33. Xia J, Chung HJ, Wihler C, Huganir RL, Linden DJ (2000) Cerebellar long-term depression requires PKC-regulated interactions between GluR2/3 and PDZ domain-containing proteins. Interactions 28:499-510

34. Seidenman KJ, Steinberg JP, Huganir R, Malinow R (2003) Glutamate receptor subunit 2 Serine 880 phosphorylation modulates synaptic transmission and mediates plasticity in CA1 pyramidal cells. J Neurosci 23:9220-9228

35. Gainey MA, Tatavarty V, Nahmani M, Lin H, Turrigiano GG (2015) Activity-dependent synaptic GRIP1 accumulation drives synaptic scaling up in response to action potential blockade. Proc Natl Acad Sci 112:E3590-E3599

36. Tan HL, Queenan BN, Huganir RL (2015) GRIP1 is required for homeostatic regulation of AMPAR trafficking. Proc Natl Acad Sci 112:10026-10031

37. Braithwaite SP, Xia H, Malenka RC (2002) Differential roles for NSF and GRIP/ABP in AMPA receptor cycling. Proc Natl Acad Sci 99:7096-7101

38. DeSouza S, Fu J, States B, Ziff EB (2002) Differential palmitoylation directs the AMPA receptor-binding protein ABP to spines or to intracellular clusters. J Neurosci 22:3493-3503

39. Hirbec H, Francis JC, Lauri SE, Braithwaite SP, Coussen F, Mulle C, Dev KK, Couthino V, Meyer G, Isaac JTR, Collingridge GL, Henley JM (2003) Rapid and differential regulation of AMPA and kainate receptors at hippocampal mossy fibre synapses by PICK1 and GRIP. Neuron 37:625-638

40. Matsuda S, Mikawa S, Hirai H (1999) Phosphorylation of serine- 880 in GluR2 by protein kinase $C$ prevents its $C$ terminus from binding with glutamate receptor-interacting protein. J Neurochem 73:1765-1768

41. Mejias R, Adamczyk A, Anggono V, Niranjan T, Thomas GM, Sharma K (2011) Gain-of-function glutamate receptor interacting protein 1 variants alter GluA2 recycling and surface distribution in patients with autism. Proc Natl Acad Sci 108:4920-4925

42. Han M, Mejias R, Chiu SL, Rose R, Adamczyk A, Huganir R, Wang T (2017) Mice lacking GRIP1/2 show increased social 
interactions and enhanced phosphorylation at GluA2-S880. Behav Brain Res 321:176-184

43. Daw MI, Chittajallu R, Bortolotto ZA, Dev KK, Duprat F, Henley JM, Collingridge GL, Isaac JTR (2000) PDZ proteins interacting with C-terminal GluR2/3 are involved in a PKC-dependent regulation of AMPA receptors at hippocampal synapses. Neuron 28:873-886

44. Fu J, DeSouza S, Ziff EB (2003) Intracellular membrane targeting and suppression of Ser880 phosphorylation of glutamate receptor 2 by the linker I-set II domain of AMPA receptor-binding protein. J Neurosci 23:7592-7601

45. Takamiya K, Mao L, Huganir RL, Linden DJ (2008) The glutamate receptor-interacting protein family of GluR2-binding proteins is required for long-term synaptic depression expression in cerebellar Purkinje cells. J Neurosci 28:5752-5755

46. Mao L, Takamiya K, Thomas G, Lin D, Huganir RL (2010) GRIP1 and 2 regulate activity-dependent AMPA receptor recycling via exocyst complex interactions. Proc Natl Acad Sci 2010:1-6

47. Lu W, Ziff EB (2005) PICK1 interacts with ABP/GRIP to regulate AMPA receptor trafficking. Neuron 47:407-421

48. Hayashi T, Huganir RL (2004) Tyrosine phosphorylation and regulation of the AMPA receptor by Src family tyrosine kinases. J Neurosci 24:6152-6160

49. States BA, Khatri L, Ziff EB (2008) Stable synaptic retention of serine-880-phosphorylated GluR2 in hippocampal neurons. Mol Cell Neurosci 38:189-202

50. Casimiro T, Sossa KG, Uzunova G, Beattie JB, Kurt C, Carroll RC (2011) mGluR and NMDAR activation internalize distinct populations of AMPARs. Mol Cell Neurosci 48(2):161-170

51. Yamazaki M, Fukaya M, Abe M, Ikeno K, Kakizaki T, Watanabe M, Sakimura K (2001) Differential palmitoylation of two mouse glutamate receptor interacting protein 1 forms with different N-terminal sequences. Neurosci Lett 304:81-84

52. Charych EI, Yu W, Li R, Serwanski DR, Miralles CP, Li X, Yang BY, Pinal N, Walikonis R, De Blas AL (2004) A four PDZ domain-containing splice variant form of GRIP1 is localized in GABAergic and glutamatergic synapses in the brain. J Biol Chem 279:38978-38990

53. Charych EI, Li R, Serwanski DR, Li X, Miralles CP, Pinal N, De Blas AL (2006) Identification and characterization of two novel splice forms of GRIP1 in the rat brain. J Neurochem 97:884-898

54. Hanley LJ, Henley JM (2010) Differential roles of GRIP1a and GRIP1b in AMPA receptor trafficking. Neurosci Lett 485:167-172

55. Thomas GM, Hayashi T, Chiu SL, Chen CM, Huganir RL (2012) Palmitoylation by DHHC5/8 targets GRIP1 to dendritic endosomes to regulate AMPA-R trafficking. Neuron 73:482-496

56. Misra C, Restituito S, Ferreira J, Rameau GA, Fu J, Ziff EB (2010) Regulation of synaptic structure and function by palmitoylated AMPA receptor binding protein. Mol Cell Neurosci 43:341-352

57. Takamiya K, Kostourou V, Adams S, Jadeja S, Chalepakis G, Scambler PJ, Huganir RL, Adams RH (2004) A direct functional link between the multi-PDZ domain protein GRIP1 and the Fraser syndrome protein Fras1. Nat Genet 36:172-177

58. Hong CJ, Hsueh YP (2006) CASK associates with glutamate receptor interacting protein and signaling molecules. Biochem Biophys Res Commun 351:771-776

59. Atasoy D, Schoch S, Ho A, Nadasy KA, Liu X, Zhang W, Mukherjee K, Nosyreva ED, Fernandez-Chacon R, Missler M, Kavalali ET, Sudhof TC (2007) Deletion of CASK in mice is lethal and impairs synaptic function. Proc Natl Acad Sci $104: 2525-2530$
60. Steiner P, Floyd Sarria JC, Glauser L, Magnin S, Catsicas S, Hirling $\mathrm{H}$ (2002) Modulation of receptor cycling by neuron-enriched endosomal protein of $21 \mathrm{kD}$. J Cell Biol 157:1197-1209

61. Steiner P, Alberi S, Kulangara K, Yersin A, Sarria JCF, Regulier E, Kasas S, Dietler G, Muller D, Catsicas S, Hirling H (2005) Interactions between NEEP21, GRIP1 and GluR2 regulate sorting and recycling of the glutamate receptor subunit GluR2. EMBO J 24:2873-2884

62. Utvik JK, Haglerød C, Mylonakou MNI, Holen T, Kropf M, Hirling H, Skare Laake P, Ottersen OP, Haug FMS, Davanger S (2009) Neuronal enriched endosomal protein of $21 \mathrm{kDa}$ colocalizes with glutamate receptor subunit GLUR $2 / 3$ at the postsynaptic membrane. Neuroscience 158:96-104

63. Alberi S, Boda B, Steiner P, Nikonenko I, Hirling H, Muller D (2005) The endosomal protein NEEP21 regulates AMPA receptor-mediated synaptic transmission and plasticity in the hippocampus. Mol Cell Neurosci 29:313-319

64. Kulangara K, Kropf M, Glauser L, Magnin S, Alberi S, Yersin A, Hirling H (2007) Phosphorylation of glutamate receptor interacting protein 1 regulates surface expression of glutamate receptors. J Biol Chem 282:2395-2404

65. Ye B, Liao D, Zhang X, Zhang P, Dong H, Huganir RL (2000) GRASP-1: a neuronal RasGEF associated with the AMPA receptor/GRIP complex. Neuron 26:603-617

66. Lu J-M, Liu D-D, Li Z-Y, Ling C, Mei Y-A (2017) Neuritin enhances synaptic transmission in medial prefrontal cortex in mice by increasing CaV3.3 surface expression. Cereb Cortex 27:3842-3855

67. Bakshi K, Gennaro S, Chan CY, Kosciuk M, Liu J, Stucky A, Trenkner E, Friedman E, Nagele RG, Wang H-Y (2009) Prenatal cocaine reduces AMPA receptor synaptic expression through hyperphosphorylation of the synaptic anchoring protein GRIP. J Neurosci 29:6308-6319

68. Bakshi K, Kosciuk M, Nagele RG, Friedman E, Wang HY (2011) Prenatal cocaine exposure increases synaptic localization of a neuronal RasGEF, GRASP-1 via hyperphosphorylation of AMPAR anchoring protein, GRIP. PLoS One 6:e25019

69. Hoogenraad CC, Popa I, Futai K, Sanchez-Martinez E, Wulf PS, Van Vlijmen T, Dortland BR, Oorschot V, Govers R, Monti M, Heck AJR, Sheng M, Klumperman J, Rehmann H, Jaarsma D, Kapitein LC, Van Der Sluijs P (2010) Neuron specific Rab4 effector GRASP-1 coordinates membrane specialization and maturation of recycling endosomes. PLoS Biol 8:e1000283

70. Chiu SL, Diering GH, Ye B, Takamiya K, Chen CM, Jiang Y, Niranjan T, Schwartz CE, Wang T, Huganir RL (2017) GRASP1 regulates synaptic plasticity and learning through endosomal recycling of AMPA receptors. Neuron 93:1405-1419.e8

71. Wyszynski M, Kim E, Dunah AW, Passafaro M, Valtschanoff JG, Serra-page C, Streuli M, Weinberg RJ, Sheng M, Hill C, Carolina $N$ (2002) Interaction between GRIP and liprin- $\alpha / S Y D 2$ is required for AMPA receptor targeting University of North Carolina at Chapel Hill. Neuron 34:39-52

72. Ko J, Kim S, Valtschanoff JG, Shin H, Lee J-R, Sheng M, Premont RT, Weinberg RJ, Kim E (2003) Interaction between liprinalpha and GIT1 is required for AMPA receptor targeting. J Neurosci 23:1667-1677

73. Dunah AW, Hueske E, Wyszynski M, Hoogenraad CC, Jaworski J, Pak DT, Simonetta A, Liu G, Sheng M (2005) LAR receptor protein tyrosine phosphatases in the development and maintenance of excitatory synapses. Nat Neurosci 8:458-467

74. Dickinson BA, Jo J, Seok H, Son GH, Whitcomb DJ, Davies CH, Sheng M, Collingridge GL, Cho K (2009) A novel mechanism of hippocampal LTD involving muscarinic receptor-triggered interactions between AMPARs, GRIP and liprin. Mol Brain 2:1-12

75. Shin H, Wyszynski M, Huh KH, Valtschanoff JG, Lee JR, Ko J, Streuli M, Weinberg RJ, Sheng M, Kim E (2003) Association of 
the kinesin motor KIF1A with the multimodular protein liprin- $\alpha$. J Biol Chem 278:11393-11401

76. Davidkova G, Carroll RC (2007) Characterization of the role of microtubule-associated protein 1B in metabotropic glutamate receptor-mediated endocytosis of AMPA receptors in hippocampus. J Neurosci 27:13273-13278

77. Palenzuela R, Gutiérrez Y, Draffin JE, Lario A, Benoist M, Esteban JA (2017) MAP1B light chain modulates synaptic transmission via AMPA receptor intracellular trapping. J Neurosci 37:0505-0517

78. Zhang J, Wang Y, Chi Z, Keuss M, Pai Y-ME, Kang HC, Shin J, Bugayenko A, Wang H, Xiong Y, Pletnikov MV, Mattson MP, Dawson TM, Dawson VL (2011) The AAA + ATPase, thorase regulates AMPA receptor-dependent synaptic plasticity and behavior. Cell 22:233-245

79. Umanah GKE, Pignatelli M, Yin X, Chen R, Crawford J, Neifert S, Scarffe L, Behensky AA, Guiberson N, Chang M, Ma E, Kim JW, Castro CC, Mao X, Chen L, Andrabi SA, Pletnikov MV, Pulver AE, Avramopoulos D, Bonci A, Valle D, Dawson TM, Dawson VL (2017) Thorase variants are associated with defects in glutamatergic neurotransmission that can be rescued by Perampanel. Sci Transl Med 9:eaah4985

80. Ahrens-Nicklas RC, Umanah GKE, Sondheimer N, Deardorff MA, Wilkens AB, Conlin LK, Santani AB, Nesbitt A, Juulsola J, Ma E, Dawson TM, Dawson VL, Marsh ED (2017) Precision therapy for a new disorder of AMPA receptor recycling due to mutations in ATAD1. Neurol Genet 3:e130

81. Piard J, Umanah GKE, Harms FL, Abalde-Atristain L, Amram D, Chang M, Chen R, Alawi M, Salpietro V, Rees MI, Chung SK, Houlden H, Verloes A, Dawson TM, Dawson VL, Van Maldergem L, Kutsche K (2018) A homozygous ATAD1 mutation impairs postsynaptic AMPA receptor trafficking and causes a lethal encephalopathy. Brain 141:651-661

82. Torres R, Firestein BL, Dong H, Staudinger J, Olson EN, Huganir RL, Bredt DS, Gale NW, Yancopoulos GD (1998) PDZ proteins bind, cluster, and synaptically colocalize with Eph receptors and their ephrin ligands. Neuron 21:1453-1463

83. Hruska M, Dalva MB (2012) Ephrin regulation of synapse formation, function and plasticity. Mol Cell Neurosci 50:35-44

84. Irie F, Okuno M, Pasquale EB, Yamaguchi Y (2005) EphrinBEphB signalling regulates clathrin-mediated endocytosis through tyrosine phosphorylation of synaptojanin 1. Nat Cell Biol 7:501-509

85. Hussain NK, Thomas GM, Luo J, Huganir RL (2015) Regulation of AMPA receptor subunit GluA1 surface expression by PAK3 phosphorylation. Proc Natl Acad Sci 112:E5883-E5890

86. Kayser MS, McClelland AC, Hughes EG, Dalva MB (2006) Intracellular and trans-synaptic regulation of glutamatergic synaptogenesis by EphB receptors. J Neurosci 26:12152-12164

87. Fu AKY, Hung KW, Fu WY, Shen C, Chen Y, Xia J, Lai KO, Ip NY (2011) APCCdh1mediates EphA4-dependent downregulation of AMPA receptors in homeostatic plasticity. Nat Neurosci 14:181-191

88. Contractor A, Rogers C, Maron C, Heinemann SF (2002) Transsynaptic Eph receptor-ephrin signaling in hippocampal mossy fiber LTP. Science 296:1864-1869

89. Aoto J, Ting P, Maghsoodi B, Xu N, Henkemeyer M, Chen L (2007) Postsynaptic EphrinB3 promotes shaft glutamatergic synapse formation. J Neurosci 27:7508-7519

90. Antion MD, Christie LA, Bond AM, Dalva MB, Contractor A (2010) Ephrin-B3 regulates glutamate receptor signaling at hippocampal synapses. Mol Cell Neurosci 45:378-388

91. Hruska M, Henderson NT, Xia NL, Le Marchand SJ, Dalva MB (2015) Anchoring and synaptic stability of PSD-95 is driven by ephrin-B3. Nat Neurosci 18:1594-1605
92. Hering H, Lin C, Sheng M (2003) Lipid rafts in the maintenance of synapses, dendritic spines, and surface AMPA receptor stability. J Neurosci 23:3262-3271

93. Essmann CL, Martinez E, Geiger JC, Zimmer M, Traut MH, Stein V, Klein R, Acker-Palmer A (2008) Serine phosphorylation of ephrinB2 regulates trafficking of synaptic AMPA receptors. Nat Neurosci 11:1035-1043

94. Bouzioukh F, Wilkinson GA, Adelmann G, Frotscher M, Stein V, Klein R (2007) Tyrosine phosphorylation sites in ephrinB2 are required for hippocampal long-term potentiation but not long-term depression. J Neurosci 27:11279-11288

95. Pfennig S, Foss F, Bissen D, Harde E, Treeck JC, Segarra M, Acker-Palmer A (2017) GRIP1 binds to ApoER2 and EphrinB2 to induce activity-dependent AMPA receptor insertion at the synapse. Cell Rep 21:84-96

96. Qiu S, Zhao LF, Korwek KM, Weeber EJ (2006) Differential reelin-induced enhancement of NMDA and AMPA receptor activity in the adult hippocampus. J Neurosci 26:12943-12955

97. Weeber EJ, Beffert U, Jones C, Christian JM, Förster E, David Sweatt J, Herz J (2002) Reelin and apoE receptors cooperate to enhance hippocampal synaptic plasticity and learning. J Biol Chem 277:39944-39952

98. Dumanis SB, Cha HJ, Song JM, Trotter JH, Spitzer M, Lee JY, Weeber EJ, Scott Turner R, Pak DTS, William Rebeck G, Hoe HS (2011) ApoE receptor 2 regulates synapse and dendritic spine formation. PLoS One 6:e17203

99. Staudinger J, Zhou J, Burgess R, Elledge SJ, Olson EN (1995) PICK1: a perinuclear binding protein and substrate for protein kinase $\mathrm{C}$ isolated by the yeast two-hybrid system. J Cell Biol 128:263-271

100. Iwakura Y, Nagano T, Kawamura M, Horikawa H, Ibaraki K, Takei N, Nawa H (2001) $N$-methyl-D-aspartate-induced a-amino-3-hydroxy-5-methyl-4-isoxazoleproprionic acid (AMPA) receptor down-regulation involves interaction of the carboxyl terminus of GluR2/3 with Pick1: ligand-binding studies using Sindbis vectors carrying AMPA receptor d. J Biol Chem 276:40025-40032

101. Perez JL, Khatri L, Chang C, Srivastava S, Osten P, Ziff EB (2001) PICK1 targets activated protein kinase Calpha to AMPA receptor clusters in spines of hippocampal neurons and reduces surface levels of the AMPA-type glutamate receptor subunit 2. J Neurosci 21:5417-5428

102. Hanley JG, Henley JM (2005) PICK1 is a calcium-sensor for NMDA-induced AMPA receptor trafficking. EMBO J 24:3266-3278

103. Jin W, Ge W-P, Xu J, Cao M, Peng L, Yung W, Liao D, Duan S, Zhang M, Xia J (2006) Lipid binding regulates synaptic targeting of PICK1, AMPA receptor trafficking, and synaptic plasticity. J Neurosci 26:2380-2390

104. Ho MT-W, Pelkey KA, Topolnik L, Petralia RS, Takamiya K, Xia J, Huganir RL, Lacaille J-C, McBain CJ (2007) Developmental expression of $\mathrm{Ca}^{2+}$-permeable AMPA receptors underlies depolarization-induced long-term depression at mossy fiber CA3 pyramid synapses. J Neurosci 27:11651-11662

105. Terashima A, Pelkey KA, Rah JC, Suh YH, Roche KW, Collingridge GLL, McBain CJ, Isaac JTR (2008) An essential role for PICK1 in NMDA receptor-dependent bidirectional synaptic plasticity. Neuron 57:872-882

106. Steinberg JP, Takamiya K, Shen Y, Xia J, Rubio ME, Yu S, Jin W, Thomas GM, Linden DJ, Huganir RL (2006) Targeted in vivo mutations of the AMPA receptor subunit GluR2 and its interacting protein PICK1 eliminate cerebellar long-term depression. Neuron 49:845-860

107. Jo J, Heon S, Kim MJ, Son GH, Park Y, Jeremy M, Weiss JL, Sheng M, Collingridge GL (2008) Metabotropic glutamate 
receptor-mediated LTD involves two interacting $\mathrm{Ca}^{2+}$ sensors, NCS-1 and PICK1. Neuron 60:1095-1111

108. Bellone C, Lüscher C (2006) Cocaine triggered AMPA receptor redistribution is reversed in vivo by mGluR-dependent long-term depression. Nat Neurosci 9:636-641

109. Lin D-T, Huganir RL (2007) PICK1 and phosphorylation of the glutamate receptor 2 (GluR2) AMPA receptor subunit regulates GluR2 recycling after NMDA receptor-induced internalization. J Neurosci 27:13903-13908

110. Sossa KG, Beattie JB, Carroll RC (2007) AMPAR exocytosis through NO modulation of PICK1. Neuropharmacology 53:92-100

111. Citri A, Bhattacharyya S, Ma C, Morishita W, Fang S, Rizo J, Malenka RC (2010) Calcium binding to PICK1 is essential for the intracellular retention of AMPA receptors underlying longterm depression. J Neurosci 30:16437-16452

112. Terashima A, Cotton L, Dev KK, Meyer G, Zaman S, Duprat F, Henley JM, Collingridge GL, Isaac JT (2004) Regulation of synaptic strength and AMPA receptor subunit composition by PICK1. J Neurosci 24:5381-5390

113. Gardner SM, Takamiya K, Xia J, Suh JG, Johnson R, Yu S, Huganir RL (2005) Calcium-permeable AMPA receptor plasticity is mediated by subunit-specific interactions with PICK1 and NSF. Neuron 45:903-915

114. Sossa KG, Court BL, Carroll RC (2006) NMDA receptors mediate calcium-dependent, bidirectional changes in dendritic PICK1 clustering. Mol Cell Neurosci 31:574-585

115. Volk L, Kim C-H, Takamiya K, Yu Y, Huganir RL (2010) Developmental regulation of protein interacting with $\mathrm{C}$ kinase 1 (PICK1) function in hippocampal synaptic plasticity and learning. Proc Natl Acad Sci 107:21784-21789

116. Makuch L, Volk L, Anggono V, Johnson RC, Yu Y, Duning K, Kremerskothen J, Xia J, Takamiya K, Huganir RL (2011) Regulation of AMPA receptor function by the human memoryassociated gene KIBRA. Neuron 71:1022-1029

117. Anggono V, Clem RL, Huganir R (2011) PICK1 loss of function occludes homeostatic synaptic scaling. J Neurosci 31:2188-2196

118. Shao X, Zhu L, Wang Y, Lu Y, Wang W, Zhu J, Shen Y, Xia J, Luo J (2010) Threonine 82 at the PDZ domain of PICK1 is critical for AMPA receptor interaction and localization. Neurochem Int 56:962-970

119. Yagishita S, Murayama M, Ebihara T, Maruyama K, Takashima A (2015) Glycogen synthase kinase $3 \beta$-mediated phosphorylation in the most $\mathrm{C}$-terminal region of protein interacting with $\mathrm{C}$ kinase 1 (PICK1) regulates the binding of PICK1 to glutamate receptor subunit GluA2. J Biol Chem 290:29438-29448

120. Thomas GM, Hayashi T, Huganir RL, Linden DJ (2013) DHHC8-dependent PICK1 palmitoylation is required for induction of cerebellar long-term synaptic depression. J Neurosci 33:15401-15407

121. Joch M, Ase AR, Chen CX-Q, MacDonald PA, Kontogiannea M, Corera AT, Brice A, Séguéla P, Fon EA (2007) Parkinmediated monoubiquitination of the PDZ protein PICK1 regulates the activity of acid-sensing ion channels. Mol Biol Cell 18:3105-3118

122. Lu W, Khatri L, Ziff EB (2014) Trafficking of $\alpha$-amino-3hydroxy-5-methyl-4-isoxazolepropionic acid receptor (AMPA) receptor subunit GluA2 from the endoplasmic reticulum is stimulated by a complex containing $\mathrm{Ca}^{2+} /$ calmodulin-activated kinase II (CaMKII) and PICK1 protein and by release of $\mathrm{Ca}^{2+}$ from internal stores. J Biol Chem 289:19218-19230

123. Hanley JG, Khatri L, Hanson PI, Ziff EB (2002) NSF ATPase and $\alpha-/ \beta$-SNAPs disassemble the AMPA receptor-PICK1 complex. Neuron 34:53-67
124. Hanley JG (2007) NSF binds calcium to regulate its interaction with AMPA receptor subunit GluR2. J Neurochem 101:1644-1650

125. Rocca DL, Martin S, Jenkins EL, Hanley JG (2008) Inhibition of Arp2/3-mediated actin polymerisation by PICK1 regulates neuronal morphology and AMPA receptor endocytosis. Cell $10: 259-271$

126. Nakamura Y, Wood CL, Patton AP, Jaafari N, Henley JM, Mellor JR, Hanley JG (2011) PICK1 inhibition of the Arp2/3 complex controls dendritic spine size and synaptic plasticity. EMBO J 30:719-730

127. Rocca DL, Amici M, Antoniou A, Suarez EB, Halemani N, Murk K, McGarvey J, Jaafari N, Mellor JR, Collingridge GL, Hanley JG (2013) The Small GTPase Arf1 Modulates Arp2/3mediated actin polymerization via PICK1 to regulate synaptic plasticity. Neuron 79:293-307

128. Rocca DL, Hanley JG (2015) PICK1 links AMPA receptor stimulation to Cdc42. Neurosci Lett 585:155-159

129. Madasu Y, Yang C, Boczkowska M, Bethoney KA, Zwolak A, Rebowski G, Svitkina T, Dominguez R (2015) PICK1 is implicated in organelle motility in an Arp2/3 complex-independent manner. Mol Biol Cell 26:1308-1322

130. Xu J, Wang N, Luo JH, Xia J (2016) Syntabulin regulates the trafficking of PICK1-containing vesicles in neurons. Sci Rep $6: 1-15$

131. Haglerød C, Kapic A, Boulland JL, Hussain S, Holen T, Skare Laake P, Ottersen OP, Haug FMS, Davanger S (2009) Protein interacting with $\mathrm{C}$ kinase 1 (PICK1) and GluR2 are associated with presynaptic plasma membrane and vesicles in hippocampal excitatory synapses. Neuroscience 158:242-252

132. Haglerød C, Hussain S, Nakamura Y, Xia J, Haug FMS, Ottersen OP, Henley JM, Davanger S (2017) Presynaptic PICK1 facilitates trafficking of AMPA-receptors between active zone and synaptic vesicle pool. Neuroscience 344:102-112

133. Fiuza M, Rostosky CM, Parkinson GT, Bygrave AM, Halemani N, Baptista M, Milosevic I, Hanley JG (2017) PICK1 regulates AMP receptor endocytosis via direct interaction with AP2 $\alpha$-appendage and dynamin. Rockefeller Univ Press J Cell Biol 216:3323-3338

134. Cao M, Xu J, Shen C, Kam C, Huganir RL, Xia J (2007) PICK1 ICA69 heteromeric BAR domain complex regulates synaptic targeting and surface expression of AMPA receptors. J Neurosci 27:12945-12956

135. Wang Z, Wang YN, Sun CL, Yang D, Da SuL, Xie YJ, Zhou L, Wang Y, Shen Y (2013) C-terminal domain of ICA69 interacts with PICK1 and acts on trafficking of PICK1-PKC $\alpha$ complex and cerebellar plasticity. PLoS One 8:1-17

136. Xu J, Kam C, Luo J, Xia J (2014) PICK1 mediates synaptic recruitment of AMPA receptors at neurexin-induced postsynaptic sites. J Neurosci 34:15415-15424

137. Anggono V, Koç-Schmitz Y, Widagdo J, Kormann J, Quan A, Chen C-M, Robinson PJ, Choi S-Y, Linden DJ, Plomann M, Huganir RL (2013) PICK1 interacts with PACSIN to regulate AMPA receptor internalization and cerebellar long-term depression. Proc Natl Acad Sci 110:13976-13981

138. Widagdo J, Fang H, Jang SE, Anggono V (2016) PACSIN1 regulates the dynamics of AMPA receptor trafficking. Sci Rep 6:1-9

139. Breiderhoff T, Christiansen GB, Pallesen LT, Vaegter C, Nykjaer A, Holm MM, Glerup S, Willnow TE (2013) Sortilin-related receptor SORCS3 is a postsynaptic modulator of synaptic depression and fear extinction. PLoS One 8:1-15

140. Christiansen GB, Andersen KH, Riis S, Nykjaer A, Bolcho U, Jensen MS, Holm MM (2017) The sorting receptor SorCS3 is a stronger regulator of glutamate receptor functions compared to GABAergic mechanisms in the hippocampus. Hippocampus 27:235-248 
141. Bassani S, Cingolani LA, Valnegri P, Folci A, Zapata J, Gianfelice A, Sala C, Goda Y, Passafaro M (2012) The X-linked intellectual disability protein TSPAN7 regulates excitatory synapse development and AMPAR trafficking. Neuron 73:1143-1158

142. Madsen KL, Eriksen J, Milan-Lobo L, Han DS, Niv MY, Ammendrup-Johnsen I, Henriksen U, Bhatia VK, Stamou D, Sitte HH, McMahon HT, Weinstein H, Gether U (2008) Membrane localization is critical for activation of the PICK1 BAR domain. Traffic 9:1327-1343

143. Karlsen ML, Thorsen TS, Johner N, Ammendrup-johnsen I, Erlendsson S, Tian X, Simonsen JB, Høiberg-nielsen R, Christensen NM, Khelashvili G, Streicher W, Teilum K, Vestergaard B, Weinstein H, Gether U, Arleth L, Madsen KL (2015) Structure of dimeric and tetrameric complexes of the BAR domain protein PICK1 determined by small-angle X-ray scattering. Structure 23:1258-1270

144. Erlendsson S, Arleth L, Madsen KL (2015) Response to the challenges of polydisperse SAXS data analysis: two different SAXS studies of PICK1 produce different structural models. Structure 23:1669-1670

145. Boczkowska M, Rebowski G, Dominguez R (2015) The challenges of polydisperse SAXS data analysis: two SAXS studies of PICK1 produce different structural models. Structure 23:1967-1968

146. Zhu J, Shang Y, Zhang M (2016) Mechanistic basis of MAGUK-organized complexes in synaptic development and signalling. Nat Rev Neurosci 17:209-223

147. Leonard AS, Davare MA, Horne MC, Garner CC, Hell JW (1998) SAP97 is associated with the $\alpha$-amino-3-hydroxy-5methylisoxazole-4-propionic acid receptor GluR1 subunit. J Biol Chem 273:19518-19524

148. Fukata Y, Tzingounis AV, Trinidad JC, Fukata M, Burlingame AL, Nicoll RA, Bredt DS (2005) Molecular constituents of neuronal AMPA receptors. J Cell Biol 169:399-404

149. Cai C, Coleman SK, Niemi K, Keinänen K (2002) Selective binding of synapse-associated protein 97 to GluR-A $\alpha$-amino5-hydroxy-3-methyl-4-isoxazole propionate receptor subunit is determined by a novel sequence motif. J Biol Chem 277:31484-31490

150. Cho KO, Hunt CA, Kennedy MB (1992) The rat brain postsynaptic density fraction contains a homolog of the drosophila discs-large tumor suppressor protein. Neuron 9:929-942

151. Kistner U, Wenzel BM, Veh RW, Cases-Langhoff C, Garner AM, Appeltauer U, Voss B, Gundelfinger ED, Garner CC (1993) SAP90, a rat presynaptic protein related to the product of the Drosophila tumor suppressor gene dlg-A. J Biol Chem 268:4580-4583

152. Migaud M, Charlesworth P, Dempster M, Webster LC, Watabe AM, Makhinson M, He Y, Ramsay MF, Morris RGM, Morrison JH, O’Dell TJ, Grant SGN (1998) Enhanced long-term potentiation and impaired learning in mice with mutant postsynaptic density-95 protein. Nature 396:433-439

153. Nagura H, Ishikawa Y, Kobayashi K, Takao K, Tanaka T, Nishikawa K, Tamura H, Shiosaka S, Suzuki H, Miyakawa T, Fujiyoshi Y, Doi T (2012) Impaired synaptic clustering of postsynaptic density proteins and altered signal transmission in hippocampal neurons, and disrupted learning behavior in PDZ1 and PDZ2 ligand binding-deficient PSD-95 knockin mice. Mol Brain 5:1

154. El-Husseini A, Schnell E, Chetkovich D (2000) PSD-95 involvement in maturation of excitatory synapses. Science 290:1364-1368

155. Ehrlich I, Klein M, Rumpel S, Malinow R (2007) PSD-95 is required for activity-driven synapse stabilization. Proc Natl Acad Sci 104:4176-4181
156. Béique J-C, Andrade R (2003) PSD-95 regulates synaptic transmission and plasticity in rat cerebral cortex. J Physiol 546:859-867

157. Stein V, House DRC, Bredt DS, Nicoll RA (2003) Postsynaptic density-95 mimics and occludes hippocampal long-term potentiation and enhances long-term depression. J Neurosci 23:5503-5506

158. Ehrlich I, Malinow R (2004) Postsynaptic density 95 controls AMPA receptor incorporation during long-term potentiation and experience-driven synaptic plasticity. J Neurosci 24:916-927

159. Elias GM, Funke L, Stein V, Grant SG, Bredt DS, Nicoll RA (2006) Synapse-specific and developmentally regulated targeting of AMPA receptors by a family of MAGUK scaffolding proteins. Neuron 52:307-320

160. Beique J-C, Lin D-T, Kang M-G, Aizawa H, Takamiya K, Huganir RL (2006) Synapse-specific regulation of AMPA receptor function by PSD-95. Proc Natl Acad Sci 103:19535-19540

161. Carlisle HJ, Fink AE, Grant SGN, O'dell TJ (2008) Opposing effects of PSD-93 and PSD-95 on long-term potentiation and spike timing-dependent plasticity. J Physiol 586:5885-5900

162. Zhao J, Murata Y, Constantine-paton M (2013) Eye opening and PSD95 are required for long-term potentiation in developing superior colliculus. Proc Natl Acad Sci 110:707-712

163. Xu W, Schlüter OM, Steiner P, Czervionke BL, Sabatini BL, Malenka RC (2008) Molecular dissociation of the role of PSD-95 in regulating synaptic strength and LTD. Neuron 57:248-262

164. Yudowski GA, Olsen O, Adesnik H, Marek KW, Bredt DS (2013) Acute inactivation of PSD-95 destabilizes AMPA receptors at hippocampal synapses. PLoS One 8:1-9

165. MacGillavry HD, Song Y, Raghavachari S, Blanpied TA (2013) Nanoscale scaffolding domains within the postsynaptic density concentrate synaptic ampa receptors. Neuron 78:615-622

166. Nair D, Hosy E, Petersen JD, Constals A, Giannone G, Choquet D, Sibarita J-B (2013) Super-resolution imaging reveals that AMPA receptors inside synapses are dynamically organized in nanodomains regulated by PSD95. J Neurosci 33:13204-13224

167. Chen L, Chetkovich DM, Petralia RS, Sweeney NT, Kawasaki Y, Wenthold RJ, Bredt DS, Nicoll RA (2000) Stargazin regulates synaptic targeting of AMPA receptors by two distinct mechanisms. Nature 408:936-943

168. Bats C, Groc L, Choquet D (2007) The interaction between stargazin and PSD-95 regulates AMPA receptor surface trafficking. Neuron 53:719-734

169. Sainlos M, Tigaret C, Poujol C, Olivier NB, Bard L, Breillat C, Thiolon K, Choquet D, Imperiali B (2011) Biomimetic divalent ligands for the acute disruption of synaptic AMPAR stabilization. Nat Chem Biol 7:81-91

170. Opazo P, Sainlos M, Choquet D (2012) Regulation of AMPA receptor surface diffusion by PSD-95 slots. Curr Opin Neurobiol 22:453-460

171. Dakoji S, Tomita S, Karimzadegan S, Nicoll RA, Bredt DS (2003) Interaction of transmembrane AMPA receptor regulatory proteins with multiple membrane associated guanylate kinases. Neuropharmacology 45:849-856

172. Penn AC, Zhang CL, Georges F, Royer L, Breillat C, Hosy E, Petersen JD, Humeau Y, Choquet D (2017) Hippocampal LTP and contextual learning require surface diffusion of AMPA receptors. Nature 549:384-388

173. Mondin M, Labrousse V, Hosy E, Heine M, Tessier B, Levet F, Poujol C, Blanchet C, Choquet D, Thoumine O (2011) Neurexinneuroligin adhesions capture surface-diffusing AMPA receptors through PSD-95 scaffolds. J Neurosci 31:13500-13515

174. Jang S, Oh D, Lee Y, Hosy E, Shin H, Van Riesen C, Whitcomb D, Warburton JM, Jo J, Kim D, Kim SG, Um SM, Kwon SK, Kim MH, Roh JD, Woo J, Jun H, Lee D, Mah W, Kim H, Kaang BK, Cho K, Rhee JS, Choquet D, Kim E (2015) Synaptic 
adhesion molecule IgSF11 regulates synaptic transmission and plasticity. Nat Neurosci 19:84-93

175. Matt L, Kim K, Hergarden AC, Patriarchi T, Malik ZA, Park DK, Chowdhury D, Buonarati OR, Henderson PB, Gökçek Saraç Ç, Zhang Y, Mohapatra D, Horne MC, Ames JB, Hell JW (2018) $\alpha$-Actinin anchors PSD-95 at postsynaptic sites. Neuron 97:1094-1109

176. Schlüter OM, Xu W, Malenka RC (2006) Alternative N-terminal domains of PSD-95 and SAP97 govern activity-dependent regulation of synaptic AMPA receptor function. Neuron 51:99-111

177. Zhang P, Lisman JE (2012) Activity-dependent regulation of synaptic strength by PSD-95 in CA1 neurons. J Neurophysiol 107:1058-1066

178. El-Husseini AE, Craven SE, Chetkovich DM, Firestein BL, Schnell E, Aoki C, Bredt DS (2000) Dual palmitoylation of PSD-95 mediates its vesiculotubular sorting, postsynaptic targeting, and ion channel clustering. J Cell Biol 148:159-171

179. El-Husseini AED, Schnell E, Dakoji S, Sweeney N, Zhou Q, Prange O, Gauthier-Campbell C, Aguilera-Moreno A, Nicoll RA, Bredt DS (2002) Synaptic strength regulated by palmitate cycling on PSD-95. Cell 108:849-863

180. Jeyifous O, Lin EI, Chen X, Antinone SE, Mastro R, Drisdel R, Reese TS, Green WN (2016) Palmitoylation regulates glutamate receptor distributions in postsynaptic densities through control of PSD95 conformation and orientation. Proc Natl Acad Sci 113:E8482-E8491

181. Fukata M, Fukata Y, Adesnik H, Nicoll RA, Bredt DS (2004) Identification of PSD-95 palmitoylating enzymes. Neuron 44:987-996

182. Yokoi N, Fukata Y, Sekiya A, Murakami T, Kobayashi K, Fukata M (2016) Identification of PSD-95 depalmitoylating enzymes. J Neurosci 36:6431-6444

183. Sturgill JF, Steiner P, Czervionke BL, Sabatini BL (2009) Distinct domains within PSD-95 mediate synaptic incorporation, stabilization, and activity-dependent trafficking. J Neurosci 29:12845-12854

184. Zhang Y, Matt L, Patriarchi T, Malik ZA, Chowdhury D, Park DK, Renieri A, Ames JB, Hell JW (2014) Capping of the N-terminus of PSD-95 by calmodulin triggers its postsynaptic release. EMBO J 33:1341-1353

185. Noritake J, Fukata Y, Iwanaga T, Hosomi N, Tsutsumi R, Matsuda N, Tani H, Iwanari H, Mochizuki Y, Kodama T, Matsuura Y, Bredt DS, Hamakubo T, Fukata M (2009) Mobile DHHC palmitoylating enzyme mediates activity-sensitive synaptic targeting of PSD-95. J Cell Biol 186:147-160

186. Chowdhury D, Hell JW (2018) Homeostatic synaptic scaling: molecular regulators of synaptic AMPA-type glutamate receptors. F1000Research 7:234

187. Steiner P, Higley MJ, Xu W, Czervionke BL, Malenka RC, Sabatini BL (2008) Destabilization of the postsynaptic density by PSD-95 serine 73 phosphorylation inhibits spine growth and synaptic plasticity. Neuron 60:788-802

188. Kim MJ, Futai K, Jo J, Hayashi Y, Cho K, Sheng M (2007) Synaptic accumulation of PSD-95 and synaptic function regulated by phosphorylation of serine-295 of PSD-95. Neuron 56:488-502

189. Nelson CD, Kim MJ, Hsin H, Chen Y, Sheng M (2013) Phosphorylation of threonine-19 of PSD-95 by GSK-3 is required for PSD-95 mobilization and long-term depression. J Neurosci 33:12122-12135

190. Wu Q, Sun M, Bernard LP, Zhang H (2017) Postsynaptic density 95 (PSD-95) serine 561 phosphorylation regulates a conformational switch and bidirectional dendritic spine structural plasticity. J Biol Chem 292:16150-16160

191. Pedersen SW, Albertsen L, Moran GE, Levesque B, Pedersen SB, Bartels L, Wapenaar H, Ye F, Zhang M, Bowen ME, Strømgaard K (2017) Site-specific phosphorylation of PSD-95 PDZ domains reveals fine-tuned regulation of protein-protein interactions. ACS Chem Biol 12:2313-2323

192. Colledge M, Snyder EM, Crozier RA, Soderling JA, Jin Y, Langeberg LK, Lu H, Bear MF, Scott JD (2003) Ubiquitination regulates PSD-95 degradation and AMPA receptor surface expression. Neuron 40:595-607

193. Bianchetta MJ, Lam TT, Jones SN, Morabito MA (2011) Cdk5 regulates PSD-95 ubiquitination in neurons. J Neurosci $31: 12029-12035$

194. Colledge M, Dean RA, Scott GK, Langeberg LK, Huganir RL, Scott JD (2000) Targeting of PKA to glutamate receptors through a MAGUK-AKAP complex. Neuron 27:107-119

195. Bhattacharyya S, Biou V, Xu W, Schlüter OM, Malenka RC (2009) A critical role for PSD-95/AKAP interactions in endocytosis of synaptic AMPA receptors. Nat Neurosci 12:172-181

196. Gan M, Jiang P, McLean P, Kanekiyo T, Bu G (2014) Low-density lipoprotein receptor-related protein 1 (LRP1) regulates the stability and function of GluA1 $\alpha$-amino-3-hydroxy-5-Methyl4-isoxazole propionic acid (AMPA) receptor in neurons. PLoS One 9:e113237

197. Kim E, Cho KO, Rothschild A, Sheng M (1996) Heteromultimerization and NMDA receptor-clustering activity of Chapsyn-110, a member of the PSD-95 family of proteins. Neuron 17:103-113

198. Kruger JM, Favaro PD, Liu M, Kitlinska A, Huang X, Raabe M, Akad DS, Liu Y, Urlaub H, Dong Y, Xu W, Schlüter OM (2013) Differential roles of postsynaptic density-93 isoforms in regulating synaptic transmission. J Neurosci 33:15504-15517

199. Nada S, Shima T, Yanai H, Husi H, Grant SGN, Okada M, Akiyama T (2003) Identification of PSD-93 as a substrate for the Src family tyrosine kinase Fyn. J Biol Chem 278:47610-47621

200. Sato Y, Tao YX, Su Q, Johns RA (2008) Post-synaptic density-93 mediates tyrosine-phosphorylation of the $N$-methyl-D-aspartate receptors. Neuroscience 153:700-708

201. Guo ML, Xue B, Jin DZ, Mao LM, Wang JQ (2012) Interactions and phosphorylation of postsynaptic density 93 (PSD-93) by extracellular signal-regulated kinase (ERK). Brain Res 1465:18-25

202. Aoki C, Miko I, Oviedo H, Mikeladze-Dvali T, Alexandre L, Sweeney N, Bredt DS (2001) Electron microscopic immunocytochemical detection of PSD-95, PSD-93, SAP-102, and SAP-97 at postsynaptic, presynaptic, and nonsynaptic sites of adult and neonatal rat visual cortex. Synapse 40:239-257

203. Sans N, Petralia RS, Wang Y, Ii JB, Hell JW, Wenthold RJ (2000) A developmental change in NMDA receptor-associated proteins at hippocampal synapses. J Neurosci 20:1260-1271

204. DeGiorgis JA, Galbraith JA, Dosemeci A, Chen X, Reese TS (2006) Distribution of the scaffolding proteins PSD-95, PSD-93, and SAP97 in isolated PSDs. Brain Cell Biol 35:239-250

205. Sun Q, Turrigiano GG (2011) PSD-95 and PSD-93 play critical but distinct roles in synaptic scaling up and down. J Neurosci 31:6800-6808

206. Brenman JE, Topinka JR, Cooper EC, McGee AW, Rosen J, Milroy T, Ralston HJ, Bredt DS (1998) Localization of postsynaptic density-93 to dendritic microtubules and interaction with microtubule-associated protein 1A. J Neurosci 18:8805-8813

207. Müller BM, Kistner U, Kindler S, Chung WJ, Kuhlendahl S, Fenster SD, Lau LF, Veh RW, Huganir RL, Gundelfinger ED, Garner CC (1996) SAP102, a novel postsynaptic protein that interacts with NMDA receptor complexes in vivo. Neuron 17:255-265

208. Lau L, Mammen A, Ehlers MD, Kindler S, Chung WJ, Garner CC, Huganir RL (1996) Interaction of the $N$-methyl-D-aspartate receptor complex with a novel synapse-associated protein, SAP102. J Biol Chem 271:21622-21628

209. Cuthbert PC, Stanford LE, Coba MP, Ainge JA, Fink AE, Opazo P, Delgado JY, Komiyama NH, Dell TJO, Grant SGN (2007) Synapse-associated protein $102 / \mathrm{dlgh} 3$ couples the NMDA 
receptor to specific plasticity pathways and learning strategies. J Neurosci 27:2673-2682

210. Chen B, Thomas EV, Sanz-clemente A, Roche KW (2011) NMDA receptor-dependent regulation of dendritic spine morphology by SAP102 splice variants. J Neurosci 31:89-96

211. Chen BS, Gray JA, Sanz-Clemente A, Wei Z, Thomas EV, Nicoll RA, Roche KW (2012) SAP102 mediates synaptic clearance of NMDA receptors. Cell Rep 2:1120-1128

212. Elias GM, Elias LAB, Apostolides PF, Kriegstein AR, Nicoll RA (2008) Differential trafficking of AMPA and NMDA receptors by SAP102 and PSD-95 underlies synapse development. Proc Natl Acad Sci 105:20953-20958

213. Bonnet SAD, Akad DS, Samaddar T, Liu Y, Huang X, Dong Y, Schlüter OM (2013) Synaptic state-dependent functional interplay between postsynaptic density-95 and synapse-associated protein 102. J Neurosci 33:13398-13409

214. Zheng C-Y, Petralia R, Wang Y, Kachar B, Wenthold RJ (2010) SAP102 is a highly mobile MAGUK in spines. J Neurosci 30:4757-4766

215. Zheng C, Wang Y, Kachar B, Petralia RS (2011) Differential localization of SAP102 and PSD-95 is revealed in hippocampal spines using super- resolution light microscopy. Commun Integr Biol 0889:3-5

216. Wei Z, Wu G, Chen B (2018) Regulation of SAP102 synaptic targeting by phosphorylation. Mol Neurobiol 55:6215-6226

217. Lauks J, Klemmer P, Farzana F, Karupothula R, Zalm R, Cooke NE, Li KW, Smit AB, Toonen R, Verhage M (2012) Synapse associated protein 102 (SAP102) binds the C-terminal part of the scaffolding protein neurobeachin. PLoS One 7:e39420

218. Nair R, Lauks J, Jung SY, Cooke NE, de Wit H, Brose N, Kilimann MW, Verhage M, Rhee JS (2013) Neurobeachin regulates neurotransmitter receptor trafficking to synapses. J Cell Biol 200:61-80

219. Farzana F, Zalm R, Chen N, Li KW, Grant SGN, Smit AB, Toonen RF, Verhage M (2016) Neurobeachin regulates glutamate- and GABA-receptor targeting to synapses via distinct pathways. Mol Neurobiol 53:2112-2123

220. Murata Y, Constantine-Paton M (2013) Postsynaptic density scaffold SAP102 regulates cortical synapse development through EphB and PAK signaling pathway. J Neurosci 33:5040-5052

221. Levy JM, Chen X, Reese TS, Nicoll RA (2015) Synaptic consolidation normalizes AMPAR quantal size following MAGUK loss. Neuron 87:534-548

222. Chen X, Levy JM, Hou A, Winters C, Azzam R, Sousa AA, Leapman RD, Nicoll RA, Reese TS (2015) PSD-95 family MAGUKs are essential for anchoring AMPA and NMDA receptor complexes at the postsynaptic density. Proc Natl Acad Sci 112:E6983-E6992

223. Levy JM, Nicoll RA (2017) Membrane-associated guanylate kinase dynamics reveal regional and developmental specificity of synapse stability. J Physiol 595:1699-1709

224. Su D, Liu H, Liu T, Zhang X, Yang W, Song Y, Liu J, Wu Y, Chang L (2018) Dynamic SAP102 expression in the hippocampal subregions of rats and APP/PS1 mice of various ages. J Anat 232:987-996

225. Sans N, Racca C, Petralia RS, Wang YX, McCallum J, Wenthold RJ (2001) Synapse-associated protein 97 selectively associates with a subset of AMPA receptors early in their biosynthetic pathway. J Neurosci 21:7506-7516

226. Rumbaugh G, Sia G-M, Garner C, Huganir RL (2003) Synapseassociated protein-97 isoform-specific regulation of surface AMPA receptors and synaptic function in cultured neurons. $\mathbf{J}$ Cell Biol 23:4567-4576

227. Waites CL, Specht CG, Hartel K, Leal-Ortiz S, Genoux D, Li D, Drisdel RC, Jeyifous O, Cheyne JE, Green WN, Montgomery JM, Garner CC (2009) Synaptic SAP97 isoforms regulate
AMPA receptor dynamics and access to presynaptic glutamate. J Neurosci 29:4332-4345

228. Li D, Specht CG, Waites CL, Butler-Munro C, Leal-Ortiz S, Foote JW, Genoux D, Garner CC, Montgomery JM (2011) SAP97 directs NMDA receptor spine targeting and synaptic plasticity. J Physiol 589:4491-4510

229. Valtschanoff JG, Burette A, Davare MA, Soren Leonard A, Hell JW, Weinberg RJ (2000) SAP97 concentrates at the postsynaptic density in cerebral cortex. Eur J Neurosci 12:3605-3614

230. Tully MD, Grossmann JG, Phelan M, Pandelaneni S, Leyland M, Lian LY (2012) Conformational characterization of synapse-associated protein 97 by nuclear magnetic resonance and small-angle X-ray scattering shows compact and elongated forms. Biochemistry 51:899-908

231. Nakagawa T, Futai K, Lashuel HA, Lo I, Okamoto K, Walz T, Hayashi Y, Sheng M (2004) Quaternary structure, protein dynamics, and synaptic function of SAP97 controlled by L27 domain interactions. Neuron 44:453-467

232. Goodman L, Baddeley D, Ambroziak W, Waites CL, Garner CC, Soeller C, Montgomery JM (2017) N-terminal SAP97 isoforms differentially regulate synaptic structure and postsynaptic surface pools of AMPA receptors. Hippocampus 27:668-682

233. Klöcker N, Bunn RC, Schnell E, Caruana G, Bernstein A, Nicoll RA, Bredt DS (2002) Synaptic glutamate receptor clustering in mice lacking the SH3 and GK domains of SAP97. Eur J Neurosci 16:1517-1522

234. Wu H, Nash JE, Zamorano P, Garner CC (2002) Interaction of SAP97 with minus-end-directed actin motor myosin VI: implications for AMPA receptor trafficking. J Biol Chem 277:30928-30934

235. Nash JE, Appleby VJ, Corrêa SAL, Wu H, Fitzjohn SM, Garner CC, Collingridge GL, Molnár E (2010) Disruption of the interaction between myosin VI and SAP97 is associated with a reduction in the number of AMPARs at hippocampal synapses. J Neurochem 112:677-690

236. Tavalin SJ, Colledge M, Hell JW, Langeberg LK, Huganir RL, Scott JD (2002) Regulation of GluR1 by the A-kinase anchoring protein 79 (AKAP79) signaling complex shares properties with long-term depression. J Neurosci 22:3044-3051

237. Mauceri D, Cattabeni F, Di Luca M, Gardoni F (2004) Printed in calmodulin-dependent protein kinase II phosphorylation drives synapse-associated protein 97 into spines. J Biol Chem 279:23813-23821

238. Nikandrova YA, Jiao Y, Baucum AJ, Tavalin SJ, Colhran RJ (2010) $\mathrm{Ca}^{2+} /$ calmodulin-dependent protein kinase II binds to and phosphorylates a specific SAP97 splice variant to disrupt association with AKAP79/150 and modulate $\alpha$-amino-3-hydroxy5-methyl-4-isoxazolepropionic acid-type glutamate receptor (AMPAR) activity. J Biol Chem 285:923-934

239. Zheng Z, Keifer J (2014) Sequential delivery of synaptic GluA1and GluA4-containing AMPa receptors (AMPARs) by SAP97 anchored protein complexes in classical conditioning. J Biol Chem 289:10540-10550

240. Cai C, Li H, Rivera C, Keinänen K (2006) Interaction between SAP97 and PSD-95, two Maguk proteins involved in synaptic trafficking of AMPA receptors. J Biol Chem 281:4267-4273

241. Howard MA, Elias GM, Elias LAB, Swat W, Nicoll RA (2010) The role of SAP97 in synaptic glutamate receptor dynamics. Proc Natl Acad Sci 107:3805-3810

242. Lin EI, Jeyifous O, Green WN (2013) CASK regulates SAP97 conformation and its interactions with AMPA and NMDA receptors. J Neurosci 33:12067-12076

243. Jeyifous O, Waites CL, Specht CG, Fujisawa S, Schubert M, Lin EI, Marshall J, Aoki C, de Silva T, Montgomery JM, Garner CC, Green WN, De Silva T, Johanna M (2009) SAP97 and 
CASK mediate sorting of N-Methyl-D-Aspartate Receptors through a novel secretory pathway. Nat Neurosci 12:1011-1019

244. Marcello E, Gardoni F, Mauceri D, Romorini S, Jeromin A, Epis R, Borroni B, Cattabeni F, Sala C, Padovani A, Di Luca M (2007) Synapse-associated protein-97 mediates a-secretase ADAM10 trafficking and promotes its activity. J Neurosci 27:1682-1691

245. Marcello E, Epis R, Saraceno C, Gardoni F, Borroni B, Cattabeni F, Padovani A, di Luca M (2012) SAP97-mediated local trafficking is altered in Alzheimer disease patients' hippocampus. Neurobiol Aging 33:422.e1-422.e10

246. Toyooka K, Iritani S, Makifuchi T, Shirakawa O, Kitamura N, Maeda K, Nakamura R, Niizato K, Watanabe M, Kakita A, Takahashi H, Someya T, Nawa H (2002) Selective reduction of a PDZ protein, SAP-97, in the prefrontal cortex of patients with chronic schizophrenia. J Neurochem 83:797-806

247. Regalado MP (2006) Transsynaptic signaling by postsynaptic synapse-associated protein 97. J Neurosci 26:2343-2357

248. Jing-Ping Z, Tian QB, Sakagami H, Kondo H, Endo S, Suzuki T (2005) p55 protein is a member of PSD scaffold proteins in the rat brain and interacts with various PSD proteins. Mol Brain Res 135:204-216

249. Rademacher N, Schmerl B, Lardong JA, Wahl MC, Shoichet SA (2016) MPP2 is a postsynaptic MAGUK scaffold protein that links SynCAM1 cell adhesion molecules to core components of the postsynaptic density. Sci Rep 6:1-10

250. Kim G, Luján R, Schwenk J, Kelley MH, Aguado C, Watanabe M, Fakler B, Maylie J, Adelman JP (2016) Membrane palmitoylated protein 2 is a synaptic scaffold protein required for synaptic SK2-containing channel function. Elife 5:1-18

251. Nakagawa T, Cheng Y, Sheng M, Walz T (2006) Three-dimensional structure of an AMPA receptor without associated stargazin/TARP proteins. Biol Chem 387:179-187

252. Kato AS, Gill MB, Yu H, Nisenbaum ES, Bredt DS (2010) TARPs differentially decorate AMPA receptors to specify neuropharmacology. Trends Neurosci 33:241-248

253. Chen RS, Deng TC, Garcia T, Sellers ZM, Best PM (2007) Calcium channel $\gamma$ subunits: a functionally diverse protein family. Cell Biochem Biophys 47:178-186

254. Menuz K, O'Brien JL, Karmizadegan S, Bredt DS, Nicoll RA (2008) TARP redundancy is critical for maintaining AMPA receptor function. J Neurosci 28:8740-8746

255. Menuz K, Kerchner GA, O’Brien JL, Nicoll RA (2009) Critical role for TARPs in early development despite broad functional redundancy. Neuropharmacology 56:22-29

256. Kim KS, Yan D, Tomita S (2010) Assembly and stoichiometry of the AMPA receptor and TARP complex. J Neurosci 30:1064-1072

257. Hastie P, Ulbrich MH, Wang H-L, Arant RJ, Lau AG, Zhang Z, Isacoff EY, Chen L (2013) AMPA receptor/TARP stoichiometry visualized by single-molecule subunit counting. Proc Natl Acad Sci 110:5163-5168

258. Shi Y, Lu W, Milstein AD, Nicoll RA (2009) The stoichiometry of AMPA receptors and TARPs Varies by neuronal cell type. Neuron 62:633-640

259. Tomita S, Chen L, Kawasaki Y, Petralia RS, Wenthold RJ, Nicoll RA, Bredt DS (2003) Functional studies and distribution define a family of transmembrane AMPA receptor regulatory proteins. J Cell Biol 161:805-816

260. Letts VA, Felix R, Biddlecome GH, Arikkath J, Mahaffey CL, Valenzuela A, Bartlett FS, Mori Y, Campbell KP, Frankel WN (1998) The mouse stargazer gene encodes a neuronal $\mathrm{Ca}^{2+}$-channel $\gamma$ subunit. Nat Genet 19:340-347

261. Bedoukian MA, Whitesell JD, Peterson EJ, Clay CM, Partin KM (2008) The stargazin $C$ terminus encodes an intrinsic and transferable membrane sorting signal. J Biol Chem 283:1597-1600
262. Jackson AC, Nicoll RA (2011) The expanding social network of ionotropic glutamate receptors: TARPs and other transmembrane auxiliary subunits. Neuron 70:178-199

263. Vandenberghe W, Nicoll RA, Bredt DS (2005) Interaction with the unfolded protein response reveals a role for stargazin in biosynthetic AMPA receptor transport. J Neurosci 25:1095-1102

264. Tomita S, Fukata M, Nicoll R, Bredt D (2004) Dynamic interaction of stargazing-like TARPs with cycling AMPA receptors at synapses. Science 303:1508-1511

265. Opazo P, Labrecque S, Tigaret CM, Frouin A, Wiseman PW, De Koninck P, Choquet D (2010) CaMKII triggers the diffusional trapping of surface AMPARs through phosphorylation of stargazin. Neuron 67:239-252

266. Constals A, Penn AC, Compans B, Toulmé E, Phillipat A, Marais S, Retailleau N, Hafner AS, Coussen F, Hosy E, Choquet D (2015) Glutamate-induced AMPA receptor desensitization increases their mobility and modulates short-term plasticity through unbinding from stargazin. Neuron 85:787-803

267. Matsuda S, Kakegawa W, Budisantoso T, Nomura T, Kohda K, Yuzaki M (2013) Stargazin regulates AMPA receptor trafficking through adaptor protein complexes during long-term depression. Nat Commun 4:1-15

268. Stein ELA, Chetkovich DM (2010) Regulation of stargazin synaptic trafficking by C-terminal PDZ ligand phosphorylation in bidirectional synaptic plasticity. J Neurochem 113:42-53

269. Nomura T, Kakegawa W, Matsuda S, Kohda K, Nishiyama J, Takahashi T, Yuzaki M (2012) Cerebellar long-term depression requires dephosphorylation of TARP in Purkinje cells. Eur J Neurosci 35:402-410

270. Louros SR, Hooks BM, Litvina L, Carvalho AL, Chen C (2014) A role for stargazin in experience-dependent plasticity. Cell Rep 7:1614-1625

271. Louros SR, Caldeira GL, Carvalho AL (2018) Stargazin dephosphorylation mediates homeostatic synaptic downscaling of excitatory synapses. Front Mol Neurosci 11:1-13

272. Chen L, El-Husseini A, Tomita S, Bredt DS, Nicoll R (2003) Stargazin differentially controls the trafficking of alpha-amino3-hydroxyl-5-methyl-4-isoxazolepropionate and kainate receptors. Mol Pharmacol 64:703-706

273. Tomita S, Adesnik H, Sekiguchi M, Zhang W, Wada K, Howe JR, Nicoll RA, Bredt DS (2005) Stargazin modulates AMPA receptor gating and trafficking by distinct domains. Nature 435:1052-1058

274. Turetsky D, Garringer E, Patneau D (2005) Stargazin modulates native AMPA receptor functional properties by two distinct mechanisms. J Neurosci 25:7438-7448

275. Bedoukian MA, Weeks AM, Partin KM (2006) Different domains of the AMPA receptor direct stargazin-mediated trafficking and stargazin-mediated modulation of kinetics. J Biol Chem 281:23908-23921

276. Tomita S, Shenoy A, Fukata Y, Nicoll RA, Bredt DS (2007) Stargazin interacts functionally with the AMPA receptor glutamatebinding module. Neuropharmacology 52:87-91

277. Roberts MF, Taylor D, Unger V (2011) Two modes of interaction between the membrane-embedded TARP stargazin's C-terminal domain and the bilayer visualized by electron crystallography. J Struct Biol 174:542-551

278. Twomey EC, Yelshanskaya MV, Grassucci RA, Frank J, Sobolevsky AI (2016) Elucidation of AMPA receptor-stargazin complexes by cryo-electron microscopy. Science 353:975-1008

279. Zhao Y, Chen S, Yoshioka C, Baconguis I, Gouaux E (2016) Architecture of fully occupied GluA2 AMPA receptor-TARP complex elucidated by cryo-EM. Nature 536:108-111

280. Shaikh SA, Dolino DM, Lee G, Chatterjee S, MacLean DM, Flatebo C, Landes CF, Jayaraman V (2016) Stargazin modulation of AMPA receptors. Cell Rep 17:328-335 
281. Ben-Yaacov A, Gillor M, Haham T, Parsai A, Qneibi M, SternBach Y (2017) Molecular mechanism of AMPA receptor modulation by TARP/stargazin. Neuron 93:1126-1137.e4

282. Chen S, Zhao Y, Wang Y, Shekhar M, Tajkhorshid E, Gouaux E (2017) Activation and desensitization mechanism of AMPA receptor-TARP complex by cryo-EM. Cell 170:1234-1246.e14

283. Shanks NF, Maruo T, Farina AN, Ellisman MH, Nakagawa T (2010) Contribution of the global subunit structure and stargazin on the maturation of AMPA receptors. J Neurosci 30:2728-2740

284. Ives JH, Fung S, Tiwari P, Payne HL, Thompson CL (2004) Microtubule-associated protein light chain 2 is a stargazinAMPA receptor complex-interacting protein in vivo. J Biol Chem 279:31002-31009

285. Cuadra AE, Kuo S-H, Kawasaki Y, Bredt D, Chetkovich D (2004) AMPA receptor synaptic targeting regulated by stargazin interactions with the Golgi-resident PDZ protein nPIST. J Neurosci 24:7491-7502

286. Hafner AS, Penn AC, Grillo-Bosch D, Retailleau N, Poujol C, Philippat A, Coussen F, Sainlos M, Opazo P, Choquet D (2015) Lengthening of the stargazin cytoplasmic tail increases synaptic transmission by promoting interaction to deeper domains of PSD-95. Neuron 86:475-489

287. Chetkovich DM, Chen L, Stocker TJ, Nicoll R, Bredt DS (2002) Phosphorylation of the postsynaptic density-95 (PSD-95)/discs large/zona occludens-1 binding site of stargazin regulates binding to PSD-95 and synaptic targeting of AMPA receptors. J Neurosci 22:5791-5796

288. Choi J, Ko J, Park E, Lee JR, Yoon J, Lim S, Kim E (2002) Phosphorylation of stargazin by protein kinase A regulates its interaction with PSD-95. J Biol Chem 277:12359-12363

289. Tomita S, Stein V, Stocker TJ, Nicoll RA, Bredt DS (2005) Bidirectional synaptic plasticity regulated by phosphorylation of stargazin-like TARPs. Neuron 45:269-277

290. Sumioka A, Yan D, Tomita S (2010) TARP phosphorylation regulates synaptic AMPA receptors through lipid bilayers. Neuron 66:755-767

291. Tsui J, Malenka RC (2006) Substrate localization creates specificity in calcium/calmodulin-dependent protein kinase II signaling at synapses. J Biol Chem 281:13794-13804

292. Nakagawa T, Cheng Y, Ramm E, Sheng M, Walz T (2005) Structure and different conformational states of native AMPA receptor complexes. Nature 433:545-549

293. Selvakumar B, Huganir RL, Snyder SH (2009) S-nitrosylation of stargazin regulates surface expression of AMPA-glutamate neurotransmitter receptors. Proc Natl Acad Sci 106:16440-16445

294. Zheng C-Y, Chang K, Suh YH, Roche KW (2015) TARP $\gamma-8$ glycosylation regulates the surface expression of AMPA receptors. Biochem J 465:471-477

295. Tao Y, Chen YJ, Shen C, Luo Z, Bates CR, Lee D, Marchetto S, Gao TM, Borg JP, Xiong WC, Mei L (2013) Erbin interacts with TARP $\gamma$-2 for surface expression of AMPA receptors in cortical interneurons. Nat Neurosci 16:290-299

296. Adotevi NK, Leitch B (2016) Alterations in AMPA receptor subunit expression in cortical inhibitory interneurons in the epileptic stargazer mutant mouse. Neuroscience 339:124-138

297. Adotevi NK, Leitch B (2017) Synaptic changes in AMPA receptor subunit expression in cortical parvalbumin interneurons in the stargazer model of absence epilepsy. Front Mol Neurosci 10:1-10

298. Kessels HW, Kopec CD, Klein ME, Malinow R (2009) Roles of stargazin and phosphorylation in the control of AMPA receptor subcellular distribution. Nat Neurosci 12:888-896

299. Deng F, Price MG, Davis CF, Mori M, Burgess DL (2006) Stargazin and other transmembrane AMPA receptor regulating proteins interact with synaptic scaffolding protein MAGI-2 in brain. J Neurosci 26:7875-7884
300. Hamad MIK, Jack A, Klatt O, Lorkowski M, Strasdeit T, Kott S, Sager C, Hollmann M, Wahle P (2014) Type I TARPs promote dendritic growth of early postnatal neocortical pyramidal cells in organotypic cultures. Development 141:1737-1748

301. Letts VA, Mahaffey CL, Beyer B, Frankel WN (2005) A targeted mutation in Cacng4 exacerbates spike-wave seizures in stargazer (Cacng2) mice. Proc Natl Acad Sci 102:2123-2128

302. Korber C, Werner M, Kott S, Ma Z-L, Hollmann M (2007) The transmembrane AMPA receptor regulatory protein $\gamma 4$ is a more effective modulator of AMPA receptor function than stargazin $(\gamma 2)$. J Neurosci 27:8442-8447

303. Ferrario CR, Loweth JA, Milovanovic M, Wang X, Wolf ME (2011) Distribution of AMPA receptor subunits and TARPs in synaptic and extrasynaptic membranes of the adult rat nucleus accumbens. Neurosci Lett 490:180-184

304. Sumioka A, Brown TE, Kato AS, Bredt DS, Kauer JA, Tomita S (2011) PDZ binding of TARP $\gamma-8$ controls synaptic transmission but not synaptic plasticity. Nat Neurosci 14:1410-1412

305. Fukaya M, Tsujita M, Yamazaki M, Kushiya E, Abe M, Akashi K, Natsume R, Kano M, Kamiya H, Watanabe M, Sakimura K (2006) Abundant distribution of TARP $\gamma-8$ in synaptic and extrasynaptic surface of hippocampal neurons and its major role in AMPA receptor expression on spines and dendrites. Eur J Neurosci 24:2177-2190

306. Yamasaki M, Fukaya M, Yamazaki M, Azechi H, Natsume R, Abe M, Sakimura K, Watanabe M (2016) TARP $\gamma-2$ and $\gamma-8$ differentially control AMPAR density across schaffer collateral/ commissural synapses in the hippocampal CA1 area. J Neurosci 36:4296-4312

307. Milstein AD, Nicoll RA (2009) TARP modulation of synaptic AMPA receptor trafficking and gating depends on multiple intracellular domains. Proc Natl Acad Sci 106:11348-11351

308. Sheng N, Bemben MA, Díaz-Alonso J, Tao W, Shi YS, Nicoll RA (2018) LTP requires postsynaptic PDZ-domain interactions with glutamate receptor/auxiliary protein complexes. Proc Natl Acad Sci 115:3948-3953

309. Inamura $M$, Itakura $M$, Okamoto $H$, Hoka $S$, Mizoguchi $A$, Fukazawa Y, Shigemoto R, Yamamori S, Takahashi M (2006) Differential localization and regulation of stargazin-like protein, $\gamma-8$ and stargazin in the plasma membrane of hippocampal and cortical neurons. Neurosci Res 55:45-53

310. Park J, Chávez AE, Mineur YS, Morimoto-Tomita M, Lutzu S, Kim KS, Picciotto MR, Castillo PE, Tomita S (2016) CaMKII phosphorylation of TARP $\gamma-8$ is a mediator of LTP and learning and memory. Neuron 92:75-83

311. Itakura M, Watanabe I, Sugaya T, Takahashi M (2014) Direct association of the unique $\mathrm{C}$-terminal tail of transmembrane AMPA receptor regulatory protein $\gamma-8$ with calcineurin. FEBS J 281:1366-1378

312. Moss FJ, Viard P, Davies A, Bertaso F, Page KM, Graham A, Canti C, Plumpton M, Plumpton C, Clare JJ, Dolphin AC (2002) The novel product of a five-exon stargazin-related gene abolishes Cav2.2 calcium channel expression. EMBO J 21:1514-1523

313. Kato AS, Zhou W, Milstein AD, Knierman MD, Siuda ER, Dotzlaf JE, Yu H, Hale JE, Nisenbaum ES, Nicoll RA, Bredt DS (2007) New transmembrane AMPA receptor regulatory protein isoform, $\gamma$-7, differentially regulates AMPA receptors. J Neurosci 27:4969-4977

314. Yamazaki M, Fukaya M, Hashimoto K, Yamasaki M, Tsujita M, Itakura M, Abe M, Natsume R, Takahashi M, Kano M, Sakimura K, Watanabe M (2010) TARPs $\gamma-2$ and $\gamma-7$ are essential for AMPA receptor expression in the cerebellum. Eur J Neurosci 31:2204-2220

315. Kato AS, Siuda ER, Nisenbaum ES, Bredt DS (2008) AMPA receptor subunit-specific regulation by a distinct family of type II TARPs. Neuron 59:986-996 
316. Yamazaki M, Le Pichon CE, Jackson AC, Cerpas M, Sakimura K, Scearce-Levie K, Nicoll RA (2015) Relative contribution of TARPs $\gamma-2$ and $\gamma-7$ to cerebellar excitatory synaptic transmission and motor behavior. Proc Natl Acad Sci 112:E371-E379

317. Bats C, Soto D, Studniarczyk D, Farrant M, Cull-Candy SG (2012) Channel properties reveal differential expression of TARPed and TARPless AMPARs in stargazer neurons. Nat Neurosci 15:853-861

318. Studniarczyk D, Coombs I, Cull-Candy SG, Farrant M (2013) TARP $\gamma$-7 selectively enhances synaptic expression of calciumpermeable AMPARs. Nat Neurosci 16:1266-1274

319. Ferron L, Davies A, Page KM, Cox DJ, Leroy J, Waithe D, Butcher AJ, Sellaturay P, Bolsover S, Pratt WS, Moss FJ, Dolphin AC (2008) The stargazin-related protein $\gamma 7$ interacts with the mRNA-binding protein heterogeneous nuclear ribonucleoprotein A2 and regulates the stability of specific mRNAs, including CaV2.2. J Neurosci 28:10604-10617

320. Waithe D, Ferron L, Dolphin AC (2011) Stargazin-related protein $\gamma 7$ is associated with signalling endosomes in superior cervical ganglion neurons and modulates neurite outgrowth. J Cell Sci 124:2049-2057

321. Ashburner M, Thompson P, Roote J, Lasko PF, Grau Y, El Messal M, Roth S, Simpson P (1990) The genetics of a small autosomal region of Drosophila melanogaster containing the structural gene for alcohol dehydrogenase. VII. Characterization of the region around the snail and cactus loci. Genetics 126:679-694

322. Schwenk J, Harmel N, Zolles G, Bildl W, Kulik A, Heimrich B, Chisaka O, Jonas P, Schulte U, Fakler B, Klöcker N (2009) Functional proteomics identify cornichon proteins as auxiliary subunits of AMPA receptors. Science 323:1313-1320

323. Mauric V, Mölders A, Harmel N, Heimrich B, Sergeeva OA, Klöcker N (2013) Ontogeny repeats the phylogenetic recruitment of the cargo exporter cornichon into AMPA receptor signaling complexes. Mol Cell Neurosci 56:10-17

324. Kato AS, Gill MB, Ho MT, Yu H, Tu Y, Siuda ER, Wang H, Qian YW, Nisenbaum ES, Tomita S, Bredt DS (2010) Hippocampal AMPA receptor gating controlled by both TARP and cornichon proteins. Neuron 68:1082-1096

325. Shi Y, Suh YH, Milstein AD, Isozaki K, Schmid SM, Roche KW, Nicoll RA (2010) Functional comparison of the effects of TARPs and cornichons on AMPA receptor trafficking and gating. Proc Natl Acad Sci 107:16315-16319

326. Harmel N, Cokic B, Zolles G, Berkefeld H, Mauric V, Fakler B, Stein V, Klöcker N (2012) AMPA receptors commandeer an ancient cargo exporter for use as an auxiliary subunit for signaling. PLoS One 7:e30681

327. Brockie PJ, Jensen M, Mellem JE, Jensen E, Yamasaki T, Wang R, Thacker C, Maxfield D, Hoerndli F, Dunn Patrick J, Tomita S, Madsen DM, Maricq AV (2013) Cornichons control ER export of AMPA receptors to regulate synaptic excitability. Neuron 80:129-142

328. Gill MB, Kato AS, Roberts MF, Yu H, Wang H, Tomita S, Bredt DS (2011) Cornichon-2 modulates AMPA receptor-transmembrane AMPA receptor regulatory protein assembly to dictate gating and pharmacology. J Neurosci 31:6928-6938

329. Gill MB, Kato AS, Wang H, Bredt DS (2012) AMPA receptor modulation by cornichon-2 dictated by transmembrane AMPA receptor regulatory protein isoform. Eur J Neurosci 35:182-194

330. Herring BE, Shi Y, Suh YH, Zheng C-Y, Blankenship SM, Roche KW, Nicoll RA (2013) Cornichon proteins determine the subunit composition of synaptic AMPA receptors. Neuron 77:1083-1096

331. Coombs ID, Soto D, Zonouzi M, Renzi M, Shelley C, Farrant M, Cull-Candy SG (2012) Cornichons modify channel properties of recombinant and glial AMPA receptors. J Neurosci 32:9796-9804
332. Boudkkazi S, Brechet A, Schwenk J, Fakler B (2014) Cornichon2 dictates the time course of excitatory transmission at individual hippocampal synapses. Neuron 82:848-858

333. Shanks NF, Cais O, Maruo T, Savas JN, Zaika EI, Azumaya CM, Yates JR, Greger I, Nakagawa T (2014) Molecular dissection of the interaction between the AMPA receptor and cornichon homolog-3. J Neurosci 34:12104-12120

334. Hawken NM, Zaika EI, Nakagawa T (2017) Engineering defined membrane-embedded elements of AMPA receptor induces opposing gating modulation by cornichon 3 and stargazin. $\mathrm{J}$ Physiol 595:6517-6539

335. Schober DA, Gill MB, Yu H, Gernert DL, Jeffries MW, Ornstein PL, Kato AS, Felder CC, Bredt DS (2011) Transmembrane AMPA receptor regulatory proteins and Cornichon-2 allosterically regulate AMPA receptor antagonists and potentiators. J Biol Chem 286:13134-13142

336. Shanks NF, Savas JN, Maruo T, Cais O, Hirao A, Oe S, Ghosh A, Noda Y, Greger IH, Yates JR, Nakagawa T (2012) Differences in AMPA and kainate receptor interactomes facilitate identification of AMPA receptor auxiliary subunit GSG1L. Cell Rep. 1:590-598

337. Gu X, Mao X, Lussier MP, Hutchison MA, Zhou L, Hamra FK, Roche KW, Lu W (2016) GSG1L suppresses AMPA receptormediated synaptic transmission and uniquely modulates AMPA receptor kinetics in hippocampal neurons. Nat Commun 7:1-18

338. Mao X, Gu X, Lu W (2017) GSG1L regulates the strength of AMPA receptor-mediated synaptic transmission but not AMPA receptor kinetics in hippocampal dentate granule neurons. J Neurophysiol 117:28-35

339. Keifer J, Tiwari NK, Buse L, Zheng Z (2017) Subunit-specific synaptic delivery of AMPA receptors by auxiliary chaperone proteins TARP $\gamma 8$ and GSG1L in classical conditioning. Neurosci Lett 645:53-59

340. Twomey EC, Yelshanskaya MV, Grassucci RA, Frank J, Sobolevsky AI (2017) Channel opening and gating mechanism in AMPA-subtype glutamate receptors. Nature 549:60-65

341. Twomey EC, Yelshanskaya MV, Grassucci RA, Frank J, Sobolevsky AI (2017) Structural bases of desensitization in AMPA receptor-auxiliary subunit complexes. Neuron 94:569580.e5

342. Pei J, Grishin NV (2012) Unexpected diversity in Shisa-like proteins suggests the importance of their roles as transmembrane adaptors. Cell Signal 24:758-769

343. von Engelhardt J, Mack V, Sprengel R, Kavenstock N, Li KW, Stern-Bach Y, Smit AB, Seeburg PH, Monyer H (2010) CKAMP44: a brain-specific protein attenuating short-term synaptic plasticity in the dentate gyrus. Science 60:1518-1522

344. Farrow P, Khodosevich K, Sapir Y, Schulmann A, Aslam M, Stern-Bach Y, Monyer H, von Engelhardt J (2015) Auxiliary subunits of the CKAMP family differentially modulate AMPA receptor properties. Elife 4:1-16

345. Khodosevich K, Jacobi E, Farrow P, Schulmann A, Rusu A, Zhang L, Sprengel R, Monyer H, von Engelhardt J (2014) Coexpressed auxiliary subunits exhibit distinct modulatory profiles on AMPA receptor function. Neuron 83:601-615

346. Chen X, Aslam M, Gollisch T, Allen K, Von Engelhardt J (2018) CKAMP44 modulates integration of visual inputs in the lateral geniculate nucleus. Nat Commun 9:1-13

347. Karataeva AR, Klaassen RV, Ströder J, Ruiperez-Alonso M, Hjorth JJJ, Van Nierop P, Spijker S, Mansvelder HD, Smit AB (2014) C-terminal interactors of the AMPA receptor auxiliary subunit Shisa9. PLoS One 9:e99280

348. Kunde SA, Rademacher N, Zieger H, Shoichet SA (2017) Protein kinase $\mathrm{C}$ regulates AMPA receptor auxiliary protein Shisa9/ CKAMP44 through interactions with neuronal scaffold PICK1. FEBS Open Bio 7:1234-1245 
349. Klaassen RV, Stroeder J, Coussen F, Hafner AS, Petersen JD, Renancio C, Schmitz LJM, Normand E, Lodder JC, Rotaru DC, Rao-Ruiz P, Spijker S, Mansvelder HD, Choquet D, Smit AB (2016) Shisa6 traps AMPA receptors at postsynaptic sites and prevents their desensitization during synaptic activity. Nat Commun 7:1-12

350. Schmitz LJM, Klaassen RV, Ruiperez-Alonso M, Zamri AE, Stroeder J, Rao-Ruiz P, Lodder JC, van der Loo RJ, Mansvelder HD, Smit AB, Spijker S (2017) The AMPA receptor-associated protein Shisa7 regulates hippocampal synaptic function and contextual memory. Elife 6:1-28

351. de Wit J, Sylwestrak E, O'Sullivan ML, Otto S, Tiglio K, Savas JN, Yates JR, Comoletti D, Taylor P, Ghosh A (2009) LRRTM2 interacts with Neurexin 1 and regulates excitatory synapse formation. Neuron 64:799-806

352. Laurén J, Airaksinen MS, Saarma M, Timmusk T (2003) A novel gene family encoding leucine-rich repeat transmembrane proteins differentially expressed in the nervous system. Genomics 81:411-421

353. Roppongi RT, Karimi B, Siddiqui TJ (2017) Role of LRRTMs in synapse development and plasticity. Neurosci Res 116:18-28

354. Linhoff MW, Laurén J, Cassidy RM, Dobie FA, Takahashi H, Nygaard HB, Airaksinen MS, Strittmatter SM, Craig AM (2009) An unbiased expression screen for synaptogenic proteins identifies the LRRTM protein family as synaptic organizers. Neuron 61:734-749

355. Ko J, Fuccillo MV, Malenka RC, Südhof TC (2009) LRRTM2 functions as a neurexin ligand in promoting excitatory synapse formation. Neuron 64:791-798

356. Um JW, Choi TY, Kang H, Cho YS, Choii G, Uvarov P, Park D, Jeong D, Jeon S, Lee D, Kim H, Lee SH, Bae YC, Choi SY, Airaksinen MS, Ko J (2016) LRRTM3 regulates excitatory synapse development through alternative splicing and neurexin binding. Cell Rep 14:808-822

357. de Wit J, O'Sullivan ML, Savas JN, Condomitti G, Caccese MC, Vennekens KM, Yates JR, Ghosh A (2013) Unbiased discovery of Glypican as a receptor for LRRTM4 in regulating excitatory synapse development. Neuron 79:696-711

358. Ko JS, Pramanik G, Um JW, Shim JS, Lee D, Kim KH, Chung G-Y, Condomitti G, Kim HM, Kim H, de Wit J, Park K-S, Tabuchi K, Ko J (2015) PTP $\sigma$ functions as a presynaptic receptor for the glypican-4/LRRTM4 complex and is essential for excitatory synaptic transmission. Proc Natl Acad Sci 112:1874-1879

359. Siddiqui TJ, Pancaroglu R, Kang Y, Rooyakkers A, Craig AM (2010) LRRTMs and neuroligins bind neurexins with a differential code to cooperate in glutamate synapse development. J Neurosci 30:7495-7506

360. Siddiqui TJ, Tari PK, Connor SA, Zhang P, Dobie FA, She K, Kawabe H, Wang YT, Brose N, Craig AM (2013) An LRRTM4HSPG complex mediates excitatory synapse development on dentate gyrus granule cells. Neuron 79:680-695

361. Soler-Llavina GJ, Arstikaitis P, Morishita W, Ahmad M, Südhof TC, Malenka RC (2013) Leucine-rich repeat transmembrane proteins are essential for maintenance of long-term potentiation. Neuron 79:439-446

362. Bhouri M, Morishita W, Temkin P, Goswami D, Kawabe H, Brose N, Südhof TC, Craig AM, Siddiqui TJ, Malenka R (2018) Deletion of LRRTM1 and LRRTM2 in adult mice impairs basal AMPA receptor transmission and LTP in hippocampal CA1 pyramidal neurons. Proc Natl Acad Sci 115:201803280

363. Sällman Almén M, Bringeland N, Fredriksson R, Schiöth HB (2012) The dispanins: a novel gene family of ancient origin that contains 14 human members. PLoS One 7:e31961

364. Kirk LM, Ti SW, Bishop HI, Orozco-Llamas M, Pham M, Trimmer JS, Díaz E (2016) Distribution of the SynDIG4/ proline-rich transmembrane protein 1 in rat brain. J Comp Neurol 524:2266-2280

365. Kalashnikova E, Lorca RA, Kaur I, Barisone GA, Li B, Ishimaru T, Trimmer JS, Mohapatra DP, Diaz (2010) SynDIG1: an activity-regulated AMPA receptor-interacting transmembrane protein that regulates excitatory synapse development. Neuron 65:80-93

366. Kaur I, Yarov-Yarovoy V, Kirk LM, Plambeck KE, Barragan EV, Ontiveros ES, Diaz E (2016) Activity-dependent palmitoylation controls SynDIG1 stability, localization, and function. J Neurosci 36:7562-7568

367. Rossi P, Sterlini B, Castroflorio E, Marte A, Onofri F, Valtorta F, Maragliano L, Corradi A, Benfenati F (2016) A novel topology of proline-rich transmembrane protein 2 (PRRT2): hints for an intracellular function at the synapse. J Biol Chem 291:6111-6123

368. Chenaux G, Matt L, Hill TC, Kaur I, Liu X-B, Kirk LM, Speca DJ, McMahon SA, Zito K, Hell JW, Diaz E (2016) Loss of SynDIG1 reduces excitatory synapse maturation but not formation in vivo. eNeuro 3:ENEURO.0130-16.2016

369. Lovero KL, Blankenship SM, Shi Y, Nicoll RA (2013) SynDIG1 promotes excitatory synaptogenesis independent of AMPA receptor trafficking and biophysical regulation. PLoS One 8:1-7

370. Matt L, Kirk LM, Chenaux G, Speca DJ, Puhger KR, Pride MC, Qneibi M, Haham T, Plambeck KE, Stern-Bach Y, Silverman JL, Crawley JN, Hell JW, Díaz E (2018) SynDIG4/Prrt1 is required for excitatory synapse development and plasticity underlying cognitive function. Cell Rep 22:2455-2468

371. Valtorta F, Benfenati F, Zara F, Meldolesi J (2016) PRRT2: from paroxysmal disorders to regulation of synaptic function. Trends Neurosci 39:668-679

372. Valente P, Castroflorio E, Rossi P, Fadda M, Sterlini B, Cervigni RI, Prestigio C, Giovedì S, Onofri F, Mura E, Guarnieri FC, Marte A, Orlando M, Zara F, Fassio A, Valtorta F, Baldelli P, Corradi A, Benfenati F (2016) PRRT2 is a key component of the $\mathrm{Ca}^{2+}$-dependent neurotransmitter release machinery. Cell Rep 15:117-131

373. Coleman J, Jouannot O, Ramakrishnan SK, Zanetti MN, Wang J, Salpietro V, Houlden H, Rothman JE, Krishnakumar SS (2018) PRRT2 regulates synaptic fusion by directly modulating SNARE complex assembly. Cell Rep 22:820-831

374. Liu Y-T, Nian F-S, Chou W-J, Tai C-Y, Kwan S-Y, Chen C, Kuo $\mathrm{P}-\mathrm{W}$, Lin P-H, Chen C-Y, Huang C-W, Lee Y-C, Soong B-W, Tsai J-W (2016) PRRT2 mutations lead to neuronal dysfunction and neurodevelopmental defects. Oncotarget 7:39184-39196

375. Li M, Niu F, Zhu X, Wu X, Shen N, Peng X, Liu Y (2015) PRRT2 mutant leads to dysfunction of glutamate signaling. Int J Mol Sci 16:9134-9151

376. Nedivi E, Hevroni D, Naot D, Israeli D, Citri Y (1993) Numerous candidate plasticity-related genes revealed by differential cDNA cloning. Nature 363:718-722

377. Nedivi E, Wu GY, Cline HT (1998) Promotion of dendritic growth by CPG15, an activity-induced signaling molecule. Science 281:1863-1866

378. Corriveau RA, Shatz CJ, Nedivi E (1999) Dynamic regulation of cpg15 during activity-dependent synaptic development in the mammalian visual system. J Neurosci 19:7999-8008

379. Cantallops I, Haas K, Cline HT (2000) Postsynaptic CPG15 promotes synaptic maturation and presynaptic axon arbor elaboration in vivo. Nat Neurosci 3:1004-1011

380. Fujino T, Lee WCA, Nedivi E (2003) Regulation of cpg 15 by signaling pathways that mediate synaptic plasticity. Mol Cell Neurosci 24:538-554

381. Shimada T, Yoshida T, Yamagata K (2016) Neuritin mediates activity-dependent axonal branch formation in part via FGF signaling. J Neurosci 36:4534-4548 
382. Javaherian A, Cline HT (2005) Coordinated motor neuron axon growth and neuromuscular synaptogenesis are promoted by CPG15 in vivo. Neuron 45:505-512

383. Picard N, Leslie JH, Trowbridge SK, Subramanian J, Nedivi E, Fagiolini M (2014) Aberrant development and plasticity of excitatory visual cortical networks in the absence of cpg15. J Neurosci 34:3517-3522

384. Fujino T, Leslie JH, Eavri R, Chen JL, Lin WC, Flanders GH, Borok E, Horvath TL, Nedivi E (2011) CPG15 regulates synapse stability in the developing and adult brain CPG15. Genes Dev 25:2674-2685

385. Yao JJ, Zhao QR, Liu DD, Chow CW, Mei YA (2016) Neuritin up-regulates Kv4.2 $\alpha$-subunit of potassium channel expression and affects neuronal excitability by regulating the calcium-calcineurin-NFATc4 signaling pathway. J Biol Chem 291:17369-17381

386. Moreno TA, Bronner-Fraser M (2002) Neural expression of mouse Noelin-1/2 and comparison with other vertebrates. Mech Dev 119:121-125

387. Anholt R (2014) Olfactomedin proteins: central players in development and disease. Front Cell Dev Biol 26:2-6

388. Barembaum M, Moreno TA, LaBonne C, Sechrist J, BronnerFraser M (2000) Noelin-1 is a secreted glycoprotein involved in generation of the neural crest. Nat Cell Biol 2:219-225

389. Nakaya N, Lee HS, Takada Y, Tzchori I, Tomarev SI (2008) Zebrafish olfactomedin 1 regulates retinal axon elongation in vivo. J Neurosci 28:7900-7910

390. Nakaya N, Sultana A, Lee HS, Tomarev SI (2012) Olfactomedin 1 interacts with the Nogo A receptor complex to regulate axon growth. J Biol Chem 287:37171-37184

391. Lee J-A, Anholt RRH, Cole GJ (2008) Olfactomedin-2 mediates development of the anterior central nervous system and head structures in zebrafish. Mech Dev 125:167-181

392. Nakaya N, Sultana A, Munasinghe J, Cheng A, Mattson MP, Tomarev SI (2013) Deletion in the N-terminal half of olfactomedin 1 modifies its interaction with synaptic proteins and causes brain dystrophy and abnormal behavior in mice. Exp Neurol 250:205-218

393. Nakaya N, Sultana A, Tomarev SI (2017) Impaired AMPA receptor trafficking by a double knockout of zebrafish olfactomedin1a/b. J Neurochem 143:635-644

394. Sultana A, Nakaya N, Dong L, Abu-Asab M, Qian H, Tomarev SI (2014) Deletion of olfactomedin 2 induces changes in the AMPA receptor complex and impairs visual, olfactory, and motor functions in mice. Exp Neurol 261:802-811

395. Pandya NJ, Seeger C, Babai N, Gonzalez-Lozano MA, Mack V, Lodder JC, Gouwenberg Y, Mansvelder HD, Danielson UH, Li KW, Heine M, Spijker S, Frischknecht R, Smit AB (2018) Noelin1 affects lateral mobility of synaptic AMPA receptors. Cell Rep 24:1218-1230

396. Koike N, Kassai Y, Kouta Y, Miwa H, Konishi M, Itoh N (2007) Brorin, a novel secreted bone morphogenetic protein antagonist, promotes neurogenesis in mouse neural precursor cells. J Biol Chem 282:15843-15850

397. Miyake A, Mekata Y, Fujibayashi H, Nakanishi K, Konishi $\mathrm{M}$, Itoh N (2017) Brorin is required for neurogenesis, gliogenesis, and commissural axon guidance in the zebra-sh forebrain. PLoS One 12:1-21

398. Miwa H, Miyake A, Kouta Y, Shimada A, Yamashita Y, Nakayama Y, Yamauchi H, Konishi M, Itoh N (2009) A novel neuralspecific BMP antagonist, Brorin-like, of the Chordin family. FEBS Lett 583:3643-3648

399. Ohyama Y, Katafuchi M, Almehmadi A, Venkitapathi S, Jaha H, Ehrenman J, Morcos J, Aljamaan R, Mochida Y (2012) Modulation of matrix mineralization by Vwc2-like protein and its novel splicing isoforms. Biochem Biophys Res Commun 418:12-16
400. Popovic M, Rensen-De Leeuw M, Rehmann H (2013) Selectivity of CDC25 homology domain-containing guanine nucleotide exchange factors. J Mol Biol 425:2782-2794

401. Uechi Y, Bayarjargal M, Umikawa M, Oshiro M, Takei K, Yamashiro Y, Asato T, Endo S, Misaki R, Taguchi T, Kariya K (2009) Rap2 function requires palmitoylation and recycling endosome localization. Biochem Biophys Res Commun 378:732-737

402. Zhu Z, Di J, Lu Z, Gao K, Zheng J (2016) Rap2B GTPase: structure, functions, and regulation. Tumor Biol 37:7085-7093

403. Zhu JJ, Qin Y, Zhao M, Van Aelst L, Malinow R (2002) Ras and Rap control AMPA receptor trafficking during synaptic plasticity. Cell 110:443-455

404. Zhu Y, Pak D, Qin Y, Mccormack SG, Kim MJ, Baumgart JP, Velamoor V, Auberson YP, Osten P, Van Aelst L, Sheng M, Zhu JJ (2005) Rap2-JNK removes synaptic AMPA receptors during depotentiation. Neuron 46:905-916

405. Kielland A, Bochorishvili G, Corson J, Zhang L, Rosin DL, Heggelund P, Zhu JJ (2009) Activity patterns govern synapsespecific AMPA receptor trafficking between deliverable and synaptic pools. Neuron 62:84-101

406. Hussain NK, Hsin H, Huganir RL, Sheng M (2010) MINK and TNIK differentially act on Rap2-mediated signal transduction to regulate neuronal structure and ampa receptor function. J Neurosci 30:14786-14794

407. Zhang L, Zhang P, Wang G, Zhang H, Zhang Y, Yu Y, Zhang M, Xiao J, Crespo P, Hell JW, Lin L, Huganir RL, Zhu JJ (2018) Ras and Rap signal bidirectional synaptic plasticity via distinct subcellular microdomains. Neuron 98:783-800.e4

408. Stornetta RL, Zhu JJ (2011) Ras and Rap signaling in synaptic plasticity and mental disorders. Neuroscientist 17:54-78

409. Fu Z, Lee SH, Simonetta A, Hansen J, Sheng M, Pak DTS (2007) Differential roles of Rap1 and Rap2 small GTPases in neurite retraction and synapse elimination in hippocampal spiny neurons. J Neurochem 100:118-131

410. Ryu J, Futai K, Feliu M, Weinberg R, Sheng M (2008) Constitutively active Rap2 transgenic mice display fewer dendritic spines, reduced extracellular signal-regulated kinase signaling, enhanced long-term depression, and impaired spatial learning and fear extinction. J Neurosci 28:8178-8188

411. Lee KJ, Lee Y, Rozeboom A, Lee JY, Udagawa N, Hoe HS, Pak DTS (2011) Requirement for Plk2 in orchestrated Ras and Rap signaling, homeostatic structural plasticity, and memory. Neuron 69:957-973

412. Marrs WR, Blankman JL, Horne EA, Thomazeau A, Lin YH, Coy J, Bodor AL, Muccioli GG, Hu SSJ, Woodruff G, Fung S, Lafourcade M, Alexander JP, Long JZ, Li W, Xu C, Möller T, MacKie K, Manzoni OJ, Cravatt BF, Stella N (2010) The serine hydrolase ABHD6 controls the accumulation and efficacy of 2-AG at cannabinoid receptors. Nat Neurosci 13:951-957

413. Wei M, Zhang J, Jia M, Yang C, Pan Y, Li S, Luo Y, Zheng J, Ji J, Chen J, Hu X, Xiong J, Shi Y, Zhang C (2016) $\alpha / \beta$-Hydrolase domain-containing 6 (ABHD6) negatively regulates the surface delivery and synaptic function of AMPA receptors. Proc Natl Acad Sci 113:E2695-E2704

414. Erlenhardt N, Yu H, Abiraman K, Yamasaki T, Wadiche JI, Tomita S, Bredt DS (2016) Porcupine controls hippocampal AMPAR levels, composition, and synaptic transmission. Cell Rep 14:782-794

415. Wei M, Jia M, Zhang J, Yu L, Zhao Y, Chen Y, Ma Y, Zhang W, Shi YS, Zhang C (2017) The inhibitory effect of $\alpha / \beta$-hydrolase domain-containing 6 (ABHD6) on the surface targeting of GluA2- and GluA3-containing AMPA receptors. Front Mol Neurosci 10:1-12

416. Brechet A, Buchert R, Schwenk J, Boudkkazi S, Zolles G, Siquier-Pernet K, Schaber I, Bildl W, Saadi A, Bole-Feysot C, Nitschke P, Reis A, Sticht H, Al-Sanna'a N, Rolfs A, Kulik A, 
Schulte U, Colleaux L, Abou Jamra R, Fakler B (2017) AMPAreceptor specific biogenesis complexes control synaptic transmission and intellectual ability. Nat Commun 8:15910

417. Casals N, Zammit V, Herrero L, Fadó R, Rodríguez-Rodríguez R, Serra D (2016) Carnitine palmitoyltransferase 1C: from cognition to cancer. Prog Lipid Res 61:134-148

418. Carrasco P, Sahún I, McDonald J, Ramírez S, Jacas J, Gratacós E, Sierra AY, Serra D, Herrero L, Acker-Palmer A, Hegardt FG, Dierssen M, Casals N (2012) Ceramide levels regulated by carnitine palmitoyltransferase $1 \mathrm{C}$ control dendritic spine maturation and cognition. J Biol Chem 287:21224-21232

419. Passafaro M, Nakagawa T, Sala C, Sheng M (2003) Induction of dendritic spines by an extracellular domain of AMPA receptor subunit GluR2. Nature 424:677-681

420. Gratacòs-Batlle E, Yefimenko N, Cascos-Garcia H, Soto D (2015) AMPAR interacting protein CPT1C enhances surface expression of GluA1-containing receptors. Front Cell Neurosci 8:1-17

421. Fadó R, Soto D, Miñano-Molina AJ, Pozo M, Carrasco P, Yefimenko N, Rodríguez-Álvarez J, Casals N (2015) Novel regulation of the synthesis of $\alpha$-Amino-3-hydroxy-5-methyl-4isoxazolepropionic Acid (ampa) receptor subunit glua1 by carnitine palmitoyltransferase 1C (CPT1C) in the Hippocampus. J Biol Chem 290:25548-25560

422. Yang G, Zhou X, Zhu J, Liu R, Zhang S, Coquinco A, Chen Y, Wen Y, Kojic L, Jia W, Cynader MS (2013) JNK3 couples the neuronal stress response to inhibition of secretory trafficking. Sci Signal 6:1-11

423. Madeo M, Stewart M, Sun Y, Sahir N, Wiethoff S, Chandrasekar I, Yarrow A, Rosenfeld JA, Yang Y, Cordeiro D, McCormick EM, Muraresku CC, Jepperson TN, McBeth LJ, Seidahmed MZ, El Khashab HY, Hamad M, Azzedine H, Clark K, Corrochano S, Wells S, Elting MW, Weiss MM, Burn S, Myers A, Landsverk M, Crotwell PL, Waisfisz Q, Wolf NI, Nolan PM, Padilla-Lopez S, Houlden H, Lifton R, Mane S, Singh BB, Falk
MJ, Mercimek-Mahmutoglu S, Bilguvar K, Salih MA, AcevedoArozena A, Kruer MC (2016) Loss-of-function mutations in FRRS1L lead to an epileptic-dyskinetic encephalopathy. Am J Hum Genet 98:1249-1255

424. Han W, Wang H, Li J, Zhang S, Lu W (2017) Ferric chelate reductase 1 like protein (FRRS1L) associates with dynein vesicles and regulates glutamatergic synaptic transmission. Front Mol Neurosci 10:1-15

425. Kadowaki T, Wilder E, Klingensmith J, Zachary K, Perrimon N (1996) The segment polarity gene porcupine encodes a putative multitransmembrane protein involved in Wingless processing. Genes Dev 10:3116-3128

426. Tanaka K, Okabayashi K, Asashima M, Perrimon N, Kadowaki $\mathrm{T}$ (2000) The evolutionarily conserved porcupine family is involved in the processing of the Wnt family. Eur J Biochem 267:4300-4311

427. Li YH, Zhang N, Wang YN, Shen Y, Wang Y (2016) Multiple faces of protein interacting with $\mathrm{C}$ kinase 1 (PICK1): structure, function, and diseases. Neurochem Int 98:115-121

428. Coley AA, Gao WJ (2018) PSD95: a synaptic protein implicated in schizophrenia or autism? Prog Neuro-Psychopharmacol Biol Psychiatry 82:187-194

429. Han J, Wu P, Wang F, Chen J (2015) S-palmitoylation regulates AMPA receptors trafficking and function: a novel insight into synaptic regulation and therapeutics. Acta Pharm Sin B 5:1-7

430. Widagdo J, Guntupalli S, Jang SE, Anggono V (2017) Regulation of AMPA receptor trafficking by protein ubiquitination. Front Mol Neurosci 10:1-10

Publisher's Note Springer Nature remains neutral with regard to jurisdictional claims in published maps and institutional affiliations. 